\title{
Geocronología de los megadeslizamientos de Tenerife del último millón de años. Parte I Revisión y nuevas dataciones Ar/Ar
}

\author{
Mercedes Ferrer Gijón ${ }^{(1)}$, Luis Ignacio González de Vallejo ${ }^{(2,3)}$ y Juan Carlos García López-Davalillo(1)
}

(1) Instituto Geológico y Minero de España. Área de Riesgos Geológicos. Ríos Rosas 23, 28003 Madrid.

(2) Universidad Complutense de Madrid. Dpto. de Geodinámica. José Antonio Novais 2, 28040 Madrid.

(3) Instituto Volcanológico de Canarias. 38320 San Cristóbal de La Laguna.

m.ferrer@igme.es; vallejo@ucm.es; jc.garcia@igme.es

\begin{abstract}
RESUMEN
Hasta el presente, las edades de los grandes deslizamientos de flanco de la isla de Tenerife (islas Canarias) ocurridos en el último millón de años, se han estimado a partir de dataciones de depósitos volcánicos relacionados cronológicamente con los deslizamientos, siendo muy escasas las dataciones realizadas exprofeso para conocer sus edades. Con el propósito de acotarlas en lo posible, se han recopilado y revisado las dataciones disponibles válidas para delimitar las edades de los deslizamientos de Icod, La Orotava, Güímary Micheque o Acentejo. Así mismo, se presentan nuevas dataciones Ar/Ar realizadas con el fin de ajustar en lo posible la edad de La Orotava, Güímar y Micheque. Por primera vez se publican dataciones en rocas de galerías en el valle de Güímar. Se han datado rocas a muro de los depósitos de los deslizamientos, donde hasta ahora se contaba con un solo dato publicado. Como resultado, se proponen las edades más representativas para los deslizamientos de Icod: 170 ka; La Orotava: 560, 530 y 500(?) ka; Güímar: 830 ka; y Micheque: 810-830 ka. Para el valle de La Orotava, las nuevas dataciones permiten proponer la ocurrencia de varios deslizamientos superpuestos con intervalos de decenas de miles de años. Esto supone un nuevo planteamiento de los procesos de desmantelamiento de los flancos de grandes islas volcánicas, y un nuevo escenario para interpretar las dataciones. Pero también una mayor complejidad y recurrencia de los procesos de inestabilidad de los volcanes. Como complemento a los datos aquí aportados, formando la Parte II del presente trabajo, en Ferrer et al. (2020-este volumen) se presentan y discuten nuevos datos relacionados con la edad, desencadenamiento y desarrollo de los deslizamientos.
\end{abstract}

Palabras clave: Dataciones, Geocronología, Islas Canarias, Megadeslizamientos volcánicos, Tenerife.

\section{Geochronology of the mega-landslides of the last million years in Tenerife. Part I A Review and new Ar/Ar ages}

\begin{abstract}
To date, the ages of the large flank landslides which occurred in Tenerife (Canary Islands) during the last million years have been estimated from the ages of the volcanic deposits chronologically related to the landslides, although very scarce data made expressly for this specific purpose are available. In order to get a more precise estimation of these ages, the bibliographical data previously published (1972-2019) on the age of subaerial and submarine volcanic deposits related to the megalandslides of Icod or Las Cañadas, La Orotava, Güímar and Micheque or Acentejo have been collected and reviewed. In addition, new Ar/Ar age determinations from rocks obtained inside the galleries crossing the filling of the landslide valleys of La Orotava, Güimar and Micheque are shown, including some age determinations of the lava flows underlying the landslide debris deposits ('mortalón'). As a result, we have obtained the following representative ages for the Tenerife landslides: Icod: 170 ka; La Orotava: 560, 530 y 500(?) ka; Güímar: $830 \mathrm{ka}$; and Micheque: 810-830 ka. In the case of the La Orotava landslide, the new age data suggest the occurrence of several overlapping landslides with time intervals of tens of thousands of years. This hypothesis represents a new approach to the study of flank instability processes in volcanic islands, and new scenarios to interpret landslide ages data. On the other hand, it also implies a greater complexity in the landslide mechanisms, and a greater recurrence of the volcanic mega-landslides. In Part II of this paper (Ferrer et al., 2020-this volume), new data related to the age, mechanisms and development of Tenerife landslides are presented and discussed, as complementary information.
\end{abstract}

Keywords: age determinations, Canary Islands, geochronology, Tenerife, volcanic megalandslides. 
M. Ferrer et al., 2020. Geocronología de los megadeslizamientos de Tenerife del último...Boletín Geológico y Minero, 131 (4): $903-940$

\section{ABRIDGED ENGLISH VERSION}

\section{Introduction}

The most remarkable and recent flank landslides occurred in Tenerife are those of Icod or Las Cañadas, La Orotava and Güímar (Figs. 1 to 4). The Micheque landslide (Carracedo et al., 2009), although without morphological reflection on the surface, can also be included.

One important aspect in the study of the mega-landslides is the determination of their age, which allows us to obtain information about the geological and morphological conditioning factors and the periods of recurrence of these large mass movements. This is a difficult question, as a direct determination is not possible, and it must be solved from chronostratigraphic relationships between the deposits and the morphological features of the landslides and other volcanic deposits related to them.

Up to now, the age of the landslides has been estimated from the ages obtained in studies carried out to know the geological history and evolution of the island, and on only a few occasions, from studies expressly focused on the landslides.

To interpret the available ages, it has been assumed, a priori, the hypothesis of single landslides as responsible for the formation of the large valleys limited by lateral escarpments hundreds of metres high penetrating into the sea. But these flank instability processes were much more complex, as some authors have proposed, with several multiple or recurrent large landslides in each case, as deduced from morphological evidence of the submarine landslide deposits (Watts and Masson, 1995; Urgeles et al., 1999; Ablay and Hurlimann, 2000) and combined with subaerial evidence (Biain et al., 2015; León et al., 2017). Therefore, it is not consistent to assume a single episode and a single age for the landslides, at least not for all of them.

\section{The age of the landslides: a review}

The age data for the last decades (1990-2019) reviewed to estimate the age of the landslides, come from: (i) landslide-related subaerial outcropping deposits; (ii) lava flows filling the valleys; and (iii) turbidite deposits from the landslides in the Moroccan Turbidite System (MTS). Tables 1 to 4 show the available data in the literature, their relationships with the landslides and the ages deduced from them; Figures 5 to 8 show their temporal distribution.

In the Icod valley, the head escarp of the landslide is exposed, as a part of the large Las Cañadas Caldera (Fig. 3), in the so-called Diego Hernández Wall (DHW), whose formation has been associated to the Icod landslide (Ancochea et al., 1999; Cantagrel et al., 1999; Huertas et al., 2002; Carracedo et al., 2007). Its upper level, the youngest deposit affected by the landslide, is a characteristic explosive breccia with syenite clasts; its age has been estimated between 173 and 183 ka (Martí et al., 1990; Mitjavila y Villa, 1993; Boulesteix et al., 2012). The Abrigo unit, a lithic breccia with syenite clasts outcroping mainly in the SE flank of Tenerife, correlated with that of the DHW, has been dated between 130 and 196 ka (Ancochea et al., 1990; Brown et al., 2003; Edgar et al., 2007). Other data are also available from lava flows filling the lcod valley, crossed by water galleries drilled through the landslide valley filling (Salto del Frontón and La Gotera galleries (Figure 11), aged 161 and 198 ka (Carracedo et al., 2007; Boulesteix et al., 2012). Finally, the age of the turbidite deposits from the Icod landslide, in the Moroccan Turbidite System (MTS), has been estimated between 160 and 200 ka (Wynn et al., 2002; Frenz et al., 2009; Hunt et al., 2013a)

On the basis of the previous data, an interval of 160-200 ka can be established for the age of the lcod landslide, which could be limited on the basis of the representativeness of the data to 165-175 $\mathrm{ka}$.

In the case of La Orotava landslide, the available ages correspond mainly to the upper lava flows of the lateral escarpments, and later deposits covering the escarpments. In the first case, ages have been obtained between 549 and 780 ka (Boulesteix et al., 2013; Abdel Monem et al., 1972; Ibarrola et al., 1993; Ancochea et al., 1990), thus indicating a younger age for the landslide. In the second case, the lava flows considered post-landslide give ages of between 508 and 566 ka (Carracedo et al., 2009; Ancochea et al., 1990). A lava flow of the valley filling, from the Pino Soler gallery, has been dated at $532 \mathrm{ka}$ (Boulesteix et al., 2013). The age determinations in turbidites in the Madeira Abyssal Plain (MAP), associated to the La Orotava landslide are: 535 and 505 ka (Hunt et al., 2013a; Weaver et al., 1992).

Therefore, as a result of the analysis of the literature data, it is not possible to establish a single representative age for the La Orotava landslide, but two ages can be clearly deduced around 560 ka and 530-535 ka (Fig. 
6). Thus, the idea can be raised that at least two large overlapping landslides took place, with a time interval of some tens of thousands of years. This proposal is reinforced by the results of the new Ar/Ar age determinations that we have carried out on rocks from the galleries of the La Orotava valley, as explained below.

In the Güimar valley the upper flows of the southern scarpment have provided an age of 830-840 ka (Abdel Monem et al., 1972; Ancochea et al., 1990). For the early filling materials of the landslide valley, ages of 831 and $818 \mathrm{ka}$ have been obtained (Carracedo et al., 2009). The turbidites of the Madeira Abyssal Plain (MAP) that can be correlated with the landslide have been dated at 830-850 ka (Hunt et al., 2013a).

Therefore, an age of around 830-850 ka can be established for the Güímar landslide, supported by age data from subaerial rocks and underwater deposits. The range could be reduced to 830-840 ka when considering the average value for the most representative submarine data.

The Micheque landslide, unlike the previous ones, does not have a morphological reflection on the surface; the most representative data comes from the lavas filling the valley (from the Dornajos gallery; Table 4), aged $830 \mathrm{ka}$ (Carracedo et al., 2009), thus indicating an older age for the landslide.

\section{New Ar/Ar age determinations, results and discussion}

New Ar/Ar age determinations have been carried out in order to contribute to adjust, as far as possible, the ages of the Güímar, La Orotava and Micheque landslides. Details of the analytical procedure and results are included in Appendix 1.

The main contribution is that, except for two samples, they all come from galleries that cross the filling of the landslide valleys, sometimes reaching the base of the deposits of 'mortalón'. So far, only two ages of rocks from galleries have been published for the aforementioned landslides: one in La Orotava and the other in Micheque. The samples from the galleries corresponded to lava flows either on the top or the bottom of the 'mortalon' deposits, thus corresponding to post or pre-landslide materials respectively. Figure 9 shows the location of the galleries and the samples. Figure 10 shows schematic sections of the galleries and the location of the samples.

The new Ar/Ar ages (Tables 5, 6 and 7) are consistent with the isotopic ages available in the literature, and provide representative information, especially in the cases of the Güimar and the Micheque landslides, where a limited number of data exist, and only one from a gallery (Dornajos gallery, in Micheque; Carracedo et al., 2009). Table 8 summarizes the data from bibliography, included in Tables 1 to 4, and those of this study, included in Table 6. The data are equally consistent with each other, especially if uncertainties are considered, and can be interpreted within the framework of the ages deduced from the most reliable data available in the literature.

In the case of the La Orotava landslide, the data point to a new and different age from that of $\sim 560 \mathrm{ka}$ proposed so far in most of the published studies. The new ages make it possible to propose the occurrence of a large landslide around $530 \mathrm{ka}$-coinciding with the age by Boulesteix et al. (2013) and the age of the turbidites from the landslide (Hunt et al., 2013a)-, thus supporting the idea proposed in this study of several large overlapping landslides.

The data from galleries have provided ages of between 500 and $~ 530 \mathrm{ka}$, so the occurrence of another possible landslide episode around $500 \mathrm{ka}$ is not ruled out, a hypothesis supported by the age of some turbidite deposits from La Orotava, $505 \mathrm{ka}$ (Weaver et al., 1992); this would imply at least three large overlapping failures on the flank. Part II of this paper (Ferrer et al., 2020-this volume) discusses this proposal of large overlapping landslides, in the light of the subaerial and underwater geological evidence.

In Güímar and Micheque landslides, the new ages coincide with those proposed in previous studies, around 830-840 ka.

\section{Conclusions}

After reviewing the available literature data from the last decades (1990-2019), the following ages have been deduced as representative for the mega-landslides: Icod: 165-175 ka; La Orotava: 530-535 and 560 ka; Güímar: 830-840 ka; and Micheque: >830 ka. Table 8 summarizes the data and the ages. In La Orotava valley, two ages have been identified that could correspond to two different events of large overlapping landslides.

The scarcity of data should be considered to delimit the ages of the Güímar landslide and, certainly, Micheque landslide. In Güímar, the most representative age is $830 \mathrm{ka}$; but if the most reliable submarine ages 
are considered, a range of between 830 and $840 \mathrm{ka}$ is obtained. For the Micheque landslide, only its upper limit can be estimated, $830 \mathrm{ka}$, from the age of early lava flows filling up the valley.

Based on the new Ar/Ar determinations carried out to contrast and delimit as far as possible the age of the landslides, the following representative ages are proposed: La Orotava: 510-530 ka; Güímar: 830 ka; and Micheque: >808 ka. The age for the Guimar and Micheque landslides coincides with those deduced from our review of the literature data, although the scarcity of age data available should be considered. Table 8 summarizes data and age results.

For the first time rocks from galleries of the Güímar valley have been dated, and also from the wall of the rock avalanche deposits from the landslides, where so far only one age data has been published.

In the La Orotava valley, the new data have allowed us to propose an age of around 530 ka for a large landslide, thus reinforcing the hypothesis of several overlapping landslides, with time intervals of some few tens of thousands of years. Indeed, the age deduced from most of the literature data, around 560 ka, cannot be ruled out, which would indicate the occurrence of two landslides separated about $30 \mathrm{ka}$, both of large magnitude. The new dates have also allowed us to propose an age around $500 \mathrm{ka}$, possibly denoting another subsequent landslide.

A series of geological evidences support the occurrence of several overlapping landslides on the flanks of the island of Tenerife, i.e. the lobes of the head scarps of the landslides, the differentiated deposits of the submarine rock avalanches from the landslides, or the different deposits of 'mortalón' that are intersected by many of the galleries excavated in the valley fillings.

This hypothesis represents a new approach to explaining the instability processes on the flanks of large volcanic islands, and represents a new scenario for interpreting the data on their age. But it also implies: i) a greater recurrence, and greater complexity in understanding the processes; ii) a greater difficulty in assessing their ages and the temporal limits of the different events and their geometric relationships; iii) and, even more, in interpreting their influence on the geological history of Tenerife and other volcanic islands.

\section{Introducción}

Los megadeslizamientos prehistóricos ocurridos en la isla deTenerife y en otras islas del archipiélago canario durante el último millón de años, se encuentran entre los mayores del planeta. Estos procesos, junto con los propios de una actividad volcánica intensa, han configurado la morfología actual de esta isla que es el tercer volcán oceánico más alto del mundo.

La historia geológica de la isla de Tenerife es, también, la historia de sus deslizamientos. La interrelación entre los acontecimientos eruptivos y destructivos que han configurado el relieve actual es tan estrecha que no puede entenderse ni explicarse la evolución de la isla sin contar con estos procesos, que a lo largo del tiempo han provocado la destrucción de partes muy importantes de los sucesivos edificios volcánicos subaéreos, incluyendo las cumbres, de $3.000 \mathrm{~m}$ de altura s.n.m. o más.

La relación entre los procesos constructivos y destructivos permite establecer correspondencias temporales entre ellos, dentro de la gran dificultad que entraña conocer la cronoestratigrafía de los grandes edificios volcánicos complejos, por la superposición de depósitos volcánicos resultante de la intensa actividad y elevadas tasas de crecimiento.

La ocurrencia de deslizamientos gigantes en las islas volcánicas -"prodigiosos" como los denominaron
Moore et al. (1989), cuando por primera vez se cartografiaron sistemáticamente los depósitos de enormes avalanchas rocosas submarinas entorno a las islas Hawaii, confirmando la teoría pionera de Moore (1964)- en los que se ven envueltos inmensos volúmenes de rocas, de decenas a cientos de $\mathrm{km}^{3}$, muy por encima de la escala humana en cuanto a magnitud y periodos de retorno, supone una oportunidad única para investigar las características y las pautas de estos cataclismos geológicos que, si bien no suponen actualmente un riesgo, son los mayores movimientos de ladera ocurridos en el planeta. La magnitud de estos procesos está en relación con la gran altura que alcanzan los edificios volcánicos oceánicos de las islas Hawaii o Canarias, algunos de los cuales forman, desde sus cumbres al fondo marino, los mayores accidentes topográficos de la Tierra, con empinadas laderas construidas prácticamente en condiciones de estabilidad límite.

En Canarias, la teoría de los grandes deslizamientos gravitatorios fue propuesta inicialmente por Bravo (1962) para explicar el origen de los valles de La Orotava y Güímar, en Tenerife (Figura 1), tras el crucial descubrimiento de un potente depósito brechoide en el fondo de las numerosas galerías de agua excavadas en las laderas del norte de la isla, denominado con el término 'fanglomerado' e interpretado como el plano de despegue de los deslizamientos por el citado autor; 


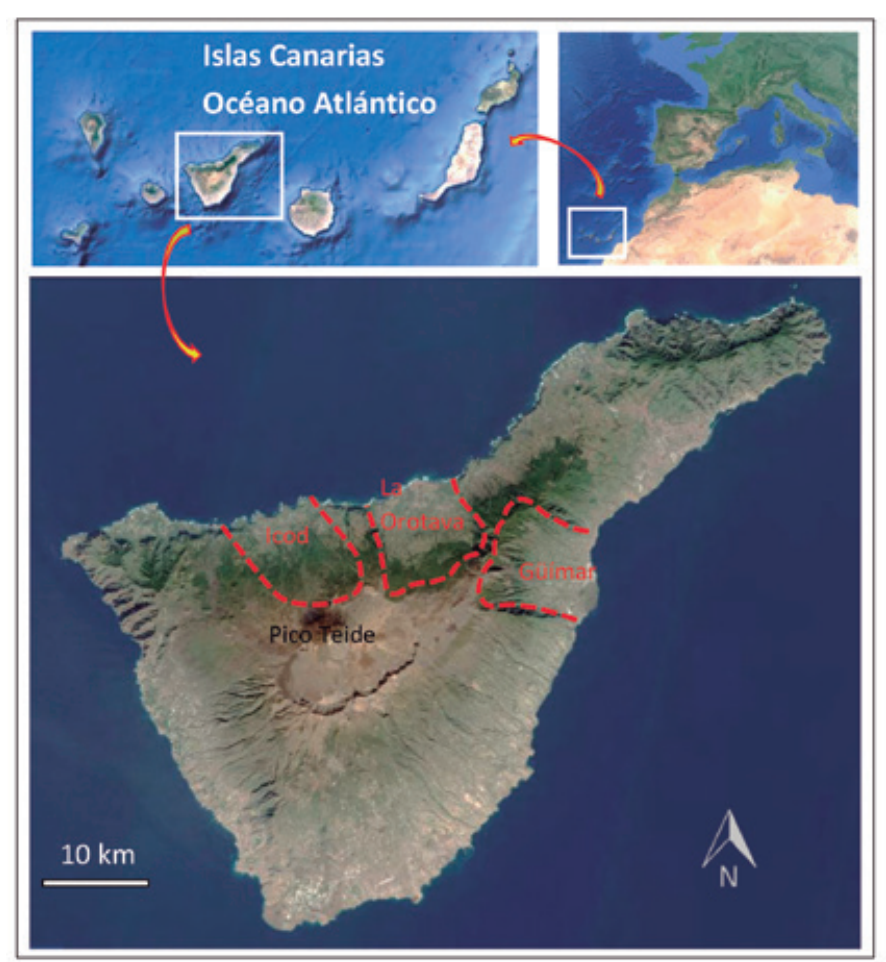

Figura 1. Situación de los valles de La Orotava, Güímar e Icod, en la isla de Tenerife, originados por megadeslizamientos de los flancos volcánicos ocurridos en el último millón de años. Imágenes: GRAFCAN y Google Earth.

Figure 1. Location of the valleys of La Orotava, Güímar and Icod on the island of Tenerife, caused by mega-landslides on the volcanic flanks in the last million years. Images: GRAFCAN and Google Earth.

la teoría de las grandes avalanchas rocosas para explicar el origen de los valles, incluyendo el valle de Icod, fue desarrollada posteriormente por Coello (1973), pero no aceptada definitivamente en el ámbito científico hasta los trabajos de Navarro y Coello (1989), Coello y Bravo (1989) y Bravo Bethencourt y Bravo (1989). A partir de entonces, autores como Ancochea et al. (1990) y Carracedo (1994), entre otros, asumen la existencia de grandes deslizamientos gravitatorios prehistóricos como origen de los valles de Tenerife y otras islas canarias.

El descubrimiento de los depósitos submarinos de los deslizamientos del norte deTenerife a mediados de la pasada década de los 90 (Watts and Masson, 1995; Teide Group, 1997) supuso la confirmación de la teoría de los grandes deslizamientos de flanco. Desde entonces, la investigación geofísica de los inmensos depósitos bajo el mar en torno a las islas Canarias occidentales y su desarrollo en la plataforma continental, ha aportado evidencias y argumentos fundamentales y necesarios para conocer y explicar la evolución de las islas (Watts and Masson, 1995; Teide Group, 1997; Krastel el al., 2001; Masson et al., 2002; León et al.,
2019). Los procesos de destrucción de grandes partes de los edificios volcánicos en episodios catastróficos, no necesariamente asociados a actividad volcánica, forma parte de la evolución de las islas oceánicas incluso en las etapas de crecimiento submarino (seamounts) y de transición (Palomino el at., 2016).

En Tenerife, la investigación de los rasgos subaéreos de los deslizamientos, espectaculares en algunos casos en forma de escarpes de cientos de metros de altura (Figura 2), y de los depósitos volcánicos afectados o relacionados de alguna manera con los deslizamientos, ha permitido ir "introduciendo" estos episodios destructivos en la frenética historia geológica de la isla (Carracedo et al., 2009 y 2011; Cantagrel et al., 1999; Ancochea et al., 1999, entre otros). Estos rasgos morfológicos dejados por los deslizamientos son junto a la caldera de Las Cañadas y el gran volcán de EI Teide, de $3.715 \mathrm{~m}$ de altura, los accidentes más característicos y emblemáticos de Tenerife.

Los deslizamientos de flanco más destacables y recientes ocurridos en Tenerife son el de Icod o Las Cañadas, el de La Orotava y el de Güímar (Figura 3); el deslizamiento de Micheque (Carracedo et al., 2009) o Acentejo, aunque sin reflejo morfológico actual en superficie, puede también incluirse entre ellos. Cada uno de estos deslizamientos, con volúmenes mínimos estimados en torno a los $50-60 \mathrm{~km}^{3}$ (Carracedo et al., 2011), representa una fase destructiva en la evolución de la isla de Tenerife, no necesariamente asociada a grandes erupciones explosivas.

Las masas rocosas movilizadas en los distintos deslizamientos penetraron en el mar en forma de violentas avalanchas de bloques y derrubios, dejando enormes depósitos submarinos de cientos de $\mathrm{km}^{3}$-más de $1.000 \mathrm{~km}^{3}$ según algunos autores-, extendidos a lo largo de varios miles de $\mathrm{km}^{2}$ sobre y a pie de los flancos volcánicos sumergidos (Watts and Masson, 1995; Teide Group, 1997; Krastel el al., 2001; Masson et al., 2002) (Figura 4).

Uno de los aspectos importantes en el estudio de los megadeslizamientos de Tenerife es la determinación de su edad, lo que permite, además de desentrañar las interrelaciones con otros episodios importantes de la historia de la isla, conocer los posibles condicionantes geológicos y morfológicos y los periodos de recurrencia de estos grandes movimientos de masas, aspectos éstos estrechamente relacionados con los mecanismos de inestabilidad y los posibles factores desencadenantes, cuyo conocimiento es a su vez fundamental para evaluar otros riesgos asociados, como los tsunamis causados por la entrada violenta de enormes masas rocosas en el océano.

La edad de los grandes deslizamientos de Tenerife es una cuestión difícil de resolver por la imposibilidad 


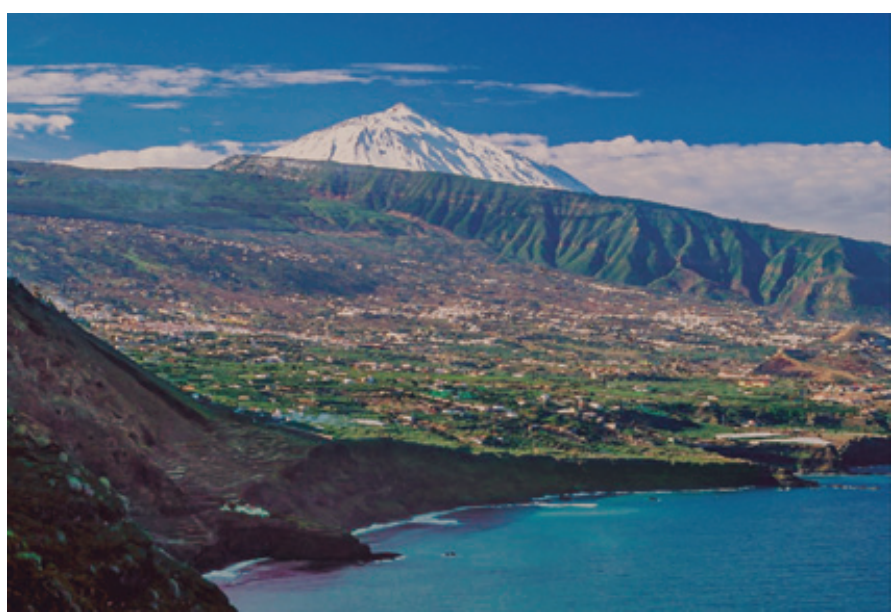

Figura 2. Vista del valle de La Orotava desde el noreste, con el pico Teide al fondo. Destaca el gran escarpe lateral que limita el valle al oeste, el escarpe deTigaiga, de hasta $600 \mathrm{~m}$ de altura.

Figura 2. View of the La Orotava valley from the northeast, with the Teide peak in the background. The great lateral scarp that limits the valley to the west stands out, the Tigaiga escarpment, up to $600 \mathrm{~m}$ high.

de realizar dataciones directas de los procesos y por la complejidad de las relaciones cronoestratigráficas entre los variados y numerosos depósitos volcánicos. La cuestión debe abordarse por tanto de forma indirecta, en base al estudio de las relaciones estratigráficas y temporales entre los depósitos y rasgos morfológicos originados por los grandes movimientos y otros depósitos que puedan ser relacionados con ellos.

En general, y sin plantearse otras hipótesis, se asume que cada uno de los grandes deslizamientos de flanco de Tenerife, y de otras islas canarias como $\mathrm{La}$ Palma o El Hierro, ocurrieron de una sola vez de forma instantánea, dejando tras ellos profundos valles encajados en escarpes de cientos o miles de metros de altura que penetraban en el mar. Pero estos procesos de inestabilidad fueron mucho más complejos, como algunos autores han propuesto para otras islas volcánicas (Oehler et al., 2008), con varios grandes deslizamientos múltiples o recurrentes en cada caso, según se deduce de evidencias morfológicas de los depósitos submarinos de los deslizamientos (Watts y Masson, 1995; Urgeles et al., 1999; Ablay y Hurlimann, 2000) y combinadas con evidencias subaéreas (Biain et al., 2015; León et al., 2017) Estos deslizamientos superpuestos configuraron finalmente grandes valles deslizados cuyos rasgos morfológicos se observan actualmente en Güímar o en La Orotava.

Por tanto, y ante la premisa anterior, no es realista asumir a priori un único episodio y una única edad para los deslizamientos, al menos para todos ellos, tal como se ha venido haciendo por lo general. El hecho de que hayan ocurrido procesos complejos con varios movimientos superpuestos implica diferentes edades

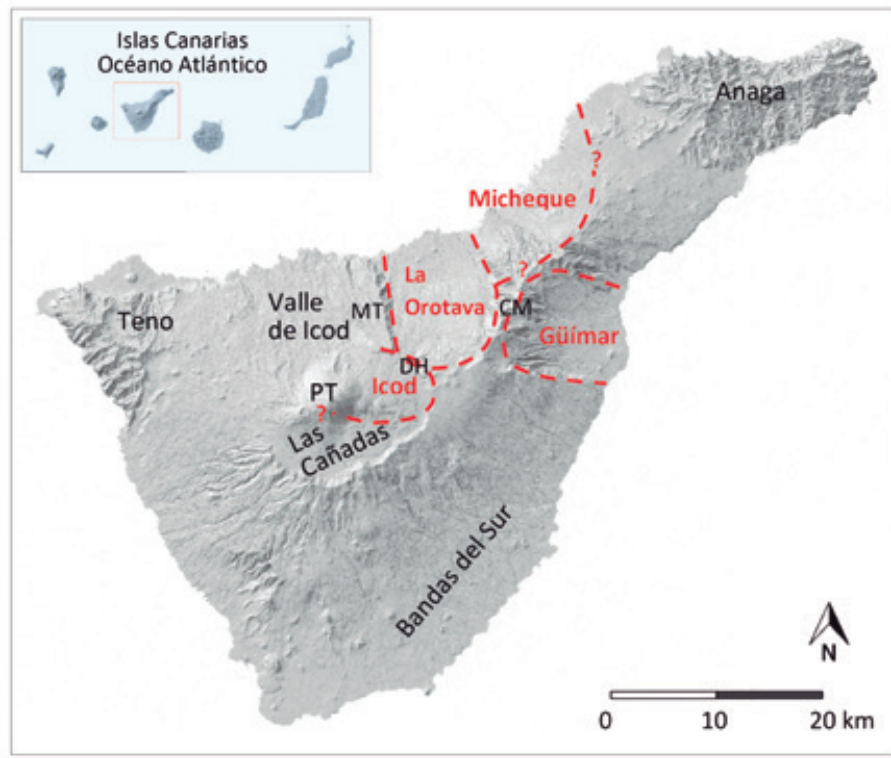

Figura 3. Representación esquemática de los límites de los deslizamientos más recientes ocurridos en Tenerife: Icod, La Orotava, Güímar y Micheque o Acentejo. DH: pared de Diego Hernández en la Caldera de Las Cañadas; MT: Macizo de Tigaiga; CM: volcán Cho Marcial; PT: Pico Teide. Los límites del deslizamiento de Micheque se han obtenido de Carracedo et al. (2011). Mapa base: GRAFCAN.

Figure 3. Sketch of the most recent landslides in Tenerife: Icod, La Orotava, Guímar and Micheque or Acentejo. DH: Diego Hernández wall in Las Cañadas Caldera; MT: Tigaiga Massif; CM: Cho Marcial volcano; PT: Teide peak. Limits of Micheque landslide from Carracedo et al. (2011). Basemap: GRAFCAN.

para cada uno de los episodios, aunque hoy por hoy no es posible estimarlas por no disponer de dataciones suficientes, $y$, por tanto, es normal que se den discrepancias cuando se pretende asignar edades únicas a los deslizamientos, ya que se pueden estar datando distintos episodios.

La revisión y análisis pormenorizado de las edades publicadas hasta ahora que sirven para datar los deslizamientos de Tenerife se ha llevado a cabo aquí considerando esta hipótesis en los casos en que los datos así lo apuntan, hipótesis que se confirma con las nuevas dataciones aportadas en este trabajo.

\section{Contenido del trabajo}

\section{Parte I}

La presente publicación forma la Parte I de un trabajo sobre las edades de los deslizamientos de Tenerife ocurridos en el último millón de años y otras cuestiones relacionadas con la edad, las características y el desarrollo de estos procesos de inestabilidad.

En esta Parte I se recopilan, explican y justifican las dataciones de depósitos volcánicos subaéreos y submarinos, publicadas en las últimas décadas por 


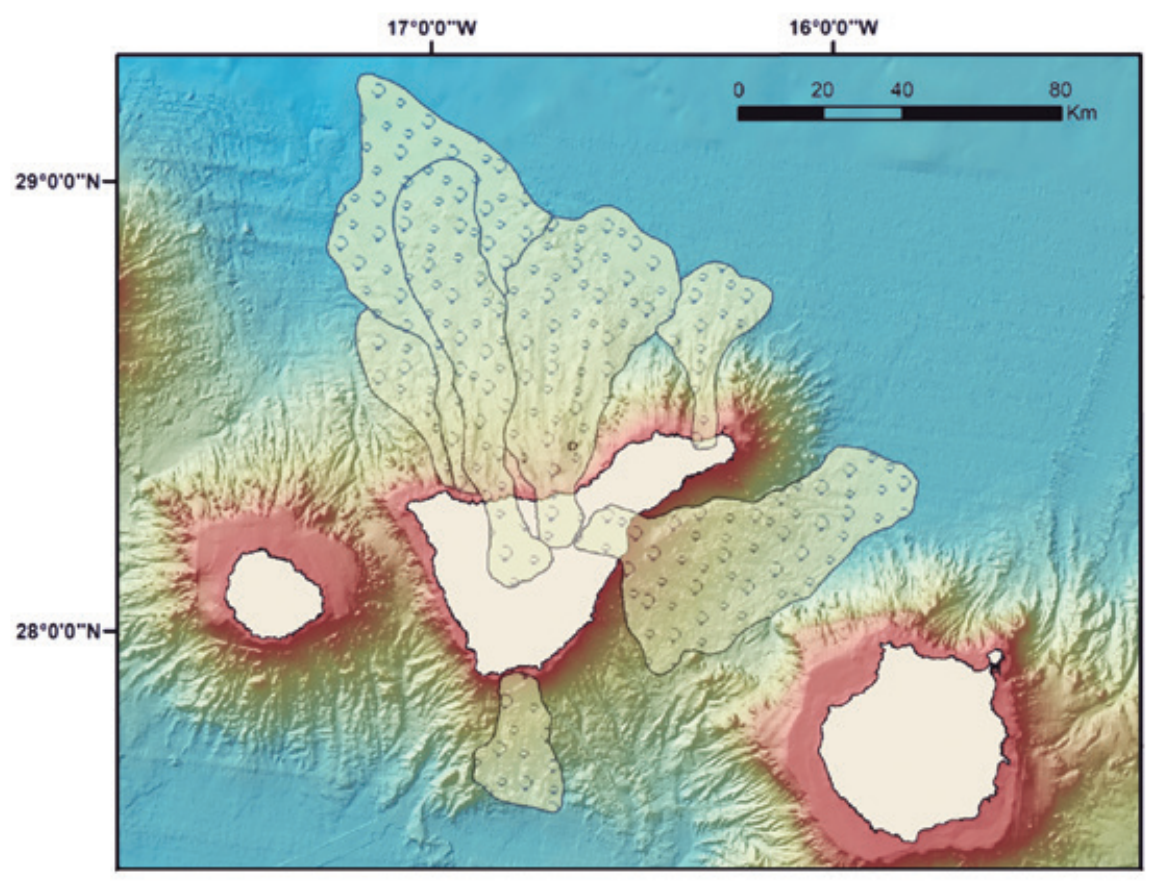

Figura 4. Mapa esquemático de los depósitos submarinos de los deslizamientos en torno a la isla de Tenerife mostrando, entre otros, los correspondientes a los deslizamientos de La Orotava e Icod al norte y Güímar al sureste (Fuente: EMODnet-Geology Project, 2019)

Figure 4. Simplified map of the submarine landslide deposits on the flanks of Tenerife, coming from La Orotava and Icod landslides to the north and Güímar to the southeast (EMODnet-Geology Project, 2019)

diferentes autores, que pueden relacionarse con los deslizamientos de Icod, La Orotava y Güímar; se incluye también el deslizamiento de Micheque o Acentejo, a pesar de ser muy escasos los datos disponibles. Se exponen las diferencias y posibles discrepancias entre las distintas dataciones a la hora de estimar las edades de los deslizamientos mencionados. Finalmente, del estudio de todos los datos disponibles se obtienen las edades más representativas para acotar el tiempo de la ocurrencia de estos procesos de inestabilidad de flanco volcánico.

Las descripciones de lugares, sitios, formaciones geológicas, etc. que se incluyen en el texto se hacen por ser importantes por su relación con los deslizamientos y las dataciones, pero no se describen aspectos geológicos más allá de esta consideración.

A modo de compendio de los trabajos de recopilación e interpretación realizados, se han preparado unas tablas donde se recogen las dataciones publicadas más significativas y representativas -tanto en lo que se refiere a la cercanía en el tiempo entre el depósito datado en cuestión y el deslizamiento como a la relación espacial entre ambos-y las edades estimadas para los deslizamientos a partir de ellas.

Se presentan después los resultados de las dataciones $\mathrm{Ar} / \mathrm{Ar}$ llevadas a cabo por los autores de este trabajo para acotar en lo posible las edades de los deslizamien- tos de La Orotava, Güímary Micheque, y se interpretan los resultados en relación a su representatividad y a los datos previos disponibles. Se establecen así las edades más probables de los citados deslizamientos. En el caso de La Orotava, se propone la ocurrencia de varios deslizamientos superpuestos con edades diferentes que, finalmente, configuraron el gran valle actual.

Las nuevas dataciones se han realizado en rocas procedentes del interior de galerías que atraviesan los rellenos de los valles deslizados y los depósitos dejados por los deslizamientos en el fondo de los mismos, denominados con el término 'mortalón'. Varias de las muestras datadas corresponden a coladas situadas a muro de los depósitos de deslizamiento, lo que supone una aportación destacable, ya que hasta ahora únicamente se contaba con una datación en estos materiales del sustrato, en una galería de Micheque. Así mismo, se han datado por primera vez rocas procedentes de las galerías del valle de Güímar.

\section{Parte II}

En la Parte II del trabajo, que constituye otra publicación (Ferrer et al., 2020-este volumen), se presentan y discuten, a la luz de una serie de evidencias geológicas de campo y de los resultados de las nuevas dataciones $\mathrm{Ar} / \mathrm{Ar}$, algunas cuestiones de interés relacionadas con la edad, desencadenamiento y desarrollo 
de los deslizamientos de Tenerife, como la ocurrencia de varios deslizamientos superpuestos o solapados en un mismo flanco volcánico, espaciados en el tiempo unas decenas de miles de años, frente a la hipótesis extendida mayoritariamente de procesos únicos; así en el caso del valle de La Orotava, se propone la ocurrencia de tres grandes deslizamientos entre los 500 ka y $560 \mathrm{ka}$. Se trata también la relación temporal y causal entre el deslizamiento de Icod y la gran erupción explosiva del final del ciclo Cañadas, y se presentan nuevos datos sobre el deslizamiento de Micheque y sobre el sustrato profundo de los deslizamientos de La Orotava y Micheque.

\section{Sobre la edad de los deslizamientos}

Las edades asignadas hasta ahora a los megadeslizamientos más recientes de Tenerife que aparecen en diferentes publicaciones, se han estimado a partir de las dataciones isotópicas de rocas afectadas o relacionadas de alguna manera con los procesos de deslizamiento, o dataciones de depósitos submarinos provenientes de las avalanchas rocosas. En escasas ocasiones, las dataciones han sido realizadas exprofeso para averiguar la edad de alguno de los deslizamientos; la mayoría de los análisis se han realizado con otros propósitos relacionados con el estudio de la historia y evolución geológica de la isla y las relaciones cronoestratigráficas de los materiales volcánicos. Esto ha llevado en general a asignar amplios rangos de edades a los diferentes deslizamientos, sin poderse establecer edades suficientemente representativas, sobre todo para los más antiguos.

La mayoría de las dataciones que se han empleado para delimitar las edades de las grandes roturas de los flancos del edificio volcánico proceden de rocas de formaciones volcánicas pre o post deslizamiento, estableciéndose la relación temporal a partir de relaciones estratigráficas: las rocas más jóvenes afectadas por los deslizamientos que aparecen en los escarpes de rotura; las coladas posteriores que recubren los escarpes; o los depósitos del relleno temprano de los valles que quedaron tras los deslizamientos. En muy contadas ocasiones se han datado rocas del interior de las galerías que, excavadas con fines de abastecimiento de agua, atraviesan los rellenos de los valles deslizados, y que permiten acotar de forma más precisa las edades de los deslizamientos; estas galerías, de hasta 5 o $6 \mathrm{~km}$ de longitud, alcanzan o atraviesan los depósitos dejados por los deslizamientos en el fondo de los valles, coloquialmente denominado 'mortalón', cuya edad puede ser acotada datando las rocas que aparecen a techo y muro del mismo.
Las edades disponibles hasta ahora se han tomado para limitar por abajo o por arriba la edad de los diferentes deslizamientos, considerando un único episodio, aunque siempre con limitaciones considerables e incertidumbres asociadas tanto a los métodos de datación como a la representatividad de las muestras y al estado de las rocas seleccionadas, de tal manera que a lo largo de los años se han ido descartando algunas de las edades publicadas, sobre todo entre las más pioneras, al estar en contradicción con datos más modernos de métodos de datación más exactos. A estas restricciones hay que añadir, además, la gran dificultad que en ocasiones entraña verificar las propias relaciones estratigráfico-geométricas de las coladas en el campo, y los errores cometidos a veces en la interpretación sobre la posición pre o post deslizamiento de las coladas u otros depósitos.

Al no ser posibles por tanto las dataciones absolutas de los propios deslizamientos, el rango de edades asignado a cada uno de ellos es más o menos amplio dependiendo tanto del número de dataciones disponibles como de la representatividad de las mismas, así como de su localización y de la relación de los depósitos datados con el deslizamiento. Además, al no haberse considerado la ocurrencia de varios deslizamientos superpuestos con diferentes edades en un mismo flanco volcánico, no se ha tenido en cuenta que las dataciones podían corresponder a diferentes procesos, como se propone en este trabajo.

Los autores que han aportado las dataciones de basaltos más válidas para estimar la edad de los deslizamientos han sido Abdel Monem et al. (1972), Ancochea et al. (1990) y Carracedo et al. (2009); Ibarrola et al. (1993) y Carracedo et al. (2011) aportan también algún dato puntual. Todos ellos, excepto el primero, deducen en sus trabajos publicados edades para los deslizamientos.

En la última década, a partir del año 2009, las investigaciones y dataciones de los depósitos distales submarinos derivados de los deslizamientos que se extienden en el Sistema Turbidítico Marroquí (MTS, Moroccan Turbidite System) han permitido establecer relaciones entre los deslizamientos y sus correspondientes depósitos turbidíticos. Así, el estudio de las turbiditas provenientes de las masas rocosas deslizadas y depositadas en las cuencas del MTS, la Cuenca de Agadir (AB), la llanura abisal de Madeira (MAP) y la llanura abisal de Seine (SAP) en menor medida, ha permitido realizar dataciones indirectas de los deslizamientos, a partir de la correlación y datación de las capas de sedimentos hemipelágicos depositados entre las turbiditas.

Las turbiditas con fuente en las distintas islas Canarias pueden identificarse y diferenciarse por su composición mineralógica y geoquímica, color, microfósiles, 
etc. y correlacionarse con los diferentes deslizamientos por su composición, su posición relativa en los testigos de los sondeos submarinos y por sus edades. Weaver et al. (1992) fueron pioneros en identificar y datar turbiditas de la MAP provenientes de Canarias, y Watts and Masson (1995) los primeros en sugerir su relación con los deslizamientos deTenerife. Posteriormente, Frenz et al. (2009) y Hunt et al. (2011 y 2013) asocian turbiditas y deslizamientos y proponen las edades para los deslizamientos a partir de las dataciones de turbiditas.

Los métodos más empleados para determinar las edades de los deslizamientos a partir de los depósitos submarinos han sido: a partir del espesory tasas de sedimentación de los sedimentos que recubren los depósitos de los deslizamientos, por correlación con la edad de los eventos turbidíticos y a partir de isótopos de oxígeno en foraminíferos planctónicos incorporados en los productos de los deslizamientos.

\section{Dataciones relacionadas con el deslizamiento de Icod}

Al hablar aquí del deslizamiento de Icod, se hace referencia al último gran deslizamiento de flanco ocurrido en la ladera del valle de Icod, ya que, como más adelante se apunta, han sido varios los grandes deslizamientos que afectaron al flanco norte del Edificio Cañadas a lo largo de cientos de miles de años.

La mayoría de los datos publicados que pueden considerarse para acotar la edad del deslizamiento de Icod (Figura 3) proceden de dataciones de depósitos subaéreos que se correlacionan temporalmente de una u otra forma con el deslizamiento, como la Formación Diego Hernández y, en particular, el nivel superior que corona esta formación, la llamada unidad ignimbrítica El Abrigo. Se han publicado también dos dataciones de basaltos de relleno basal del valle originado por el deslizamiento. Se dispone, además, de dataciones de depósitos submarinos de turbiditas provenientes de este deslizamiento. Las Tablas $1 \mathrm{a}$ y $1 \mathrm{~b}$ muestran los datos de estas dataciones, sus relaciones con el deslizamiento y las edades deducidas a partir de ellas; en la Figura 5 se representa su distribución temporal.

Nota: La unidad El Abrigo tiene una gran importancia por su relación con la ocurrencia del deslizamiento de Icod. Fue inicialmente descrita por Alonso (1989), en la costa sur de Tenerife entre las localidades de Poris de Abona y Los Abrigos, como una colada piroclástica con gran heterogeneidad composicional, alto contenido en fragmentos líticos, entre ellos de sienita, con espesores de hasta $10 \mathrm{~m}$, a techo de la serie piroclástica que cubre los flancos próximos a la costa del sur de la isla. El nombre de El Abrigo corresponde al del antiguo caserío situado donde actualmente se encuentra la localidad de Los Abrigos (Alonso, J.J. com. pers.). No obstante, autores como Rodríguez Losada (2000) denominan a esta unidad Los Abrigos, en referencia al nombre actual de la población.

\section{Datación de materiales de afloramientos relacionados con el deslizamiento}

En el valle de Icod no afloran los escarpes laterales del deslizamiento de flanco, como si ocurre en los casos de La Orotava y Güímar, a pesar de ser el más reciente ocurrido; el gran volumen de materiales procedentes de las sucesivas erupciones del edificio Teide ha cubierto y enmascarado los rasgos morfológicos de estas roturas en el flanco $\mathrm{N}$ de la isla.

Sin embargo, sí está expuesto el escarpe de cabecera del deslizamiento, formando una parte de la gran caldera de Las Cañadas. Como concluyen diversos autores, los diferentes sectores o tramos lobulados de la pared de la caldera de Las Cañadas corresponden a los escarpes de cabecera de varios deslizamientos del flanco N del Edificio Cañadas, ocurridos entre los 2,6 y 0,18 Ma (Ancochea et al., 1995 y 1999; Cantagrel et al., 1999; Arnaud et al., 2001), no necesariamente relacionados con erupciones explosivas, de los que el deslizamiento de Icod es el más reciente.

En efecto, la llamada pared o cañada de Diego Hernández constituye la parte más oriental y más moderna del escarpe de la caldera de Las Cañadas, y su formación se asocia al deslizamiento de Icod (Ancochea et al., 1999; Cantagrel et al., 1999; Huertas et al., 2002; Carracedo et al., 2007; Hunt et al., 2011). Esta relación entre la formación de esta parte de la caldera y el deslizamiento permite estimar su edad de forma indirecta, a partir de las dataciones realizadas por diversos autores para establecer la cronología de la formación y evolución de la caldera de las Cañadas.

Los mismos materiales que forman la pared o escarpe de Diego Hernández, también depositados en retazos en otros sectores de la actual caldera, aparecen repartidos por toda la isla, principalmente en el flanco sureste, en las llamadas Bandas del Sur (sucesiones que corresponden a los ciclos más modernos explosivos del Edificio Cañadas, de 0,7-0,15 Ma; Ancochea et al., 2000) y constituyen la Ilamada Formación Diego Hernández (FDH), que representa los niveles superiores de los depósitos piroclásticos más modernos del Edificio Cañadas. Según los diferentes esquemas cronoestratigráficos propuestos para el Edificio Cañadas, esta formación se engloba en la denominada Fase III o CE-III (1,1-0,15 Ma) de Ancochea et al. (1999) y Huertas et al. (2002); Grupo Superior (1,6-0,18 Ma) de Martí et al. (1994) y Edgar et al. (2007); Grupo Bandas del Sur 


\begin{tabular}{|c|c|c|c|c|c|}
\hline \multicolumn{2}{|c|}{$\begin{array}{l}\text { Colada o depósito volcánico datado } \\
\text { (pre/post deslizamiento) }\end{array}$} & \multirow{2}{*}{\begin{tabular}{|l|}
$\begin{array}{l}\text { Edad } \\
\text { obtenida }^{1}\end{array}$ \\
$178 \pm 20 \mathrm{ka}$ \\
$173 \pm 31 \mathrm{ka}$ \\
$176 \pm 35 \mathrm{ka}$ \\
$(\sim 175 \pm 15)$ \\
\end{tabular}} & \multirow{2}{*}{\begin{tabular}{|l|} 
Referencia \\
$\begin{array}{l}\text { Martí et al., } \\
1990 \text { y } 1994\end{array}$
\end{tabular}} & \multirow{4}{*}{$\begin{array}{l}\text { Explicación } \\
\text { Depósito que representa el final de la tercera } \\
\text { y última fase explosiva del Edificio Cañadas } \\
\text { III, asociado con la formación de la } \\
\text { depresión actual de Las Cañadas, y al } \\
\text { deslizamiento de Icod. } \\
\text { Deposito considerado inmediatamente } \\
\text { anterior, o contemporáneo, al deslizamiento } \\
\text { (ver explicaciones en el texto). }\end{array}$} & \multirow{4}{*}{\begin{tabular}{|l}
$\begin{array}{l}\text { Edad del } \\
\text { deslizamento }\end{array}$ \\
\\
$\leq 173-183$ ka \\
Valor medio: \\
$\sim 175 \mathrm{ka}$
\end{tabular}} \\
\hline \multirow{8}{*}{ 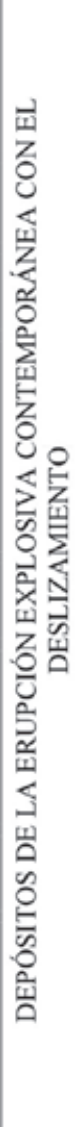 } & \multirow{3}{*}{$\begin{array}{l}\text { Nivel superior de la pared de Diego } \\
\text { Hernández en la Caldera de Las } \\
\text { Cañadas. } \\
\text { Brecha piroclástica explosiva con } \\
\text { cantos de sienita que corona la } \\
\text { Formación Diego Hernandez, FDH, } \\
\text { correlacionada con la ignimbrita El } \\
\text { Abrigo. }\end{array}$} & & & & \\
\hline & & $\begin{array}{l}179 \pm 9 \mathrm{ka} \\
183 \pm 4 \mathrm{ka}\end{array}$ & $\begin{array}{l}\text { Mitjavila y } \\
\text { Villa, } 1993\end{array}$ & & \\
\hline & & $175 \pm 3 \mathrm{ka}$ & $\begin{array}{l}\text { Boulesteix et } \\
\text { al., } 2012\end{array}$ & & \\
\hline & \multirow{4}{*}{$\begin{array}{l}\text { Nivel superior de la Formación Diego } \\
\text { Hernández, FDH. } \\
\text { Depósito explosivo (colada fonolítica) } \\
\text { en la zona SW del borde de la caldera, } \\
\text { en la cumbre del Edificio Cañadas. } \\
\begin{array}{l}\text { Unidad El Abrigo: nivel superior de la } \\
\text { Formación Diego Hernandez, FDH. } \\
\text { Aflora principalmente en el flanco SE } \\
\text { de la isla. } \\
\text { Brecha ignimbrítica con clastos de } \\
\text { sienita. Se correlaciona con el nivel } \\
\text { superior de la pared de Diego } \\
\text { Hernández. }\end{array}\end{array}$} & $<200 \mathrm{ka}$ & $\begin{array}{l}\text { Abdel Monem } \\
\text { et al., } 1972\end{array}$ & $\begin{array}{l}\text { Este dato indica una edad máxima de unos } \\
200 \text { ka para la formación de la caldera de las } \\
\text { Cañadas, edad que sería igual o anterior al } \\
\text { deslizamiento. } \\
\text { Deposito anterior o contemporáneo al } \\
\text { deslizamiento. }\end{array}$ & $\leq 200 \mathrm{ka}$ \\
\hline & & $130 \pm 20 \mathrm{ka}$ & $\begin{array}{l}\text { Ancochea } e t \\
\text { al., } 1990\end{array}$ & $\begin{array}{l}\text { El Abrigo es el depósito más joven y } \\
\text { extendido de la FDH, representa el evento }\end{array}$ & \multirow{3}{*}{$\leq 130-196 \mathrm{ka}$} \\
\hline & & $171 \pm 2 \mathrm{ka}$ & $\begin{array}{l}\text { Brown et al., } \\
2003 \text { (edad } \\
\text { recalculada por } \\
\text { Edgar } \text { et al., } \\
2007 \text { ) }\end{array}$ & $\begin{array}{l}\text { del edificio Cañadas. } \\
\text { Su origen, al igual que el nivel superior de } \\
\text { la pared de DH, se asocia a la formación de } \\
\text { la caldera de las Cañadas. }\end{array}$ & \\
\hline & & $196 \pm 6 \mathrm{ka}$ & $\begin{array}{l}\text { Edgar } \text { et al., } \\
2007\end{array}$ & $\begin{array}{l}\text { Depósito inmediatamente anterior o } \\
\text { contemporáneo al deslizamiento. }\end{array}$ & \\
\hline & $\begin{array}{l}\text { Nivel superior del macizo de Tigaiga, } \\
\text { en el sector de Fortaleza. } \\
\text { Depósito piroclástico con fragmentos } \\
\text { de sienitas que aparece coronando en } \\
\text { parte el macizo de Tigaiga. }\end{array}$ & $\begin{array}{l}170-200 \mathrm{ka} \\
(170 \pm 16 \mathrm{ka}) \\
(199 \pm 18 \mathrm{ka})\end{array}$ & $\begin{array}{l}\text { Mitjavila, } 1990 \\
\text { (En: Ancochea } \\
\text { et al., } 1995 \text { y } \\
\text { Ibarrola et al., } \\
\text { 1993) }\end{array}$ & $\begin{array}{l}\text { Este depósito se considera equivalente al } \\
\text { nivel superior de la pared de Diego } \\
\text { Hernández. } \\
\text { Deposito anterior o contemporáneo al } \\
\text { deslizamiento. }\end{array}$ & $\leq 170-200 \mathrm{ka}$ \\
\hline \multirow{3}{*}{ 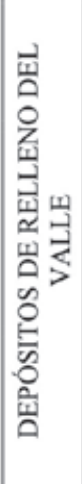 } & \multirow{3}{*}{$\begin{array}{l}\text { Coladas de lava de relleno del valle de } \\
\text { Icod, sobre los depósitos de 'mortalón'. } \\
\text { Depósitos subterráneos cortados en las } \\
\text { galerías Salto del Frontón y La Gotera. }\end{array}$} & $198 \pm 5 \mathrm{ka}$ & $\begin{array}{l}\text { Carracedo et } \\
\text { al., } 2007\end{array}$ & $\begin{array}{l}\text { Colada en la galeria Salto del Frontón (a } \\
2.700 \mathrm{~m} \text { de bocamina) } \\
\text { Depósito posterior al deslizamiento. }\end{array}$ & \multirow{3}{*}{$\begin{array}{l}>198 \mathrm{ka} \\
>158 \mathrm{ka}^{(*)}\end{array}$} \\
\hline & & $\begin{array}{l}158 \pm 5 \mathrm{ka} \\
(*)\end{array}$ & $\begin{array}{l}\text { Carracedo et } \\
\text { al., } 2006\end{array}$ & $\begin{array}{l}\text { Colada a techo del 'mortalón' en la galeria } \\
\text { Salto del Frontón (a } 4.190 \mathrm{~m} \text { de bocamina) } \\
\text { Depósito posterior al deslizamiento. } \\
\left({ }^{*}\right) \text { Procede de una unidad muy alterada, } \\
\text { según los propios autores (ver texto). }\end{array}$ & \\
\hline & & $161 \pm 5 \mathrm{ka}$ & $\begin{array}{l}\text { Boulesteix et } \\
\text { al., 2012; } \\
\text { Gillot } \text { et al., } \\
2001\end{array}$ & $\begin{array}{l}\text { Primera colada de relleno sobre el } \\
\text { 'mortalón' en la galería La Gotera (a } 4.370 \\
\text { m de bocamina) } \\
\text { Depósito posterior al deslizamiento. }\end{array}$ & \\
\hline
\end{tabular}

${ }^{1}$ Todas las edades son K/Ar, excepto las de Mitjavila y Villa (1993), Brown et al. (2003) y Edgar et al. (2007) que son Ar/Ar.

${ }^{2}$ Edad deducida por la relación temporal de los depósitos con el deslizamiento, según las dataciones publicadas por los diferentes autores.

NOTA EXPLICATIVA: En las primeras columnas se presentan los datos publicados hasta 2019, incluyendo las incertidumbres proporcionadas por cada autor; en las dos últimas columnas se explica la relación del depósito datado con el deslizamiento, y la edad limite (por arriba o por abajo) que se deduce para el mismo, según que el depósito datado sea o se considere anterior o posterior al deslizamiento a criterio de cada autor; en caso de desacuerdo de los autores de este trabajo con alguna de las estimaciones, se indica en el lugar correspondiente.

En los casos en que alguno/s de los autores citados ha propuesto una edad o rango de edades para el deslizamiento, estas edades se han incluido a pie de Tabla; en ocasiones son rangos de edades muy amplias, como los casos de La Orotava y de Güímar (Tablas 2a y 3a). En los últimos años, al disponerse de nuevos datos, sobre todo submarinos, las edades se han ido ajustando. Ver explicaciones en el texto.

Tabla 1a. Dataciones de depósitos volcánicos relacionados con el deslizamiento de Icod.

Table 1a. Ages of volcanic deposits related to the lcod landslide. 


\begin{tabular}{|c|c|c|c|c|c|}
\hline $\begin{array}{l}\text { Depósito } \\
\text { submarino }\end{array}$ & Método de datación & $\begin{array}{l}\text { Edad } \\
\text { estimada }\end{array}$ & Referencia & Explicación & $\begin{array}{l}\text { Edad del } \\
\text { deslizamiento }^{1}\end{array}$ \\
\hline $\begin{array}{l}\text { Turbidita "g" } \\
\text { MAP }\end{array}$ & $\begin{array}{l}\text { Correlación de sedimentos } \\
\text { pelágicos con estratigrafia de } \\
\text { isótopos de oxígeno (MIS) }\end{array}$ & $\begin{array}{l}190 \mathrm{ka} \\
\text { Limite } \\
\text { MIS 6-7 }\end{array}$ & $\begin{array}{l}\text { Weaver et al., } \\
1992\end{array}$ & $\begin{array}{l}\text { Se datan turbiditas de la MAP, entre ellas la } \\
\text { turbidita "g", sin establecer correlación con } \\
\text { deslizamientos. } \\
\text { Posteriormente otros autores relacionarán } \\
\text { estos datos con la edad de los deslizamientos. }\end{array}$ & $\sim 190$ ka \\
\hline $\begin{array}{l}\text { Depósitos } \\
\text { proximales de } \\
\text { deslizamiento }\end{array}$ & $\begin{array}{l}\text { A partir de la tasa de sedimentación } \\
\text { del los sedimentos que cubren los } \\
\text { depósitos de deslizamiento. }\end{array}$ & $170 \mathrm{ka}$ & $\begin{array}{l}\text { Watts and } \\
\text { Masson, } 1995\end{array}$ & $\begin{array}{l}\text { Los autores, además, sugieren la relación de } \\
\text { la turbidita "g" de Weaver et al. (1992) con } \\
\text { el deslizamiento de Icod, por primera vez. }\end{array}$ & $\sim 170 \mathrm{ka}$ \\
\hline $\begin{array}{l}\text { Turbidita " } 14 " \\
\mathrm{AB}\end{array}$ & $\begin{array}{l}\text { Relación de edades } \\
\text { bioestratigráficas con los MIS. }\end{array}$ & $\begin{array}{l}175 \pm 25 \mathrm{ka} \\
200 \pm 25 \mathrm{ka} \\
\text { MIS } 6 \text { Medio }\end{array}$ & $\begin{array}{l}\text { Wynn et al., } \\
2002\end{array}$ & $\begin{array}{l}\text { En este trabajo se datan turbiditas de la } \mathrm{AB} \text {, } \\
\text { entre ellas la turbidita "14", sin establecer } \\
\text { correlación con deslizamientos. }\end{array}$ & $175-200 \mathrm{ka}$ \\
\hline $\begin{array}{l}\text { Turbidita } \\
\text { "AB14" } \\
\mathrm{AB}\end{array}$ & $\begin{array}{l}\text { Correlación con marcadores } \\
\text { bioestratigráficos. }\end{array}$ & $\begin{array}{l}\sim 160 \mathrm{ka} \\
\text { MIS } 6 \text { Medio }\end{array}$ & $\begin{array}{l}\text { Frenz et al., } \\
2009^{*}\end{array}$ & $\begin{array}{l}\text { Se establece una relación entre la turbidita } \\
\text { "AB14" y el deslizamiento de Icod, por } \\
\text { composición mineralógica y geoquímica de } \\
\text { los sedimentos marinos y las rocas subaéreas. }\end{array}$ & $\sim 160 \mathrm{ka}$ \\
\hline \multirow[t]{3}{*}{$\begin{array}{l}\text { Turbidita } \\
\text { "Mg" } \\
\text { MAP }\end{array}$} & $\begin{array}{l}\text { Correlación con marcadores } \\
\text { bioestratigráficos. } \\
\text { A partir de registros ODP y } \\
\text { datación de hemipelagitas. }\end{array}$ & $\begin{array}{l}165 \pm 5 \mathrm{ka} \\
170 \mathrm{ka}\end{array}$ & \multirow[t]{3}{*}{$\begin{array}{l}\text { Hunt et al., } \\
2013 \mathrm{a}^{*}\end{array}$} & \multirow[t]{3}{*}{$\begin{array}{l}\text { Se establece una relación entre la turbidita } \\
\text { "Mg" y el deslizamineto de Icod, por la } \\
\text { composición mineralógica y geoquimica de } \\
\text { los sedimentos marinos y la de las rocas } \\
\text { subaéreas. }\end{array}$} & \multirow{3}{*}{$165-170 \mathrm{ka}$} \\
\hline & $\begin{array}{l}\text { A partir de la velocidad de } \\
\text { sedimentación. }\end{array}$ & $\begin{array}{l}168 \pm 10 \mathrm{o} \\
182 \pm 9 \mathrm{ka}\end{array}$ & & & \\
\hline & $\begin{array}{l}\text { Fotoespectrometria (según la } \\
\text { posición de la capa en el testigo) }\end{array}$ & $\begin{array}{l}165 \pm 5 \mathrm{ka} \\
\text { MIS } 6 \text { Medio }\end{array}$ & & & \\
\hline
\end{tabular}

Tabla 1b. Dataciones de depósitos submarinos relacionados con el deslizamiento de Icod.

Table 1b. Ages of submarine deposits related to the Icod landslide.

Superior (0,67-0,17 ka) de Brown et al. (2003); o Ciclo 3 de las Bandas del Sur (0,37-0,17 Ma) según Bryan et al. (2002), coincidiendo en este caso el ciclo con la FDH.

La Formación Diego Hernández ha sido datada en la pared de la caldera, obteniéndose edades representativas entre 540 y 170-178 ka (Ancochea et al., 1990 y 1999); otras edades aportadas por varios autores indican un rango más amplio para la FDH, entre 600-700 ka y 180 ka (Mitjavila y Villa, 1993; Edgar et al., 2007; Brown et al., 2003), o más corto, entre 370 y 170 ka (Martí et al., 1994; Bryan et al., 2002).

Es decir, mientras que hay un consenso para la edad mínima en torno a los $170-180 \mathrm{ka}$, su edad máxima se establece entre $>540$ y $700 \mathrm{ka}$, por dataciones en niveles del propio escarpe de Diego Hernández o por correlaciones estratigráficas con los niveles de techo de la Formación Guajara, correspondiente al anterior ciclo eruptivo. Martí et al. (1994), basándose en datos de Mitjavila y Villa (1993), restringen el rango al no considerar representativo el dato de $540 \mathrm{ka}$ de Ancochea et al. (1990), tomando como edad máxima de la FDH otro dato de los mismos autores de 370 ka correspondiente a rocas fonolíticas del sector de La Fortaleza, al noreste de la caldera, asociadas cronológicamente a los niveles basales de la FDH.

La FDH de las Bandas del Sur está coronada por el depósito ignimbrítico de El Abrigo, que corresponde a una brecha con clastos juveniles y fragmentos de sienita, descrita en los afloramientos del flanco sur de la isla (Alonso, 1989; Pittari et al., 2006 y 2008; Edgar et al., 2007; Brown et al., 2003), con espesores máximos de 20-25 m (Bryan et al., 2002; Brown et al., 2003; Edgar et al., 2007) y edad de 0.17-0.18 Ma. El Abrigo es el depósito más joven y extendido de la FDH, formado por una gran explosión de la última fase del Edificio Cañadas (Ancochea et al., 1999; Boulesteix et al., 2012).

El nivel superior de la pared de Diego Hernández (DH) en la caldera de Las Cañadas es una brecha ignimbrítica con clastos de sienita que se ha correlacionado con la ignimbrita El Abrigo (Ancochea et al., 1990 y 1999; Martí et al., 1994; Bryan et al., 1998; Rodríguez Losada, 2000; Pittari et al., 2006 y 2008), interpretándose, al igual que ésta, como el producto de la última erupción explosiva en el Edificio Cañadas III y asociada a la formación de la parte más joven de la caldera. Para 


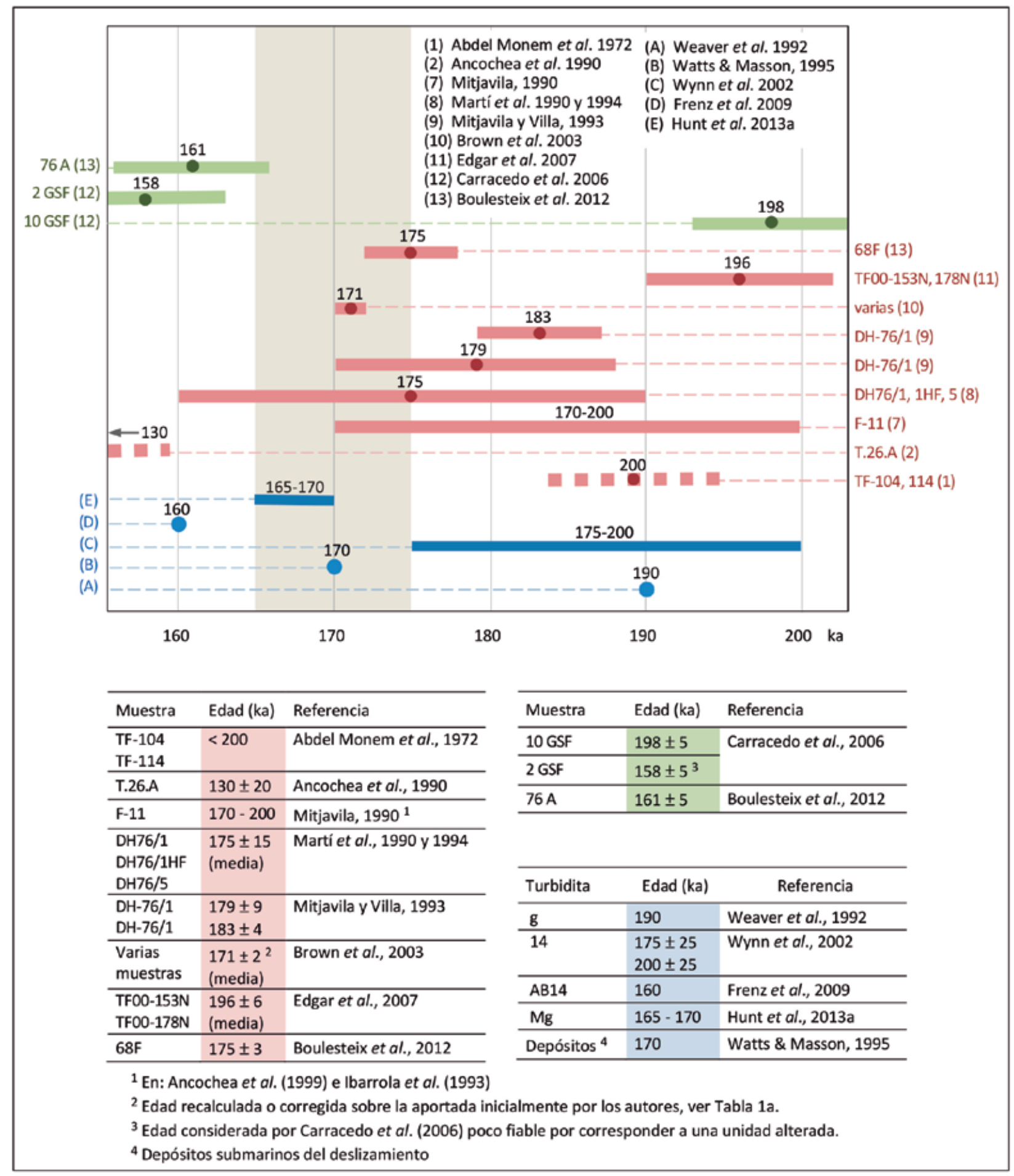

Figura 5. Dataciones relacionadas con el deslizamiento de Icod. Las edades en rojo y verde corresponden respectivamente a depósitos post y predeslizamiento (ver Tabla 1a para explicación); por tanto el deslizamiento habría sido anterior a las edades en rojo y posterior a las edades en verde. Las edades en azul corresponden a dataciones de depósitos submarinos (Tabla 1b). Las barras horizontales representan los rangos de edades, considerando las incertidumbres correspondientes aportadas por cada autor; alineados con cada barra aparecen en los márgenes las referencias al autor y el $\mathrm{n}^{\circ}$ de muestra. La franja vertical gris indica la edad más representativa para el deslizamiento: 165-175 ka.

Figure 5. Ages related to the Icod landslide. The ages in red and green correspond respectively to post and pre-landslide deposits (see Table 1 a for explanation); therefore the rockslide would have occurred before the red ages and after the green ages. The ages in blue correspond to underwater deposits (Table 1b). Horizontal bars represent the age ranges, considering the corresponding uncertainties provided by each author. Aligned with each bar, the references to the author and the sample number appear in the margins. The grey vertical stripe represents the most representative age for the landslide: 165-175 ka. 
este nivel superior ha sido estimada una edad similar a la de la unidad El Abrigo: 170-180 ka (Martí et al., 1990 y 1994; Mitjavila y Villa, 1993; Ancochea, 1999). Por otro lado, la unidad de El Abrigo ha sido datada en uno de los afloramientos de la zona sureste deTenerife, junto a la costa, en 130 ka (Alonso, 1989; Ancochea et al., 1990).

Los depósitos ignimbríticos que coronan la FDH se han relacionado por su naturaleza, distribución, posición estratigráfica y relación geométrica con respecto al escarpe de Diego Hernández, con la ocurrencia del deslizamiento de Icod que formó la pared oriental de la caldera (Ancochea et al., 1999; Huertas et al., 2002; Hunt et al., 2011), asumiendo que la gran erupción explosiva que dio lugar a los depósitos ignimbríticos de El Abrigo y del nivel de coronación del escarpe de $\mathrm{DH}$ y el deslizamiento de Icod fueron coetáneos. Bravo Bethencourt y Bravo (1989) ya relacionaron los depósitos explosivos con el "gran fenómeno de la desaparición de la cúpula central" del edificio volcánico, aunque sin aludir a un deslizamiento, estableciendo también una relación cronológica al indicar que no existen depósitos sieníticos de proyección explosiva sobre los materiales posteriores al "gran fenómeno".

Sobre esta relación, Ancochea et al. (1999) indican que el último nivel del depósito de la pared de $\mathrm{DH}$, con fragmentos de sienitas nefelínicas, predata o es contemporáneo al episodio de la formación de la caldera actual; Hunt et al. (2011) inciden en la relación entre la erupción que dio lugar a la unidad El Abrigo y el deslizamiento de Icod; y Boulesteix et al. (2012) asocian la erupción explosiva, hace unos $175 \mathrm{ka}$, a la descarga instantánea que habría provocado el deslizamiento de Icod, como ya habían propuesto Huertas et al. (2002) y Carracedo et al. (2007).

Así, partiendo de la relación temporal establecida por criterios estratigráficos entre el deslizamiento y los depósitos considerados prácticamente simultáneos al mismo, puede estimarse la edad de forma indirecta, a partir de las dataciones disponibles de los materiales de estos depósitos, como se explica en los siguientes subapartados.

\section{Nivel superior del escarpe de deslizamiento}

Considerando que el escarpe de Diego Hernández (DH) en la caldera de Las Cañadas corresponde al escarpe de cabecera del deslizamiento de lcod (Ancochea et al., 1999; Cantagrel et al., 1999; Huertas et al., 2002; Hunt et al., 2011), la edad de éste último sería menor que la edad del nivel de brechas sieníticas que corona el escarpe, el nivel más moderno afectado por la rotura del flanco volcánico. Por otro lado, al establecerse una relación temporal entre el deslizamiento y la erupción explosiva que depositó el nivel brechoide (Ancochea et al., 1999; Huertas et al., 2002; Hunt et al., 2011 y 2013), ambos eventos podrían considerarse contemporáneos.

Las dataciones publicadas del nivel superior ignimbrítico de la pared de DH son las siguientes (Tabla 1a): 173-178 ka (Martí et al., 1990), 179-183 ka (Mitjavila y Villa, 1993) y 175 ka (Boulesteix et al., 2012).

Por tanto, y como resumen de los datos anteriores, puede deducirse para el deslizamiento de Icod una edad en torno a los 173-183 ka.

\section{Depósitos considerados contemporáneos al desliza- miento de Icod (unidad El Abrigo)}

La edad del deslizamiento de Icod puede estimarse por la edad de la unidad El Abrigo, que corona la Formación Diego Hernández, correlacionada con el nivel superior del escarpe del deslizamiento de la pared de Diego Hernández. Se trata en ambos casos de depósitos ignimbríticos brechoides con clastos de sienitas nefelínicas. De hecho, para algunos autores, aunque con composición y características variables según las zonas, estos depósitos se engloban en la unidad ignimbrítica El Abrigo (Pittari et al., 2006 y 2008).

Las dataciones del depósito El Abrigo en los afloramientos del flanco SE de la isla son: $130 \mathrm{ka}$ (Ancochea et al., 1990), 169 ka (Brown et al., 2003; recalculada a 171 ka por Edgar et al., 2007) y 196 ka (Edgar et al., 2007).

Por tanto, considerando que el depósito explosivo El Abrigo es simultáneo al deslizamiento de Icod, o inmediatamente anterior, éste tendría una edad en el rango 130-196 ka.

Otros datos que pueden considerarse son los siguientes: (1) la edad de un depósito piroclástico con fragmentos de sienitas que aparece coronando el macizo de Tigaiga, que limita al este el valle de Icod, considerado equivalente al nivel de coronación de la pared de DH por Ancochea et al. (1999), datado entre 0,17 y 0,20 Ma (Mitjavila, 1990; en Ancochea et al., 1999); (2) Abdel Monem et al. (1972), en base a la datación de una colada fonolítica en la zona de cumbre del Edificio Cañadas, de los últimos estadios de la serie relacionada con la formación de la caldera, establecieron una edad $<0.2$ Ma para su formación, edad que sería anterior o igual al deslizamiento; otra datación de los mismos autores en la misma serie da una edad de 0,2 Ma (0,189 Ma según corrección realizada por Mitjavila y Villa, 1993).

De estos últimos datos puede establecerse para el deslizamiento una edad menor o igual que 170-200 ka.

\section{Depósitos de megatsunamis originados por el desli-} zamiento

En el marco de proyectos de investigación llevados a cabo en los últimos años sobre los deslizamientos de 
Tenerife, liderados por el IGME, se han identificado diversos afloramientos de depósitos de megatsunami sobre las plataformas costeras de Teno y Buenavista, al NE de la isla de Tenerife (Madeira et al., 2011; Ferrer et al., 2013), asociados al deslizamiento de Icod y a la gran erupción explosiva del final del ciclo Cañadas (Coello et al., 2014; Paris et al., 2017; Ferrer et al., 2020-este volumen). Estos depósitos se han datado tentativamente por la edad de las coladas de lava sobre las que se depositaron. En el caso de Teno, los sedimentos detríticos fosilíferos se extienden desde la costa, hasta una distancia de 500 metros tierra adentro (en algunas zonas se alcanzan los 800 metros), ocupando varios $\mathrm{km}^{2}$, y se sitúan sobre una plataforma formada por coladas de lava del cercano volcán Teno Alto, datadas puntualmente en $178 \pm 6$ ka (Carracedo et al., 2007); en la zona de Buenavista, los depósitos fosilíferos se sitúan sobre lavas datadas en 194 \pm 8 ka (Carracedo et al., 2007; París et al., 2017).

Es decir, la edad del deslizamiento de Icod, que originó los depósitos de megatsunami, sería, según estas dataciones, menor de $178 \mathrm{ka}$; considerando las incertidumbres, la edad puede situarse por debajo de $172 \mathrm{ka}$.

\section{Datación de basaltos de relleno del valle}

Se dispone de un par de dataciones de los materiales de relleno del valle de deslizamiento, en basaltos atravesados por galerías excavadas en el flanco $\mathrm{N}$ del valle de Icod: $198 \pm 5$ ka (galería Salto del Frontón, a unos $1.650 \mathrm{~m}$ antes de alcanzar el techo del depósito del deslizamiento, llamado 'mortalón'; Carracedo et al., 2006 y 2007) y $161 \pm 5$ ka (galería La Gotera, a techo del 'mortalón'; Boulesteix et al., 2012). Otro dato obtenido por los primeros autores citados a mayor profundidad en la galería Salto del Frontón, a techo del 'mortalón', de $158 \pm 5 \mathrm{ka}$, es considerado por ellos mismos poco fiable por corresponder a una unidad alterada; sin embargo, esta edad resulta similar a la edad de $161 \pm 5 \mathrm{ka}$, y sería más consecuente que la de $198 \mathrm{ka}$ (mayor que todas las otras dataciones), dada la cercanía de ambas galerías que, con toda probabilidad, cortan el mismo depósito de 'mortalón'; en este caso, habría que desechar la edad de 198 ka a efectos de datación del deslizamiento. En la Figura 11 se representa la situación de las dos galerías.

\section{Datación de turbiditas abisales y otros depósitos submarinos}

Como pioneros, Weaver et al. (1992) estudian y datan las turbiditas de la Llanura Abisal de Madeira (MAP, Madeira Abyssal Plain) y las agrupan según su com- posición, asignando a las turbiditas ricas en minerales volcánicos (volcanic rich turbidites) una procedencia de las islas Madeira o las Canarias. Pearce and Jarvis (1992), mediante análisis geoquímicos de vidrios volcánicos de las turbiditas arenosas de la MAP, identifican que provienen principalmente de las Canarias. Una de las turbiditas de composición volcánica identificada por Weaver et al. (1992), la turbidita g, es datada por correlación entre los marcadores bioestratigráficos y los estadios isotópicos marinos (MIS, marine oxigen-isotope stages) en aproximadamente $190 \mathrm{ka}$, en el límite entre los MIS 6 y 7.

Posteriomente, Wynn et al. (2002) estudian las turbiditas de la Cuenca de Agadir (AB, Agadir Basin) e identifican la turbidita 14 , con área fuente en el $\mathrm{N}$ de la isla de Tenerife (por composición mineralógica), que correlacionan con la turbidita g de la MAP y datan en $175 \pm 25$ y $200 \pm 25$ ka por estratigrafía de isótopos de oxígeno. Hasta aquí, ninguno de los autores citados establece relación entre las turbiditas y los deslizamientos de Tenerife.

Frenz et al. (2009), datan la turbidita AB14 de la Cuenca de Agadir (la misma que la turbidita 14), por marcadores bioestratigráficos, en $160 \mathrm{ka}$, hacia la mitad del MIS 6, y establecen por primera vez la relación entre la turbidita $A B 14$ y el deslizamiento de Icod (así como relaciones de otras turbiditas con otros deslizamientos); previamente, Watts and Masson (1995) habían sugerido una correlación entre la turbidita $g$ de Weaver et al. (1992) y el deslizamiento de Icod. Hunt et al. (2011) establecen, a partir de estudios sedimentológicos y geoquímicos de testigos de la turbidita procedente de Icod, en la Cuenca de Agadir, su relación con el depósito El Abrigo y el deslizamiento de Icod.

Hunt et al. (2013) realizan un exhaustivo estudio y datan las turbiditas volcanoclásticas de la zona norte de la Llanura Abisal de Madeira (MAP), donde está depositado el registro temporal más extenso de turbiditas volcanoclásticas del SistemaTurbidítico Marroquí; estas turbiditas se asocian a las islas Canarias por composición mineralógica y geoquímica. Los autores realizan dataciones en los sedimentos hemipelágicos por correlaciones entre marcadores bioestratigráficos y litoestratigráficos con los MIS, además de otros métodos como la fotoespectometría o las tasas de sedimentación. Datan la turbidita volcánica Mg (la misma que la turbidita g), proveniente del deslizamiento de Icod, en 165-170 ka, dentro del MIS 6 glacial.

En resumen, los autores citados identifican y correlacionan niveles de turbiditas en la llanura abisal de Madeira (turbidita $\mathrm{g} \circ \mathrm{Mg}$ ) y en la cuenca de Agadir (turbidita 14 o AB14), datándolos por estratigrafía isotópica (MIS) y otros métodos entre 160 y 200 ka BP (verTabla 1b): 
- turbidita g: 190 ka (Weaver et al., 1992)

- turbidita 14: 175 y 200 ka (Wynn et al., 2002)

- turbidita AB14: 160 ka (Frenz et al., 2009)

- turbidita Mg: 165-170 ka (Hunt et al., 2013)

Estos niveles de turbiditas se asocian al deslizamiento de Icod en la isla de Tenerife por análisis geoquímicos y mineralógicos, y por su edad. Los resultados se enmarcan mayoritariamente dentro del MIS 6, ciclo glacial entre 186 y 130 ka BP, o en el límite entre los MIS 5 y 6 (en los casos de 190 ka y 200 ka).

La edad del deslizamiento de Icod también fue estimada por Watts and Masson (1995), de una manera poco precisa, a partir del espesor de los sedimentos hemipelágicos que tapizan los depósitos submarinos del deslizamiento en el flanco norte de la isla de Tenerife: considerando una velocidad de sedimentación de $6 \mathrm{~cm} / \mathrm{ka}$, se obtiene una edad de unos $170 \mathrm{ka}$. Hunt et al. (2013) aplican este mismo procedimiento en los depósitos de sedimentos pelágicos y turbiditas de la MAP, obteniendo edades de $168 \pm 10$ y $182 \pm 9$ ka.

\section{Edad del deslizamiento de Icod}

A modo de resumen de los párrafos anteriores, se indican a continuación los aspectos más importantes y las edades deducidas para el deslizamiento.

El rango de edades estimadas en diferentes publicaciones anteriores al año 2000 para el deslizamiento de Icod, entre 130 y 200 ka (Ancochea et al., 1999; Cantagrel et al., 1999), se ha ido reduciendo al disponerse desde entonces de más dataciones, tanto de depósitos subaéreos como submarinos, de tal forma que actualmente se acepta una edad máxima de $175 \mathrm{ka}$, que coincide con la edad media de las dataciones del nivel superior de la Formación Diego Hernández aportadas por Martí et al. (1990) y Boulesteix et al. (2012).

Al ser el deslizamiento de lcod el más reciente ocurrido en Tenerife y estar relacionado con los prominentes eventos volcánicos y sus correspondientes depósitos piroclásticos de la última fase explosiva del Edificio Cañadas, sobre los que se han desarrollado numerosas investigaciones y estudios de detalle, se cuenta con información muy representativa para su datación y para establecer su relación con otros procesos volcánicos contemporáneos. Estos aspectos han sido tratados por diferentes autores citados en los párrafos anteriores.

El aspecto más importante para establecer la edad del último gran deslizamiento de flanco son los depósitos explosivos sieníticos que aparecen repartidos por la isla y que, por su naturaleza similar, se consideran de igual origen; estos son los siguientes: el depósito que forma el nivel superior de la pared de Diego
Hernández, que aparece también tapizando otras zonas del borde oriental de la caldera; los depósitos sobre el flanco SE de Tenerife, en las Ilamadas Bandas del Sur, coronando la Formación Diego Hernández (unidad EI Abrigo); y algunos depósitos aislados en la zona norte de la isla, en Buenavista y las zonas más elevadas del macizo de Tigaiga.

Estos niveles piroclásticos representan el último ciclo del vulcanismo fonolítico del edificio Cañadas, que culminó con la gran erupción explosiva que dio lugar al depósito ignimbrítico de El Abrigo, relacionado directamente con el deslizamiento y con la formación de la parte más moderna de la caldera de Las Cañadas. Las dataciones disponibles de estos depósitos (verTabla 1a) han dado resultados en torno a 170-180 $k a$, excepción hecha de dos dataciones de depósitos en el flanco SE de la isla, de 130 ka (Ancochea et al., 1990) y 196 ka (Edgar et al., 2007) que, aunque no demasiado alejados, quedarían claramente fuera del rango.

Tras la revisión llevada a cabo en el presente trabajo de las edades disponibles de los distintos depósitos pre y postdeslizamiento, se pueden establecer los siguientes rangos de edades: $\leq 173-183$ ka para las dataciones de las rocas más modernas del escarpe de cabecera; $\leq 130-196$ ka para los depósitos sieníticos asociados temporalmente al deslizamiento; >161-198 ka para las rocas del relleno temprano del valle; y 160 200 ka para las dataciones de las turbiditas submarinas profundas. En la Figura 5 se ha representado la distribución temporal de las dataciones.

Con estos datos, se puede establecer un intervalo de 160 a 200 ka que, en base a la representatividad y coherencia de los datos disponibles, y a la confianza de los métodos de datación, puede acotarse entre 165 y $175 \mathrm{ka}$. No obstante, si se consideran solo las edades de los depósitos más directamente relacionados con la ocurrencia del deslizamiento, como son el nivel superior del escarpe de Diego Hernández y los rellenos tempranos del valle, resulta un rango de edad representativo entre 160 y $180 \mathrm{ka}$.

\section{Dataciones relacionadas con el deslizamiento de La Orotava}

La edad del deslizamiento de La Orotava (Figura 3) puede estimarse a partir de las dataciones de las rocas de las coladas superiores de sus escarpes laterales (materiales pre-deslizamiento), de las coladas que tapizan los escarpes del deslizamiento (post-deslizamiento), de los depósitos del relleno del valle (materiales post-deslizamiento) y otros depósitos también relacionados cronológicamente con su ocurrencia. 
Las Tablas $2 a$ y $2 b$ muestra estas dataciones, su relación con el deslizamiento y las edades deducidas a partir de aquellas. La Figura 6 representa las relaciones temporales entre estos datos.

\section{Datación de coladas en los escarpes del valle de deslizamiento}

Los escarpes que limitan al oeste y al este el valle de La Orotava, el de Tigaiga y el de Santa Úrsula respectivamente, forman unas paredes de hasta $600 \mathrm{~m}$ de altura con respecto al valle.

Las coladas de los niveles superiores del escarpe deTigaiga se han datado (verTabla 2a) en 549 ka y 526 ka (Boulesteix et al., 2013) y 690 ka (Abdel Monem et al., 1972; Ibarrola et al., 1993); la edad de 526 ka de Boulesteix et al. (2013) no corresponde en realidad a una colada del escarpe, sino a la última colada de, según los autores, la misma sucesión, muestreada más allá del escarpe, en la superficie estructural del macizo deTigaiga, y asumen que se trata de un depósito predeslizamiento. Ibarrola et al. (1993), aportan el dato de 560 ka para una colada fonolítica recubriendo el macizo de Tigaiga, más allá del escarpe, considerada anterior al deslizamiento.

Con respecto al escarpe de Santa Úrsula, los niveles superiores del mismo, considerados previos al deslizamiento, han sido datados en 561 ka por Boulesteix et al. (2013), en un trabajo ex profeso para datar el deslizamiento, y en 780 ka (Ancochea et al., 1990).

Por otro lado, las dataciones de coladas depositadas sobre los escarpes, consideradas posteriores al deslizamiento por los correspondientes autores, dan las edades: $508 \mathrm{ka}$ en el escarpe deTigaiga (Carracedo et al., 2011); 566 ka (Carracedo et al., 2009) y 560 ka (Ancochea et al., 1990) en el escarpe de Santa Úrsula.

\section{Datación de basaltos de relleno del valle}

Los materiales que forman la pared de Diego Hernández $(\mathrm{DH})$ de la caldera de Las Cañadas corresponden al relleno de la cabecera del paleovalle originado por el deslizamiento de La Orotava (Bravo Bethencourt y Bravo, 1989; Ancochea et al., 1990); estos depósitos fueron cortados por el escarpe del deslizamiento de Icod, como apuntan Ancochea et al. (1995) y Boulesteix et al. (2012) entre otros autores, de tal forma que se intersectaron ambos escarpes de rotura. Por tanto, si los materiales que forman la pared de $\mathrm{DH}$ en la caldera son los depósitos más modernos del relleno de La Orotava, la edad de los niveles más basales que afloran en la pared indicaría una edad mínima del deslizamiento de La Orotava.
Dicho de otro modo, el valle dejado por el deslizamiento de La Orotava se rellena, y estos depósitos son cortados después por la cabecera del deslizamiento de lcod (o el último episodio del deslizamiento de Icod, en el caso de varios deslizamientos); actualmente estos depósitos afloran en el escarpe de $\mathrm{DH}$, y permiten acotar la edad de La Orotava.

Los materiales más antiguos del escarpe han sido datados en $540 \mathrm{ka}$ (Ancochea et al., 1990). Martí et al. (1994) dan una edad de 650 ka para el final del ciclo previo a la formación de la pared de Diego Hernández (Fm. Guajara), descartan la edad de 540 ka por exceso de Ar en la muestra y toman la edad de 370 ka (de Ancochea et al., 1990, en rocas de La Fortaleza) como edad máxima de la Formación Diego Hernández (FDH). Para descartar la edad de 540 ka, Martí et al. (1994) se basan en datos de Mitjavila (1990) y Mitjavila and Villa (1993), aunque éstos solo aluden al exceso de Ar en la muestra como una posibilidad.

Martí et al. (1997), en referencia a la edad del deslizamiento, indican que el hecho de que no existan productos piroclásticos de la Formación Guajara en el valle de La Orotava, y la coincidencia de las edades de los últimos depósitos de esta formación (560 $\pm 70 \mathrm{ka}$; lbarrola et al., 1993) y de las coladas más antiguas de relleno del valle ( $540 \pm 60 \mathrm{ka}$; Ancochea et al., 1990) sugieren que la formación del valle ocurrió al final del ciclo Guajara (para ello, Martí et al., 1997, asumen la edad de Ancochea et al., 1990, previamente cuestionada por ellos mismos, y toman la edad de Ibarrola et al., 1993, para el final del ciclo Guajara, en lugar de los 650 ka de Martí et al., 1994).

Por otro lado, Carracedo et al. (2009) datan las lavas del volcán Cho Marcial, que rellenan parcialmente la cabecera del valle del deslizamiento de Güímar, y a las que corta el escarpe de cabecera del deslizamiento de La Orotava, en $818 \mathrm{ka}$.

Una datación de lavas de relleno del valle, en la galería Pino Soler (ver situación de la galería en la Figura 11), da una edad de 532 ka (Boulesteix et al., 2013, en un trabajo exprofeso para datar el deslizamiento de La Orotava).

Otras dataciones relacionadas de alguna manera con el deslizamiento de La Orotava son las siguientes: 730 ka de un bloque fonolítico en un depósito brechoide en la base del valle de La Orotava, asumiendo que se trata del depósito del deslizamiento, el Ilamado 'mortalón' (Ibarrola et al., 1993); y 530540 ka de una colada traquítica de la misma serie del relleno más reciente del valle, aunque alejada del mismo (Abdel Monem et al., 1972; Ancochea et al., 1990). 


\begin{tabular}{|c|c|c|c|c|c|}
\hline \multicolumn{2}{|c|}{$\begin{array}{l}\text { Colada o depósito volcánico datado } \\
\text { (pre/post deslizamiento) }\end{array}$} & \multirow{2}{*}{$\begin{array}{l}\begin{array}{l}\text { Edad } \\
\text { obtenida }^{1}\end{array} \\
690 \pm 10 \mathrm{ka} \\
\end{array}$} & \multirow{2}{*}{\begin{tabular}{|l|} 
Referencia \\
Abdel Monem \\
et al., 1972 \\
(edad \\
recalculada por \\
Ancochea et al., \\
$1990)$
\end{tabular}} & \multirow{2}{*}{$\begin{array}{l}\text { Explicación } \\
\begin{array}{l}\text { Estos depósitos se consideran anteriores al } \\
\text { deslizamiento, al formar parte del escarpe. }\end{array}\end{array}$} & \multirow{3}{*}{$\begin{array}{l}\begin{array}{l}\text { Edad del } \\
\text { deslizamiento }\end{array} \\
\\
<690 \mathrm{ka}\end{array}$} \\
\hline \multirow{10}{*}{ 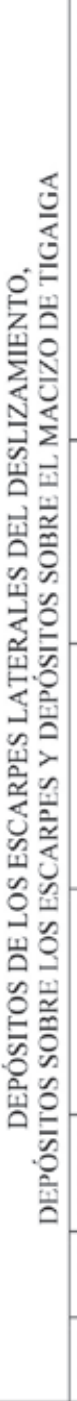 } & \multirow[t]{3}{*}{$\begin{array}{l}\text { Coladas de la parte superior del escarpe } \\
\text { de Tigaiga (escarpe oeste del } \\
\text { deslizamiento) }\end{array}$} & & & & \\
\hline & & $690 \pm 100 \mathrm{ka}$ & $\begin{array}{l}\text { Ibarrola et al., } \\
1993\end{array}$ & $\begin{array}{l}\text { Edad más joven obtenida en las coladas del } \\
\text { escarpe, que predatarian el mismo y, por } \\
\text { tanto, el deslizamiento. }\end{array}$ & \\
\hline & & $549 \pm 9 \mathrm{ka}$ & $\begin{array}{l}\text { Boulesteix et } \\
\text { al., } 2013\end{array}$ & $\begin{array}{l}\text { Coladas superiores más jóvenes expuestas } \\
\text { en el escarpe, afectadas por el desliza- } \\
\text { miento, y por tanto anteriores al mismo. }\end{array}$ & $\begin{array}{l}<549 \mathrm{ka} \\
(<558 \mathrm{ka})^{*}\end{array}$ \\
\hline & \multirow[t]{2}{*}{$\begin{array}{l}\text { Coladas de la parte alta del escarpe de } \\
\text { Sta. Ursula (escarpe este del } \\
\text { deslizamiento) }\end{array}$} & $780 \pm 180 \mathrm{ka}$ & $\begin{array}{l}\text { Ancochea et al., } \\
1990\end{array}$ & $\begin{array}{l}\text { Depósitos más jóvenes de la parte superior } \\
\text { de la sucesión que aflora en el escarpe del } \\
\text { deslizamiento, anteriores al mismo. }\end{array}$ & $<780 \mathrm{ka}$ \\
\hline & & $561 \pm 8 \mathrm{ka}$ & $\begin{array}{l}\text { Boulesteix et } \\
\text { al., } 2013\end{array}$ & $\begin{array}{l}\text { Depósitos de la parte alta del escarpe del } \\
\text { deslizamiento, anteriores al mismo. }\end{array}$ & $<561 \mathrm{ka}$ \\
\hline & $\begin{array}{l}\text { Colada fonolítica en la parte alta del } \\
\text { macizo de Tigaiga. }\end{array}$ & $\begin{array}{l}560 \pm 70 \mathrm{ka} \\
560 \pm 30 \mathrm{ka}\end{array}$ & $\begin{array}{l}\text { Ibarrola et al., } \\
1993\end{array}$ & $\begin{array}{l}\text { Depósito que representa los últimos } \\
\text { productos piroclásticos de la Fm. Guajara } \\
\text { (ver texto). Estos materiales no aparecen en } \\
\text { el valle de La Orotava, por lo que puede } \\
\text { interpretarse que son anteriores o } \\
\text { contemporáneos al deslizamiento (según } \\
\text { Martí et al., 1997) }\end{array}$ & $\leq 560 \mathrm{ka}$ \\
\hline & $\begin{array}{l}\text { Colada sobre la superficie estructural } \\
\text { del macizo de Tigaiga. }\end{array}$ & $526 \pm 8 \mathrm{ka}$ & $\begin{array}{l}\text { Boulesteix et } \\
\text { al., } 2013\end{array}$ & $\begin{array}{l}\text { Depósito considerado por los autores de la } \\
\text { misma sucesión que las coladas más jóvenes } \\
\text { del escarpe de Tigaiga, datadas por ellos en } \\
549 \pm 9 \text { ka y consideradas predeslizamiento. } \\
\text { ** Edad posible según los autores de este } \\
\text { trabajo (ver explicaciones en el texto) }\end{array}$ & $\begin{array}{l}\leq 526 \mathrm{ka} \\
(<534 \mathrm{ka})^{*} \\
(>526 \mathrm{ka} ?)^{* *}\end{array}$ \\
\hline & $\begin{array}{l}\text { Colada traquítica superior de una } \\
\text { sucesión cubriendo la cabecera del } \\
\text { escarpe de Sta. Úrsula en cotas altas. }\end{array}$ & $560 \pm 30 \mathrm{ka}$ & $\begin{array}{l}\text { Ancochea } e t \text { al., } \\
1990\end{array}$ & $\begin{array}{l}\text { Depósito sobre el escarpe, posterior al } \\
\text { deslizamiento, según los autores. }\end{array}$ & $>560 \mathrm{ka}$ \\
\hline & $\begin{array}{l}\text { Lavas cubriendo la parte superior del } \\
\text { escarpe de Tigaiga. }\end{array}$ & $508 \pm 11 \mathrm{ka}$ & $\begin{array}{l}\text { Carracedo } e t \\
\text { al., } 2011\end{array}$ & Depósito posterior al deslizamiento. & $>508 \mathrm{ka}$ \\
\hline & $\begin{array}{l}\text { Lavas en "cascada" sobre el escarpe de } \\
\text { Sta. Úrsula. }\end{array}$ & $566 \pm 13 \mathrm{ka}$ & $\begin{array}{l}\text { Carracedo et } \\
\text { al., } 2009\end{array}$ & $\begin{array}{l}\text { Depósito sobre la parte alta del escarpe, } \\
\text { posterior al deslizamiento según los autores. }\end{array}$ & $>566 \mathrm{ka}$ \\
\hline \multirow{3}{*}{ 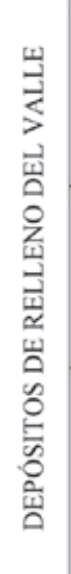 } & $\begin{array}{l}\text { Depósitos más antiguos (de la parte } \\
\text { inferior) expuestos en el escarpe de } \\
\text { Diego Hernández, en la zona oriental } \\
\text { de la caldera de las Cañadas. }\end{array}$ & $540 \pm 60 \mathrm{ka}$ & $\begin{array}{l}\text { Ancochea } e t \text { al., } \\
1990\end{array}$ & $\begin{array}{l}\text { Los materiales del escarpe representan el } \\
\text { relleno de la cabecera del valle tras el } \\
\text { deslizamiento de La Orotava, como ya } \\
\text { indican Bravo Bethencourt y Bravo (1989). } \\
\text { Depósitos posteriores al deslizamiento. }\end{array}$ & $>540 \mathrm{ka}$ \\
\hline & $\begin{array}{l}\text { Lavas del volcán Cho Marcial, en el } \\
\text { escarpe de cabecera del deslizamiento. }\end{array}$ & $818 \pm 18 \mathrm{ka}$ & $\begin{array}{l}\text { Carracedo et } \\
\text { al., } 2009 \mathrm{y} \\
2011\end{array}$ & $\begin{array}{l}\text { Depósitos de relleno temprano de la } \\
\text { cabecera del valle que quedó tras el } \\
\text { deslizamiento de Güimar, cortados por el } \\
\text { escarpe de cabecera del deslizamiento de La } \\
\text { Orotava; serian anteriores al deslizamiento. }\end{array}$ & $<818$ ka \\
\hline & $\begin{array}{l}\text { Colada traquítica de la parte superior de } \\
\text { la misma serie que la del relleno del } \\
\text { valle (en la zona de El Sauzal) }\end{array}$ & $540 \pm 30 \mathrm{ka}$ & $\begin{array}{l}\text { Abdel Monem } \\
\text { et al., } 1972 \\
\text { (edad } \\
\text { recalculada por } \\
\text { Ancochea } \text { et al., } \\
1990 \text { ) }\end{array}$ & $\begin{array}{l}\text { Este dato, aunque de un depósito alejado del } \\
\text { deslizamiento, es tenido en cuenta por } \\
\text { algunos autores para la datación del mismo. }\end{array}$ & $>540 \mathrm{ka}$ \\
\hline
\end{tabular}

Tabla 2a. Dataciones de depósitos volcánicos relacionados con el deslizamiento de La Orotava. 


\begin{tabular}{|c|c|c|c|c|c|}
\hline \multicolumn{2}{|c|}{$\begin{array}{l}\text { Colada o depósito volcánico datado } \\
\text { (pre/post deslizamiento) }\end{array}$} & \multirow{2}{*}{\begin{tabular}{|l|}
$\begin{array}{l}\text { Edad } \\
\text { obtenida }^{1}\end{array}$ \\
$730 \pm 50 \mathrm{ka}$
\end{tabular}} & \multirow{2}{*}{$\begin{array}{l}\text { Referencia } \\
\text { Ibarrola et al., } \\
1993\end{array}$} & \multirow{2}{*}{\begin{tabular}{|l} 
Explicación \\
Este depósito se interpreta por los autores \\
como similar a los depósitos del \\
deslizamiento ('mortalón') en la base del \\
relleno del valle. El deslizamiento tendría \\
una edad menor que la del bloque.
\end{tabular}} & \multirow{2}{*}{\begin{tabular}{|l}
$\begin{array}{l}\text { Edad del } \\
\text { deslizamiento }\end{array}$ \\
$<730 \mathrm{ka}$
\end{tabular}} \\
\hline & $\begin{array}{l}\text { Bloque fonolítico en un depósito } \\
\text { brechoide en la base del valle de La } \\
\text { Orotava (Callao de Méndez) }\end{array}$ & & & & \\
\hline 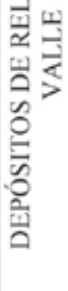 & $\begin{array}{l}\text { Lavas de relleno del valle de La } \\
\text { Orotava, antes de alcanzar los depósitos } \\
\text { de 'mortalón'. }\end{array}$ & $532 \pm 9 \mathrm{ka}$ & $\begin{array}{l}\text { Boulesteix et } \\
\text { al., } 2013\end{array}$ & $\begin{array}{l}\text { Lavas cortadas en la galeria Pino Soler (a } \\
2.600 \mathrm{~m} \text { de bocamina). } \\
\text { Depósito posterior al deslizamiento. } \\
\text { ** La galeria atraviesa el relleno del valle, } \\
\text { llegando hasta el 'mortalón'. La muestra } \\
\text { datada aparece a varios cientos de metros } \\
\text { antes del depósito de 'mortalón' (ver } \\
\text { explicaciones en el texto). }\end{array}$ & $>532 \mathrm{ka}^{* *}$ \\
\hline \multicolumn{6}{|c|}{$\begin{array}{l}\text { Algunos autores citados en la Tabla establecen en sus trabajos edades para el deslizamiento, como Ancochea et al. (1990): 560-780 ka; Ibarrola } \\
\text { et al. (1993): 560-690 ka; Ancochea et al. (1995) y Cantagrel et al. (1999): 540-690 ka; Marti et al. (1997): } 560 \mathrm{ka} \text {; Carracedo et al. (2009): } \\
\text { 566-690 ka; Boulesteix et al. (2013): 523-534 ka. }\end{array}$} \\
\hline \multicolumn{6}{|c|}{$\begin{array}{l}{ }^{1} \text { Todas las edades son } \mathrm{K} / \mathrm{Ar} \text {. } \\
{ }^{2} \text { Edad deducida por la relación temporal de los depósitos con el deslizamiento, según las dataciones publicadas por los diferentes autores. } \\
\text { " Edad considerando la correspondiente incertidumbre. } \\
{ }^{* *} \text { Edades posibles según los autores de este trabajo; ver explicaciones en el texto. }\end{array}$} \\
\hline
\end{tabular}

Ver NOTA EXPLICATIVA a pie de la Tabla la.

Tabla 2a. Dataciones de depósitos volcánicos relacionados con el deslizamiento de La Orotava.

Table 2a. Ages of volcanic deposits related to the La Orotava landslide.

\section{Datación de turbiditas abisales y otros depósitos submarinos}

En el trabajo de Hunt et al. (2013) sobre las turbiditas volcanoclásticas de la zona norte de la Llanura Abisal de Madeira, MAP (ver referencias a este trabajo en el apartado sobre las dataciones del deslizamiento de Icod), la turbidita volcánica denominada Mo se relaciona con el deslizamiento de La Orotava, y se data en 530-540 ka (a partir de marcadores bioestratigráficos y fotoespectrometría en los testigos de la turbidita); entre 443 y 780 ka (datación de hemipelagitas); y en 495545 ka considerando la velocidad de sedimentación de los depósitos de sedimentos pelágicos y turbiditas. Considerando la representatividad y los métodos empleados para las anteriores dataciones, puede establecerse una edad media de 535 ka para la turbidita proveniente de La Orotava.

Anteriormente a estas dataciones, una de las turbiditas de composición volcánica identificada por Weaver et al. (1992) en la MAP, la turbidita o, es datada en unos $505 \mathrm{ka}$, por correlación entre marcadores bioestratigráficos y estadios isotópicos marinos (los autores no plantean en su trabajo las relaciones entre turbiditas y deslizamientos, solo la proveniencia y datación de turbiditas; por lo que esta edad serviría para apoyar otras edades de turbiditas).

Como resumen, las dataciones realizadas en turbi- ditas de la Llanura Abisal de Madeira que pueden ser correlacionadas con el deslizamiento de La Orotava son: 535 ka (turbidita Mo; Hunt et al., 2013), y 505 ka (turbidita o; Weaver et al., 1992).

De forma imprecisa, Masson et al. (2002) proponen una edad en el rango de 500-700 ka, basándose en la posible velocidad de sedimentación de los aproximadamente $20 \mathrm{~m}$ de potencia de los sedimentos acumulados sobre los depósitos de avalancha procedentes del deslizamiento, cartografiados bajo el mar en zonas proximales.

\section{Edad del deslizamiento de La Orotava}

A modo de resumen y discusión de los datos incluidos en los párrafos anteriores, se indican a continuación los aspectos más reseñables y las edades deducidas para el deslizamiento.

El análisis e interpretación de las edades disponibles se han enmarcado, a priori, dentro de la hipótesis de un único deslizamiento como responsable de la formación del valle de La Orotava, como implícitamente se asume en las publicaciones que hasta ahora han aportado datos cronológicos. Sin embargo, los datos permiten plantear la hipótesis de que hayan tenido lugar varios deslizamientos, como aquí se expone y justifica.

Hasta ahora, en la mayoría de las publicaciones que estiman o hacen referencia a la edad del deslizamien- 


\begin{tabular}{|c|c|c|c|c|c|}
\hline $\begin{array}{l}\text { Depósito } \\
\text { submarino }\end{array}$ & Método de datación & $\begin{array}{l}\text { Edad } \\
\text { estimada }\end{array}$ & Referencia & Explicación & $\begin{array}{l}\text { Edad del } \\
\text { deslizamento }^{1}\end{array}$ \\
\hline $\begin{array}{l}\text { Turbidita "o". } \\
\text { MAP }\end{array}$ & $\begin{array}{l}\text { Correlación de sedimentos } \\
\text { pelágicos con estratigrafia de } \\
\text { isótopos de oxigeno (MIS) }\end{array}$ & $505 \mathrm{ka}$ & $\begin{array}{l}\text { Weaver et al., } \\
1992\end{array}$ & $\begin{array}{l}\text { Los autores no establece relación entre } \\
\text { turbiditas de la MAP y deslizamientos. } \\
\text { Posteriormente otros autores relacionarán } \\
\text { estos datos con la edad de los deslizamientos. }\end{array}$ & $\sim 505 \mathrm{ka}$ \\
\hline $\begin{array}{l}\text { Depósitos } \\
\text { distales de } \\
\text { deslizamiento }\end{array}$ & $\begin{array}{l}\text { A partir de la tasa de sedimentación } \\
\text { de los sedimentos que cubren los } \\
\text { depósitos de deslizamiento }\end{array}$ & $500-700 \mathrm{ka}$ & $\begin{array}{l}\text { Masson et al., } \\
2002\end{array}$ & $\begin{array}{l}\text { Edad compatible con los } 20 \mathrm{~m} \\
\text { aproximadamente de potencia de los } \\
\text { sedimentos que cubren los depósitos de } \\
\text { avalancha. }\end{array}$ & $500-700$ ka \\
\hline \multirow[t]{4}{*}{$\begin{array}{l}\text { Turbidita "Mo" } \\
\text { MAP }\end{array}$} & $\begin{array}{l}\text { Correlación con marcadores } \\
\text { bioestratigráficos }\end{array}$ & $540 \pm 5 \mathrm{ka}$ & \multirow[t]{4}{*}{$\begin{array}{l}\text { Hunt et al., } \\
\text { 2013a* }\end{array}$} & \multirow{4}{*}{$\begin{array}{l}\text { Se establece relación entre la turbidita "Mo" } \\
\text { y el deslizamineto de La Orotava, asumiendo } \\
\text { que la primera proviene del segundo, por } \\
\text { composición mineralógica y geoquimica de } \\
\text { los sedimentos marinos y las rocas subaéreas. }\end{array}$} & \multirow{4}{*}{$\sim 535 \mathrm{ka}$} \\
\hline & $\begin{array}{l}\text { A partir de registros ODP y } \\
\text { datación de hemipelagitas }\end{array}$ & $443-780 \mathrm{ka}$ & & & \\
\hline & $\begin{array}{l}\text { A partir de la velocidad de } \\
\text { sedimentación }\end{array}$ & $\begin{array}{l}495 \pm 30 \circ \\
545 \pm 8 \mathrm{ka}\end{array}$ & & & \\
\hline & $\begin{array}{l}\text { Fotoespectrometría (según posición } \\
\text { de la capa en el testigo) }\end{array}$ & $530 \pm 5 \mathrm{ka}$ & & & \\
\hline \multicolumn{6}{|c|}{$\begin{array}{l}{ }^{1} \text { Edad deducida como la más representativa según las dataciones disponibles. } \\
\text { * Estos autores aportan edades para el deslizamiento de La Orotava a partir de sus dataciones. }\end{array}$} \\
\hline
\end{tabular}

Tabla 2b. Dataciones de depósitos submarinos relacionados con el deslizamiento de La Orotava.

Table $\mathbf{2 b}$. Ages of submarine deposits related to the La Orotava landslide.

to de La Orotava, se adoptan los rangos de edad 540690 ka o 566-690 ka (Ancochea et al., 1990; Ibarrola et al., 1993; Carracedo et al., 2011, entre otros) o un valor en torno a los $600 \mathrm{ka}$ (Cantagrel et al., 1999). El límite superior de ambos rangos se basa únicamente en una datación, de Ancochea et al. (1990) y otra de Carracedo et al. (2009) respectivamente; el límite inferior se basa en dos dataciones de $690 \mathrm{ka}$, una de Abdel Monem et al. (1972) y otra de lbarrola et al. (1993). Otros autores han propuesto una edad mínima de $560 \mathrm{ka}$, también a partir de una única datación de Ancochea et al. (1990).

La revisión de las edades disponibles en la bibliografía de los materiales prey postdeslizamiento de los escarpes del valle de La Orotava, y de los materiales de relleno del valle, muestran algunas contradicciones a la hora de estimar una edad representativa para el deslizamiento. Los datos del escarpe este, el de Santa Úrsula, indicarían una edad en torno a los 560 ka o algo mayor, mientras que en el escarpe oeste, el del macizo de Tigaiga, todas las dataciones excepto una se han realizado en rocas previas al deslizamiento, indicando una edad $<560$ o $<549$ ka (sin considerar, entre los siete datos disponibles, el de 526 ka; ver Tabla 2a). Con los datos de los dos escarpes, y considerando la incertidumbre \pm 9 ka en la edad de 549 ka (Boulesteix et al., 2013) podría deducirse una edad representativa en torno a los $560 \mathrm{ka}$.

Las otras edades disponibles de materiales de relleno del valle indican para el deslizamiento una edad
$>532$ y $<730 \mathrm{ka}$, en consonancia con los $560 \mathrm{ka}$ deducidos de los datos de los escarpes.

Otras dataciones recogidas en la Tabla 2 a son coherentes igualmente con la edad de 560 ka, excepto el dato de 526 ka (Boulesteix et al., 2013), a priori incompatible con las demás. Boulesteix et al. (2013) dudan de la representatividad de los datos de otros autores para encajar los suyos propios; así, plantean que los datos de Ancochea et al. (1990), de $560 \mathrm{ka}$, y de Carracedo et al. (2009), de 566 ka, correspondan a lavas pre-deslizamiento, en vez de a lavas post-deslizamiento como consideran ambos autores. De la misma manera, y a modo de hipótesis, podría considerarse la posibilidad de que la edad de 526 ka corresponda a lavas previas al deslizamiento, ya que la muestra datada no procede del escarpe del valle, sino de la superficie del macizo de Tigaiga, sin continuidad con las lavas superiores del escarpe; en el supuesto de ser lavas post-deslizamiento, la edad cuadraría con el resto de todas las edades subaéreas disponibles.

Con respecto a la edad de $532 \pm 9$ ka de estos mismos autores para una muestra de lava del interior de la galería Pino Soler, y en el contexto de asumir una edad en torno a los 560 ka para el deslizamiento, cabe hacer la siguiente consideración. En esta galería, con un ramal de 4.840 m de longitud, visitada por los autores del presente trabajo, el primer tramo de 'mortalón' (el más próximo a bocamina) aparece unos 400 metros más profundo (hacia los $3.010 \mathrm{~m}$ desde la 


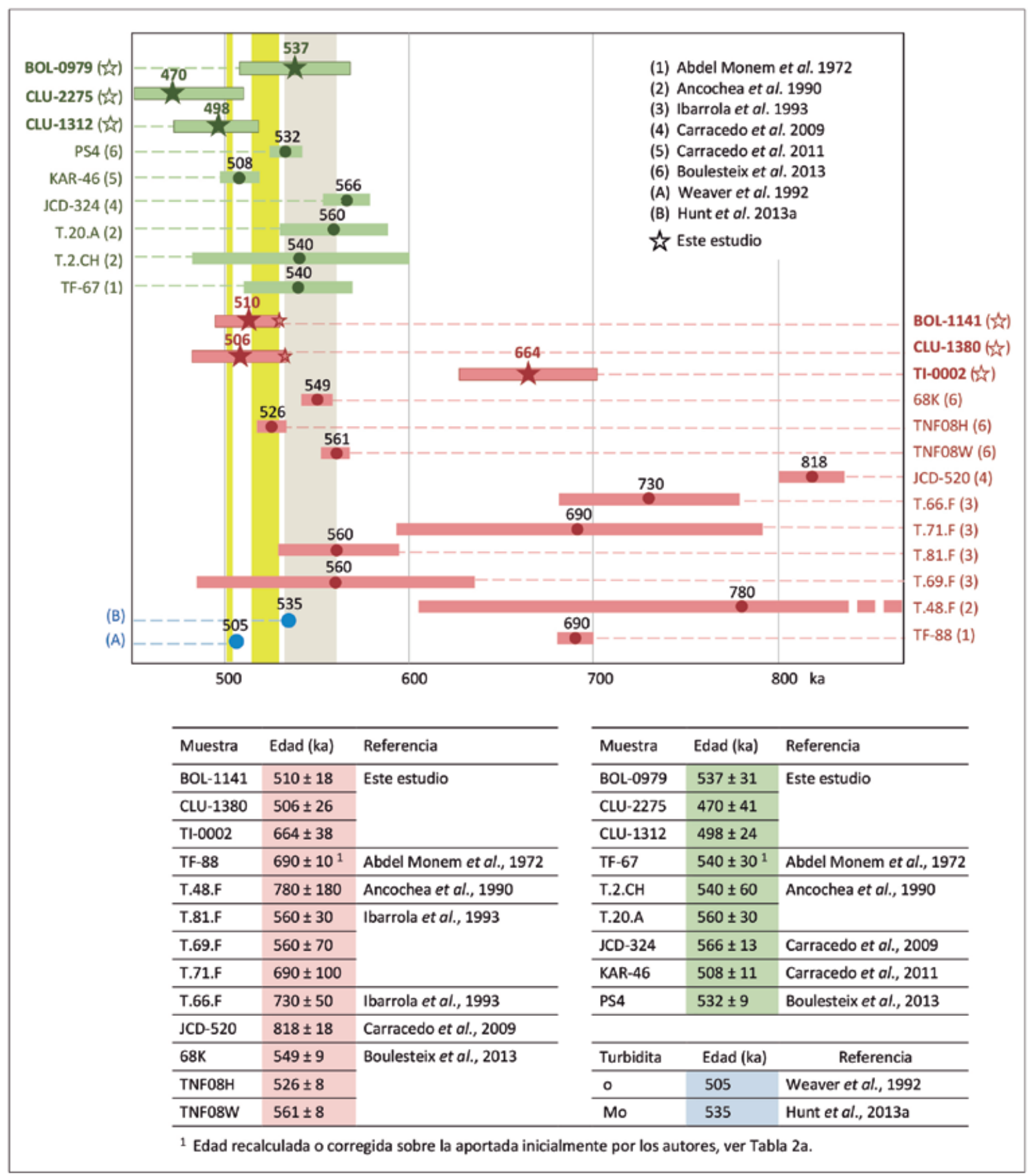

Figura 6. Dataciones relacionadas con el deslizamiento de La Orotava. Las edades en rojo y verde corresponden respectivamente a depósitos post y predeslizamiento (verTabla 2a para explicación); por tanto el deslizamiento habría sido anterior a las edades en rojo y posterior a las edades en verde. Las edades en azul corresponden a dataciones de depósitos submarinos (Tabla 2b). Las barras horizontales representan los rangos de edades, considerando las incertidumbres correspondientes aportadas por cada autor; alineados con cada barra aparecen en los márgenes las referencias al autor y el $\mathrm{n}^{\circ}$ de muestra. La franja vertical gris indica las edades más representativas del deslizamiento: 530-560 ka. Las estrellas corresponden a las dataciones Ar/Ar realizadas para este estudio (ver explicaciones en el texto), y las franjas amarillas representan las edades deducidas de estas últimas dataciones.

Figure 6. Ages related to the La Orotava landslide. The ages in red and green correspond respectively to post and pre-landslide deposits (see Table 2a for explanation); therefore the rockslide would have occurred before the red ages and after the green ages. The ages in blue correspond to underwater deposits (Table 2b). Horizontal bars represent the age ranges, considering the corresponding uncertainties provided by each author. Aligned with each bar, the references to the author and the sample number appear in the margins. The grey vertical stripe represents the most representative age for the landslide: 530-560 ka. The star symbols correspond to the Ar/Ar dates for this study (see explanations in the text), and the yellow stripes represent the ages deduced from these dates. 
entrada) que el punto de toma de la muestra datada por Boulesteix et al. (2013), a 2.600 m, con lo que cabría esperar una edad de alguna decena de miles de años mayor para las lavas del relleno inicial sobre el 'mortalón'. A este respecto, también cabe indicar que en la galería aparecen 2 tramos de 'mortalón', entre 3.010-3.268 m y 3.360-3.470 m, y la datación de $532 \pm 9$ ka corresponde a lavas por encima del primer tramo, y podría no representar al deslizamiento profundo y principal, sino a uno posterior. Esta hipótesis se plantea y justifica más adelante en este apartado.

Considerando que las lavas datadas por Boulesteix et al. (2013) en $526 \pm 8$ ka pudieran ser anteriores o posteriores al deslizamiento, caben dos hipótesis, que se exponen aquí brevemente por su interés a la hora de interpretar otras dataciones disponibles. 1) Si se acepta el criterio de los autores y se considera la incertidumbre (+ $8 \mathrm{ka})$, el dato indicaría para el deslizamiento una edad menor o en el entorno de los $534 \mathrm{ka}$. 2) Si por contra la colada fuera posterior al deslizamiento, la edad encajaría con los demás datos disponibles en la bibliografía, apoyando la edad general deducida más arriba en torno a 560 ka para el deslizamiento de La Orotava.

Por las anteriores consideraciones, las edades de 526 ka y de 532 ka se toman aquí con ciertas reservas a la hora de acotar la edad del deslizamiento (considerando un deslizamiento único, como se ha venido asumiendo generalmente a la hora de datar el proceso) de La Orotava. No obstante, Boulesteix et al. (2013) basan la principal conclusión de su trabajo en estos dos datos, jugando con las incertidumbres de ambas dataciones, asignando una edad al deslizamiento entre 523 ka y 534 ka (ver Tabla 2a). Aceptar esta edad como única y representativa implicaría desechar todos los datos previos disponibles que indican una edad para el deslizamiento en torno a los $560 \mathrm{ka}$, que son la mayoría.

Al asumir un único deslizamiento en La Orotava, para su datación Boulesteix et al. (2013) toman la edad de $526 \mathrm{ka}$, incluso obviando otras de sus edades (p.e. la de 549 ka de una colada de lava del escarpe de Tigaiga, que se ajusta más a otros datos previos de la bibliografía). Deducen una edad entre 523 y 534 ka para el deslizamiento, jugando con las incertidumbres de sus dataciones (532-9 ka y 526+8 ka, verTabla 2a). Además, como ya se ha dicho, para justificar esta edad dudan de las interpretaciones de otros autores, sugiriendo que determinadas muestras datadas corresponderían a depósitos anteriores al deslizamiento (muestra KAR-46, 508 ka, Carracedo et al., 2011; muestra R10879, 560 ka, Ancochea et al., 1990) en lugar de a depósitos post-deslizamiento como consideran los autores en sus respectivos trabajos.
Dejando de lado las consideraciones anteriores, estas edades en torno a los 530 ka aportadas por Boulesteix et al. (2013) están en consonancia con las dataciones de depósitos submarinos turbidíticos procedentes del deslizamiento de La Orotava (verTabla 2b), ninguna de las cuales supera los 540-545 ka: los datos más recientes y representativos (Hunt et al., 2013), indican una edad media de unos 535 ka para estos depósitos.

Por tanto, y como resultado del análisis de las dataciones y datos disponibles, no es posible establecer una edad única representativa para el deslizamiento de La Orotava, y sí pueden deducirse claramente dos edades en torno a los 560 ka y los 530-535 ka, avaladas principalmente por los datos de rocas subaéreas o de los depósitos submarinos respectivamente, como se refleja en la Figura 6. Así, puede plantearse la idea de que tuvieran lugar, al menos, dos grandes deslizamientos superpuestos, con intervalos de unas decenas de miles de años.

Esta conclusión se refuerza y justifica por los resultados de las nuevas dataciones Ar/Ar llevadas a cabo por los autores en el interior de las galerías del valle de La Orotava, como más adelante se explica. En Ferrer et al. (2020-estevolumen), publicación que constituye la Parte Il de este trabajo, se desarrolla y discute esta propuesta a la luz de una serie de evidencias geológicas que apuntan a la ocurrencia de varios deslizamientos superpuestos en el valle de La Orotava, como aquí se plantea.

\section{Dataciones relacionadas con el delizamiento de Güímar}

La edad del deslizamiento de Güímar (Figura 3) puede estimarse a partir de las dataciones realizadas en las coladas de la parte superior de los escarpes laterales del deslizamiento (materiales pre-deslizamiento) y en las coladas del relleno inicial del valle (materiales post-deslizamiento). Las Tablas 3a y $3 \mathrm{~b}$ muestran las edades disponibles y sus relaciones con el deslizamiento. La Figura 7 representa la distribución temporal de estas edades.

\section{Datación de materiales de los escarpes del deslizamiento}

Delimitando el valle de Güímar afloran los asimétricos escarpes laterales de este deslizamiento de flanco, destacando la escarpada pared sur con alturas que superan los $500 \mathrm{~m}$; el escarpe norte es más suave y aparece erosionado y desdibujado, al igual que el escarpe de cabecera, afectado por erupciones posteriores y por la erosión. El pie del escarpe sur, o pared de Güímar, queda además profundizado por el 


\begin{tabular}{|c|c|c|c|c|c|}
\hline \multicolumn{2}{|c|}{$\begin{array}{l}\text { Colada o depósito volcánico datado } \\
\text { (pre/post deslizamiento) }\end{array}$} & \multirow{2}{*}{$\begin{array}{l}\text { Edad } \\
\text { estimada }^{1}\end{array}$} & \multirow{2}{*}{$\begin{array}{l}\text { Referencia } \\
\text { Abdel Monem } \\
\text { et al., 1972 } \\
\text { (edad } \\
\text { recalculada por } \\
\text { Ancochea et } \\
\text { al., 1990) }\end{array}$} & \multirow{5}{*}{$\begin{array}{l}\text { Explicación } \\
\text { Datos procedentes de varios autores de } \\
\text { depósitos de la parte alta del escarpe sur } \\
\text { afectados por el deslizamiento que, por } \\
\text { tanto, serian anteriores al mismo. } \\
\text { Carracedo et al. (2009) considera } \\
\text { demasiado joven la edad de } 840 \pm 30 \mathrm{ka} \\
\text { de Ancochea et al. (1990), asi como otra } \\
\text { del mismo autor de } 870 \pm 40 \mathrm{ka} \text {, por } \\
\text { incompatibiliudad con datos propios, } \\
\text { aunque posteriormente (Carracedo et al. } \\
\text { 2011) aporta una edad de } 860 \pm 18 \mathrm{ka} \\
\text { para los materiales de la parte superior } \\
\text { de la pared de Güímar. }\end{array}$} & \multirow{5}{*}{\begin{tabular}{|l}
$\begin{array}{l}\text { Edad del } \\
\text { deslizamiento }\end{array}$ \\
\\
$<\mathbf{8 3 0 - 8 4 0 ~ k a}$
\end{tabular}} \\
\hline \multirow{5}{*}{ 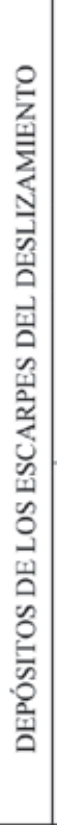 } & \multirow[t]{4}{*}{$\begin{array}{l}\text { Lavas de los niveles superiores del escarpe } \\
\text { Sur del deslizamiento (pared de Gúimar) } \\
\text { (El escarpe Sur del deslizamiento forma a } \\
\text { su vez la pared sur del Barranco de Badajoz) }\end{array}$} & & & & \\
\hline & & $840 \pm 30 \mathrm{ka}$ & $\begin{array}{l}\text { Ancochea et } \\
\text { al., } 1990\end{array}$ & & \\
\hline & & $963 \pm 21 \mathrm{ka}$ & $\begin{array}{l}\text { Carracedo et } \\
\text { al., } 2009\end{array}$ & & \\
\hline & & $860 \pm 18 \mathrm{ka}$ & $\begin{array}{l}\text { Carracedo et } \\
\text { al., } 2011\end{array}$ & & \\
\hline & Parte alta de la pared Norte del deslizamiento & $806 \pm 18 \mathrm{ka}$ & $\begin{array}{l}\text { Carracedo et } \\
\text { al., } 2009\end{array}$ & $\begin{array}{l}\text { Depósitos de la parte alta del escarpe } \\
\text { afectados por el deslizamiento y, por } \\
\text { tanto, anteriores al mismo. } \\
\text { Esto es cuestionado por el propio autor } \\
\text { (Carracedo et al., 2011), indicando que } \\
\text { probablemente las lavas sean post- } \\
\text { deslizamiento. } \\
\text { * Según los autores de este trabajo, esta } \\
\text { edad es más representativa para el } \\
\text { deslizamiento. }\end{array}$ & $\begin{array}{l}<806 \mathrm{ka} \\
>806 \mathrm{ka}^{*}\end{array}$ \\
\hline \multirow{2}{*}{ 号 } & $\begin{array}{l}\text { Lavas de relleno temprano del valle, aflorando } \\
\text { en la pared Norte del Barranco de Badajoz }\end{array}$ & $831 \pm 18 \mathrm{ka}$ & \multirow[t]{2}{*}{$\begin{array}{l}\text { Carracedo et } \\
\text { al., } 2009\end{array}$} & \multirow[t]{2}{*}{$\begin{array}{l}\text { Depósitos de coladas que rellenan el } \\
\text { valle dejado por el deslizamiento. }\end{array}$} & \multirow{2}{*}{$>831 \mathrm{ka}$} \\
\hline & $\begin{array}{l}\text { Lavas del volcán Cho Marcial, relleno del valle } \\
\text { en cabecera del deslizamiento }\end{array}$ & $818+18 \mathrm{ka}$ & & & \\
\hline \multicolumn{6}{|c|}{$\begin{array}{l}\text { Algunos autores citados en la Tabla establecen en sus trabajos edades para el deslizamiento, como Ancochea et al. (1990): } 560-840 \mathrm{ka} \text {; } \text { Carracedo et } \\
\text { al. (2009): } 830 \mathrm{ka} \text {. }\end{array}$} \\
\hline \multicolumn{6}{|c|}{${ }^{1}$ Todas las edades son $\mathrm{K} / \mathrm{Ar}$. } \\
\hline
\end{tabular}

Ver NOTA EXPLICATIVA a pie de la Tabla la.

Tabla 3a. Dataciones de depósitos volcánicos relacionados con el deslizamiento de Güímar.

Table 3a. Ages of volcanic deposits related to the Güímar landslide.

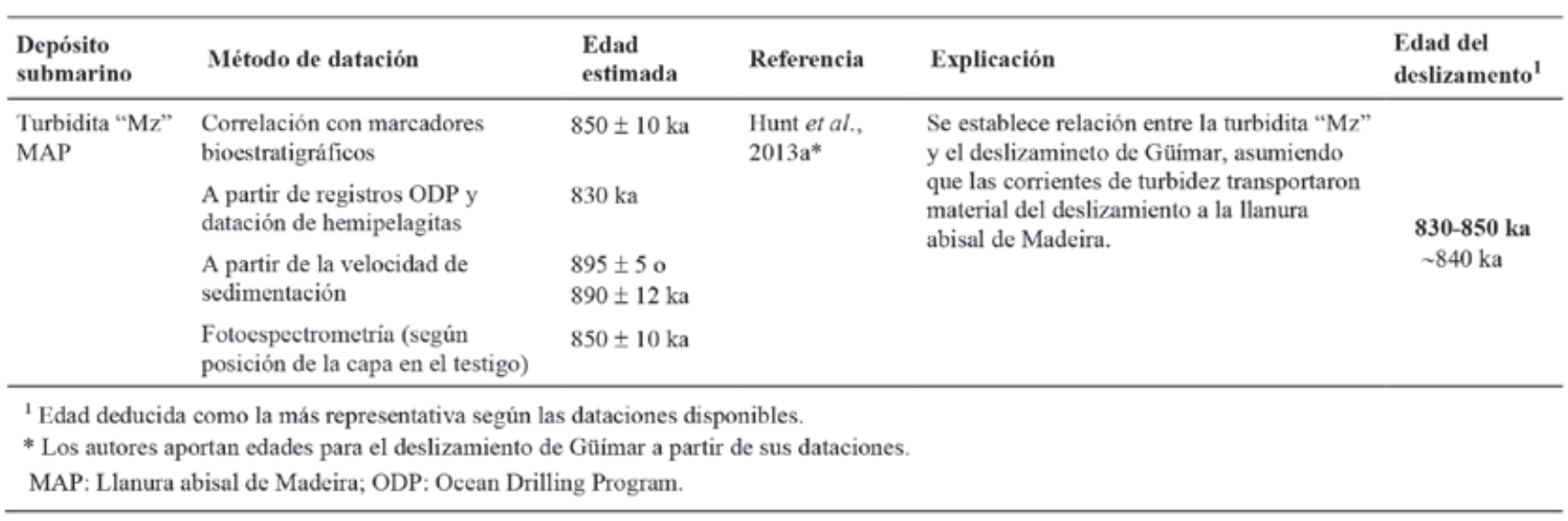

Tabla 3b. Dataciones de depósitos submarinos relacionados con el deslizamiento de Güímar.

Table 3b. Ages of submarine deposits related to the Güímar landslide. 


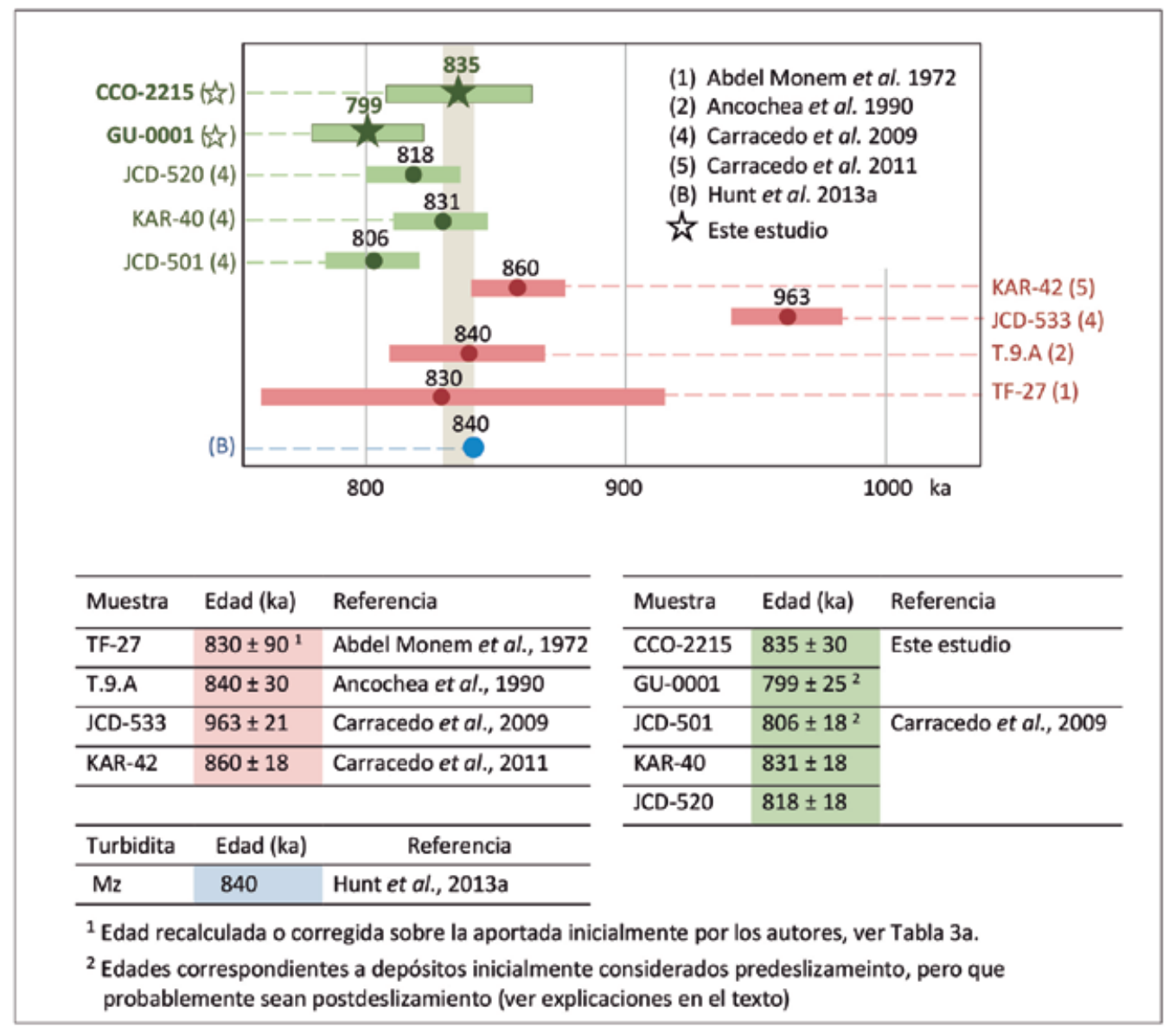

Figura 7. Dataciones relacionadas con el deslizamiento de Güímar. Las edades en rojo y verde corresponden respectivamente a depósitos post y predeslizamiento (verTabla 3a para explicación); por tanto el deslizamiento habría sido anterior a las edades en rojo y posterior a las edades en verde. Las edad en azul corresponde a un depósito submarino (Tabla 3b). Las barras horizontales representan los rangos de edades, considerando las incertidumbres correspondientes aportadas por cada autor; alineados con cada barra aparecen en los márgenes las referencias al autor y el $\mathrm{n}^{\circ}$ de muestra. La franja vertical gris indica la edad más representativa del deslizamiento: 830-840 ka; esta edad es soportada por todos los datos disponibles. Las estrellas corresponden a las dataciones Ar/Ar realizadas para este estudio (ver explicaciones en el texto).

Figure 7. Ages related to the Güímar landslide. The ages in red and green correspond respectively to post and pre-landslide deposits (see Table 3a for explanation); therefore the rockslide would have occurred before the red ages and after the green ages. The age in blue corresponds to an underwater deposit (Table 3b). Horizontal bars represent the age ranges, considering the corresponding uncertainties provided by each author. Aligned with each bar, the references to the author and the sample number appear in the margins. The grey vertical stripe represents the most representative age for the landslide: 830-840 ka. The star symbols correspond to the Ar/Ar dates for this study (see explanations in the text).

pronunciado barranco de Badajoz, que en parte de su recorrido se encaja entre los materiales antiguos pre-deslizamiento de la pared y los materiales de relleno del valle.

Las dataciones publicadas para las coladas superiores de la pared sur del deslizamiento (verTabla 3a) son: 830-840 ka (Abdel Monem et al., 1972; Ancochea et al., 1990), 963 ka (Carracedo et al., 2009) y 860 ka (Carracedo et al., 2011). Sobre la única datación disponible de la parte alta del escarpe norte del valle, de 806 ka (Carracedo et al., 2009) no está claro que corresponda a lavas predeslizamiento (Carracedo et al., 2011), siendo descartada para la data- ción por ser incompatible con la edad de las lavas de relleno temprano del valle. Si correspondiera a lavas postdeslizamiento, la edad encajaría con las otras disponibles.

\section{Datación de basaltos de relleno del valle}

Para los materiales de relleno temprano del valle de deslizamiento se han publicado edades de 831 y 818 ka (Carracedo et al., 2009), correspondientes a lavas que afloran en la pared $\mathrm{N}$ del barranco de Badajoz, y a lavas del volcán Cho Marcial rellenando la parte alta del valle de Güímar, respectivamente. 


\section{Datación de turbiditas abisales y otros depósitos submarinos}

En el trabajo de Hunt et al. (2013) sobre las turbiditas volcanoclásticas de la zona norte de la Llanura Abisal de Madeira, MAP (ver referencias a este trabajo en el apartado sobre las dataciones del deslizamiento de lcod), se relaciona la turbidita volcánica denominada $\mathrm{Mz}$ con el deslizamiento de Güímar (asumiendo que, a pesar de la distancia y la dirección hacia el sureste de las avalanchas de derrubios, las corrientes de turbidez pudieran haber alcanzado la MAP), y se data en 830-850 ka por marcadores bioestratigráficos, datación de hemipelagitas y fotoespectometría de testigos de turbiditas, y en 890 ka por tasas de sedimentación.

\section{Edad del deslizamiento de Güímar}

En las principales publicaciones que hacen referencia a la edad del deslizamiento de Güímar se indican edades en torno a los 830-840 ka (Ancochea et al., 1990; Carracedo et al., 2011), ajustadas a partir de dos dataciones de los niveles superiores del escarpe Sury una datación del relleno del valle. Debido al menor número de dataciones disponibles que puedan servir para acotar la edad del deslizamiento, comparando con los deslizamientos de La Orotava e Icod, el rango de edades es muy estrecho.

Tras la revisión de las edades más representativas proporcionadas por diferentes métodos de datación en rocas de los escarpes y de relleno del valle (Tabla 3a), se puede considerar una edad en torno a los 830 ka para el deslizamiento: según las dataciones del escarpe sur, el deslizamiento habría sido posterior a los $830 \mathrm{ka}$; y según los datos del relleno sería anterior a los $831 \mathrm{ka}$. Sobre el único dato disponible del escarpe norte, de $806 \pm 18$ ka (Carracedo et al., 2009), el propio autor cuestiona si el depósito datado es anterior o posterior al deslizamiento, decantándose más por lo segundo (Carracedo et al., 2011), lo que apoyaría la edad deducida de las demás dataciones. En la Figura 7 se ha representado la distribución temporal de las dataciones.

Con respecto a los únicos datos disponibles sobre dataciones de las turbiditas profundas relacionadas con los depósitos del deslizamiento, Hunt et al. (2013) obtienen, mediante distintos métodos de datación, edades entre los 830 y 895 ka (Tabla 3b). Si se descartan los datos basados en la estimación de la tasa de sedimentación (por ser los menos precisos) la horquiIla se reduce a 830-850 ka (Figura 7).

Por tanto, y como conclusión general, puede establecerse para el deslizamiento de Güímar una edad en torno a los 830-850 ka, avalada por los datos de rocas subaéreas y de los depósitos submarinos. La horquilla podría reducirse a los 830-840 ka si se considera un valor medio para las dataciones submarinas más representativas, coincidiendo así con las estimaciones realizadas por autores como Ancochea et al. (1990) y Carracedo et al. (2011).

\section{Dataciones relacionadas con el deslizamiento de Micheque}

El deslizamiento de Micheque o Acentejo, en el flanco norte de la Dorsal Noreste, al norte del deslizamiento de La Orotava (Figura 3), no tiene reflejo morfológico en superficie, a pesar de habérsele calculado un gran volumen ( $60 \mathrm{~km}^{3}$; Carracedo et al., 2011). Su ocurrencia se evidencia de manera irrefutable por la presencia de depósitos de deslizamiento ('mortalón') en el interior de las galerías que atraviesan este flanco, bajo cientos de metros de coladas de relleno del valle por erupciones posteriores que han ocultado cualquier rasgo del deslizamiento.

En efecto, en las galerías Fuentenueva $(4.350 \mathrm{~m}$ de longitud) y Las Breñas (5.490 m), en las zonas de Santa Úrsula y El Sauzal respectivamente, visitadas por los autores, aflora el 'mortalón' a lo largo de más de 640 m en la primera y unos $330 \mathrm{~m}$ en la segunda, a distancias de $3.700 \mathrm{~m}$ y $4.963 \mathrm{~m}$ de bocamina respectivamente. Estas galerías alcanzan la cabecera del deslizamiento $\mathrm{y}$, aunque separadas más de $4 \mathrm{~km}$, tienen cota similar: $435 \mathrm{~m}$ y $440 \mathrm{~m}$. En las galerías Dornajos y EI Loro, ambas en la zona de Santa Úrsula, muy cercanas a la galería Fuentenueva, aparece igualmente el depósito de 'mortalón' aproximadamente hacia los 2.600 m y 2.800 $\mathrm{m}$ de bocamina respectivamente (Carracedo et al., 2009). Cabe indicar que, según la información disponible del CIATF (2019) sobre las galerías, estos autores confunden en las figuras de su publicación la situación y los trazados de ambas galerías con otras cercanas de la zona, y aportan un dato erróneo para la longitud de la galería Dornajos, de 3.007 m según el CIATF (según indican en el texto los autores, la muestra GLD-20, a base del 'mortalón', se toma a los $3.070 \mathrm{~m}$ de bocamina, lo que no resulta congruente). No obstante, se ha considerado que, a pesar de estos errores, y en base a la revisión y cotejo de los datos de la citada publicación, las descripciones y datos sobre la posición del 'mortalón' sí corresponden a las galerías Dornajos y EI Loro.

Para estimar la edad del deslizamiento de Micheque se cuenta, únicamente, con algunas dataciones de los materiales que rellenaron el valle tras el deslizamiento, que aportan una edad mínima. La Tabla 4 muestra estos datos, y su relación con el deslizamien- 
M. Ferrer et al., 2020. Geocronología de los megadeslizamientos deTenerife del último...Boletín Geológico y Minero, 131 (4): $903-940$

\begin{tabular}{|c|c|c|c|c|c|}
\hline \multicolumn{2}{|c|}{$\begin{array}{l}\text { Colada o depósito volcánico datado } \\
\text { (pre/post deslizamiento) }\end{array}$} & \multirow{2}{*}{\begin{tabular}{|l|}
$\begin{array}{l}\text { Edad } \\
\text { estimada }^{1}\end{array}$ \\
$830 \pm 19 \mathrm{ka}$ \\
\end{tabular}} & \multirow{2}{*}{$\begin{array}{l}\text { Referencia } \\
\begin{array}{l}\text { Carracedo } e t \\
\text { al., } 2009\end{array}\end{array}$} & \multirow{2}{*}{$\begin{array}{l}\text { Explicación } \\
\text { Lavas cortadas en la galería Dornajos (a } \\
2.200 \mathrm{~m} \text { de bocamina). } \\
\text { Depósito posterior al deslizamiento. } \\
\text { Muestra a algunos cientos de metros antes } \\
\text { del techo del 'mortalón' }(\sim 400 \mathrm{~m}) \\
\end{array}$} & \multirow{2}{*}{$\begin{array}{c}\begin{array}{l}\text { Edad del } \\
\text { deslizamiento }^{2}\end{array} \\
>830\end{array}$} \\
\hline 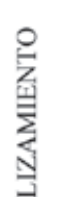 & $\begin{array}{l}\text { Lavas de relleno del valle, sobre los depósitos } \\
\text { de 'mortalón'. } \\
\text { Depósitos subterráneos cortados en la galería } \\
\text { Dornajos * }\end{array}$ & & & & \\
\hline 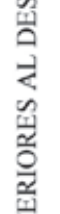 & $\begin{array}{l}\text { Lavas de relleno del valle, aflorando en la base } \\
\text { del acantilado costero en la costa NE (entre Sta. } \\
\text { Úrsula y Tacoronte) }\end{array}$ & $694 \pm 15 \mathrm{ka}$ & $\begin{array}{l}\text { Carracedo et } \\
\text { al., } 2007 \text { y } \\
2009\end{array}$ & $\begin{array}{l}\text { En el acantilado costero afloran los } \\
\text { materiales de relleno de la cuenca de } \\
\text { deslizamiento, reflejando una fase } \\
\text { avanzada de la colmatación de la } \\
\text { depresión (Carracedo et al., 2009). } \\
\text { Depósito posterior al deslizamiento. }\end{array}$ & $>694$ \\
\hline 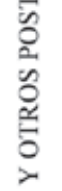 & $\begin{array}{l}\text { Lavas cayendo en cascada sobre el escarpe de } \\
\text { Sta. Úrsula, pared Este del deslizamiento de La } \\
\text { Orotava }\end{array}$ & $566 \pm 13 \mathrm{ka}$ & $\begin{array}{l}\text { Carracedo et } \\
\text { al., } 2009\end{array}$ & $\begin{array}{l}\text { Se considera esta edad asumiendo que los } \\
\text { materiales del escarpe correspondan al } \\
\text { relleno del valle dejado por el } \\
\text { deslizamiento de Micheque. } \\
\text { Depósito posterior al deslizamiento. }\end{array}$ & $>566$ \\
\hline 号 & $\begin{array}{l}\text { Coladas del escarpe de Sta. Ursula (Mirador de } \\
\text { Humbolt). }\end{array}$ & $780 \pm 180 \mathrm{ka}$ & $\begin{array}{l}\text { Ancochea } e t \\
\text { al., } 1990\end{array}$ & $\begin{array}{l}\text { Asumiendo que los materiales del escarpe } \\
\text { correspondan a los depósitos de relleno } \\
\text { del valle de Micheque, como propone } \\
\text { Carracedo et al. (2009). }\end{array}$ & $>780$ \\
\hline $\begin{array}{l}0 \\
0 \\
0 \\
0 \\
0 \\
0 \\
0\end{array}$ & $\begin{array}{l}\text { Colada traquitica de relleno del valle en } \\
\text { superficie, parte superior de la serie (en la zona } \\
\text { de El Sauzal) }\end{array}$ & $540 \pm 30 \mathrm{ka}$ & $\begin{array}{l}\text { Abdel Monem } \\
\text { et al., } 1972 \\
\text { (edad } \\
\text { recalculada } \\
\text { por Ancochea } \\
\text { et al., 1990) }\end{array}$ & Depósito posterior al deslizamiento. & $>540$ \\
\hline \multicolumn{6}{|c|}{ Carracedo et al. (2009) aportan la edad de $\sim 830$ ka para el deslizamiento. } \\
\hline \multicolumn{6}{|c|}{$\begin{array}{l}1 \text { Todas las edades son } \mathrm{K} / \mathrm{Ar} \text {. } \\
2 \text { Edad basada en la relación temporal de los depósitos con el deslizamiento, según las dataciones publicadas por los diferentes autores. } \\
\text { Al fondo de esta misma galeria (a unos } 3.000 \mathrm{~m} \text { de bocamina) Carracedo et al. (2009) datan una formación basáltica alterada bajo el depósito de } \\
\text { 'mortalón' en } 2.710 \pm 58 \mathrm{ka} \text {, interpretada como el sustrato del deslizamiento de Micheque; ver explicaciones en Ferrer et al. (2020-este volumen) }\end{array}$} \\
\hline
\end{tabular}

Ver NOTA EXPLICATIVA a pie de la Tabla la.

Tabla 4. Dataciones de depósitos volcánicos relacionados con el deslizamiento de Micheque o Acentejo.

Table 4. Ages of volcanic deposits related to the Micheque landslide.

to y con su edad; la Figura 8 representa las relaciones temporales entre ellos.

\section{Datación de materiales de relleno del valle}

Los materiales de relleno del valle atravesados por la galería Dornajos se han datado en 830 ka a $2.200 \mathrm{~m}$ de la bocamina (Carracedo et al., 2009), indicando por tanto una edad más antigua para el deslizamiento. En esta galería los depósitos deslizados, el 'mortalón', aparecen a unos $2.600 \mathrm{~m}$ de la bocamina.

Además de este dato, existen algunas referencias que pueden relacionarse cronológicamente con el deslizamiento de Micheque. Carracedo et al. (2011) proponen que el escarpe este del deslizamiento de La Orotava (escarpe de Santa Úrsula) está excavado en materiales del relleno del valle dejado por el deslizamiento de Mi- cheque, y por tanto puede asumirse para este deslizamiento una edad mayor de $780 \mathrm{ka}$, que es la edad de una colada datada en este escarpe por Ancochea et al. (1990), (ver Tabla 2a; el problema en considerar esta edad es su gran incertidumbre: $\pm 180 \mathrm{ka}$ ). Por otro lado, Carracedo et al. (2007) datan en 694 ka unas lavas en la base de un acantilado costero en la costa NE, formado por los materiales de relleno de la cuenca del deslizamiento, reflejando una fase avanzada de la colmatación de la depresión (Carracedo et al., 2009). Se cuenta también con una datación de 566 ka de unas lavas cubriendo el escarpe de Santa Úrsula, posteriores al mismo (Carracedo et al., 2009), y un dato de Abdel Monem et al. (1972) de 540 ka para unas lavas en superficie del relleno del valle de Micheque. De todos los datos anteriores se podría tomar un amplio rango de 700-800 ka para la edad mínima del deslizamiento. 


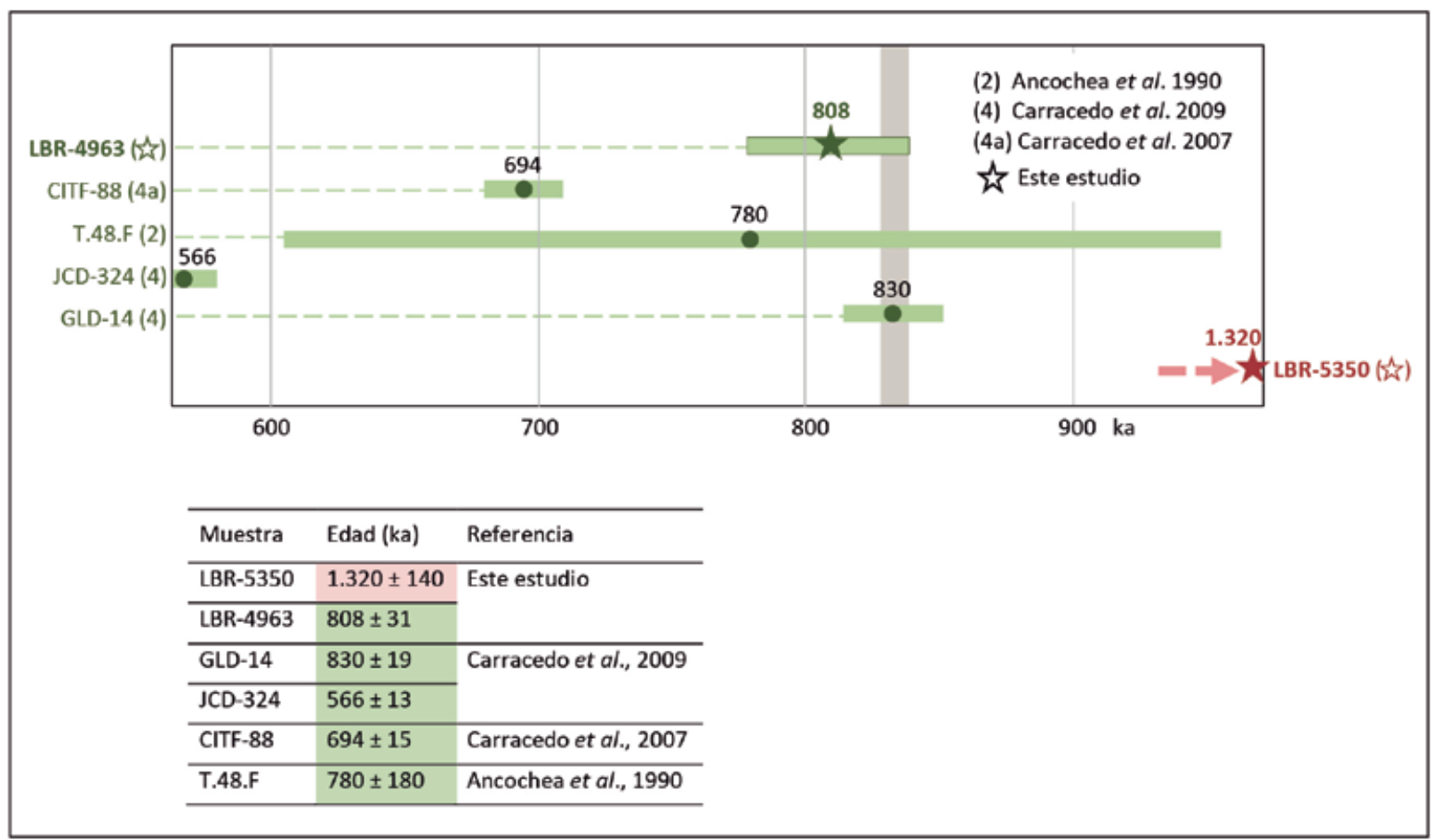

Figura 8. Dataciones relacionadas con el deslizamiento de Micheque o Acentejo. Las edades en rojo y verde corresponden respectivamente a materiales post y predeslizamiento (ver Tabla 4 para explicación); por tanto el deslizamiento habría sido anterior a las edades en rojo y posterior a las edades en verde. Las barras horizontales representan los rangos de edades, considerando las incertidumbres correspondientes aportadas por cada autor; alineados con cada barra aparecen en los márgenes las referencias al autor y el $n^{\circ}$ de muestra. La franja vertical gris indica la edad más representativa del deslizamiento: >830 ka. Las estrellas corresponden a las dataciones Ar/Ar realizadas para este estudio (ver explicaciones en el texto).

Figure 8. Ages related to the Micheque or Acentejo landslide. The ages in red and green correspond respectively to post and pre-landslides deposits (see Table 4 for explanation); therefore the rockslide would have occurred before the red ages and after the green ages. Horizontal bars represent the age ranges, considering the corresponding uncertainties provided by each author. Aligned with each bar, the references to the author and the sample number appear in the margins. The grey vertical stripe represents the most representative age for the landslide: $>830 \mathrm{ka}$. The star symbols correspond to the Ar/Ar dates for this study (see explanations in the text).

\section{Edad del deslizamiento de Micheque}

Actualmente es un hecho la existencia del deslizamiento de Micheque, cuya edad es tratada por Carracedo et al. (2009) en el contexto de la evolución de la Dorsal Noreste de Tenerife, proponiendo una edad similar al deslizamiento de Güímar, en torno a los 830 ka o mayor.

Los escasos datos disponibles de edades que puedan relacionarse con el deslizamiento de Micheque no permiten ir más allá de la apreciación anterior, y únicamente permiten establecer un límite superior en torno a los 780-830 ka, según los datos más representativos, teniendo en cuenta las incertidumbres de las edades (ver Tabla 4 y Figura 8); los otros datos no aportan información relevante, al corresponder todos ellos a depósitos posteriores.

\section{Nuevas dataciones Ar/Ar}

Se han realizado una serie de dataciones en muestras de rocas con la finalidad de acotar las edades de los deslizamientos de Güímar, La Orotava y Micheque. Estos análisis se llevaron a cabo en el marco de proyectos de investigación financiados por el Instituto Geológico y Minero de España. Las dataciones se realizaron en 2014 en el Ar/Ar Research Laboratory, Centre for Earth, Planetary, Space \& Astronomical Research (CEPSAR), The Open University (UK).

La principal aportación de los nuevos datos es que, excepto dos muestras, todas proceden del interior de las galerías que atraviesan el relleno de los flancos deslizados y, en ocasiones, los depósitos de 'mortalón'. Hasta hora, solo se han publicado 2 dataciones de rocas de galerías para los citados deslizamientos: una en La Orotava y otra en Micheque.

Se recogieron numerosas muestras en el interior de galerías que atraviesan los materiales que rellenan los valles de La Orotava, Güímar y Micheque, en coladas a techo y a muro del 'mortalón', la brecha caótica polimíctica y heterométrica cuya génesis está asociada a los deslizamientos. Es de destacar que en alguna de las galerías muestreadas se atravesaron dos tramos o de- 
pósitos de 'mortalón', hecho que se tiene en consideración a la hora de interpretar las dataciones, y que puede suponer una evidencia de la ocurrencia de más de un deslizamiento en el valle. Este aspecto se trata más adelante, y con mayor detalle, en Ferrer et al. (2020este volumen).

\section{Muestras y métodos}

La selección de las galerías a muestrear se realizó por la presencia en su interior de depósitos representativos de 'mortalón', y por el interés de los resultados de las dataciones para verificar la edad de los deslizamientos, teniendo en cuenta la información ya disponible en la bibliografía; aunque el principal condicionante inicial fueron la garantía de seguridad de las galerías para acceder y permanecer en su interior, para lo que se contó con la inestimable ayuda de técnicos y especialistas locales.

Las muestras tomadas en las galerías correspondían bien a coladas de relleno sobre los paquetes de 'mortalón' o bien a coladas inmediatamente por debajo de estos, es decir, materiales post-deslizamiento o pre-deslizamiento respectivamente. Se descartaron las coladas alteradas, eligiendo las rocas más sanas o 'frescas' lo más cerca posible de los depósitos de 'mortalón'.

Adicionalmente, se recogieron algunas muestras en superficie en las coladas superiores de los escarpes laterales de los valles de La Orotava y Güímar, supuestamente afectadas por los deslizamientos en base a la cartografía geológica y a indicios de campo.

La selección de las muestras a datar se realizó tras llevar a cabo estudios petrográficos microscópicos de detalle (láminas delgadas, difracción de rayos X) y análisis geoquímicos, con la finalidad de asegurar la inalterabilidad y las mejores condiciones de las rocas con vistas a las dataciones radiométricas. Todos los análisis mineralógicos y geoquímicos se realizaron en los laboratorios del IGME. Finalmente se seleccionaron 12 muestras de roca.

Las dataciones se realizaron mediante el método Ar/Ar. En el Apéndice se incluyen los detalles sobre el procedimiento analítico y los resultados.

En la Figura 9 se muestra la situación de las galerías y la localización de las muestras datadas. Se dataron muestras en coladas inalteradas a techo y a muro de los depósitos de deslizamiento en las galerías Cruz de Luis y Bolaños, en el valle de La Orotava; Cueva de Las Colmenas, en el valle de Güímar; y Las Breñas, en la zona del paleo-deslizamiento de Micheque. Algunas de estas galerías atraviesan varios tramos de 'mortalón', cuya longitud, a lo largo de la galería, varía entre decenas y centenares de metros (más de $300 \mathrm{~m}$ en el caso de Las Breñas).
La menor cantidad de muestras en el valle de Güímar se debe a las malas condiciones en que se encuentran las galerías, que hace difícil y peligroso el acceso a las mismas.

La Figura 10 presenta los esquemas de las galerías visitadas y la situación de las muestras datadas.

\section{Resultados e interpretación de las dataciones Ar/Ar}

Los análisis proporcionaron 11 dataciones consideradas fiables: 9 de muestras procedentes de galerías de los valles de La Orotava (6), Güímar (1) y Micheque (2), y 2 muestras de los escarpes de los deslizamientos de La Orotava y Güímar. Se desestimó un resultado por mostrar discordancias posiblemente asociadas a un exceso de Ar por alteración de los basaltos (edad de $4.130 \pm 120 \mathrm{ka}$, obtenida para un dique a muro del 'mortalón' en la galería Cueva de Las Colmenas, a 2.372 m de $\mathrm{m}$ distancia desde bocamina, muestra CCO-2372).

En la Tabla 5 y en la Figura 9 se presentan la situación de las muestras datadas y las edades obtenidas.

Los resultados de las dataciones corresponden a 9 edades entre $470 \pm 41$ ka y $835 \pm 30 \mathrm{ka}$, y 2 edades mayores, de 1,32 \pm 0.14 Ma y 2,55 \pm 0.05 Ma para las muestras LBR-5350 y CLU-2312 respectivamente. En el Apéndice se presentan los detalles de los resultados.

En la Tabla 6 se muestran los datos correspondientes a las muestras datadas y su localización en las galerías, las edades obtenidas y las edades estimadas para los deslizamientos a partir de ellas. En esta Tabla se incluyen también algunos resultados de otras dataciones llevadas a cabo previamente por los autores, que se discuten más adelante. A continuación, se detallan y explican estos datos que aparecen en la Tabla 6 , y sus relaciones con la edad de los deslizamientos.

\section{Valle de La Orotava}

En la galería Cruz de Luis del valle de La Orotava, se han datado las coladas a techo y a muro de los 2 paquetes de 'mortalón' que atraviesa esta galería, separados entre ellos casi $1 \mathrm{~km}$, resultando edades entre 470 y 506 ka, excepto para la muestra del muro del 'mortalón' más profundo, con $>2,5 \mathrm{Ma}$ (Tabla 6). Aunque las tres edades más modernas presentan contradicciones si se consideran los valores absolutos, tomando en cuenta las incertidumbres asociadas a las dataciones, la edad del conjunto de las rocas por encima del 'mortalón' más profundo (Figura 10) puede establecerse alrededor de 510-530 ka, indicando la edad máxima para el deslizamiento que originó el depósito más profundo de 'mortalón'. El 'mortalón' 1, más cercano a la boca de la galería, podría datarse en torno a los 500 ka. No obstante, con los datos disponibles 


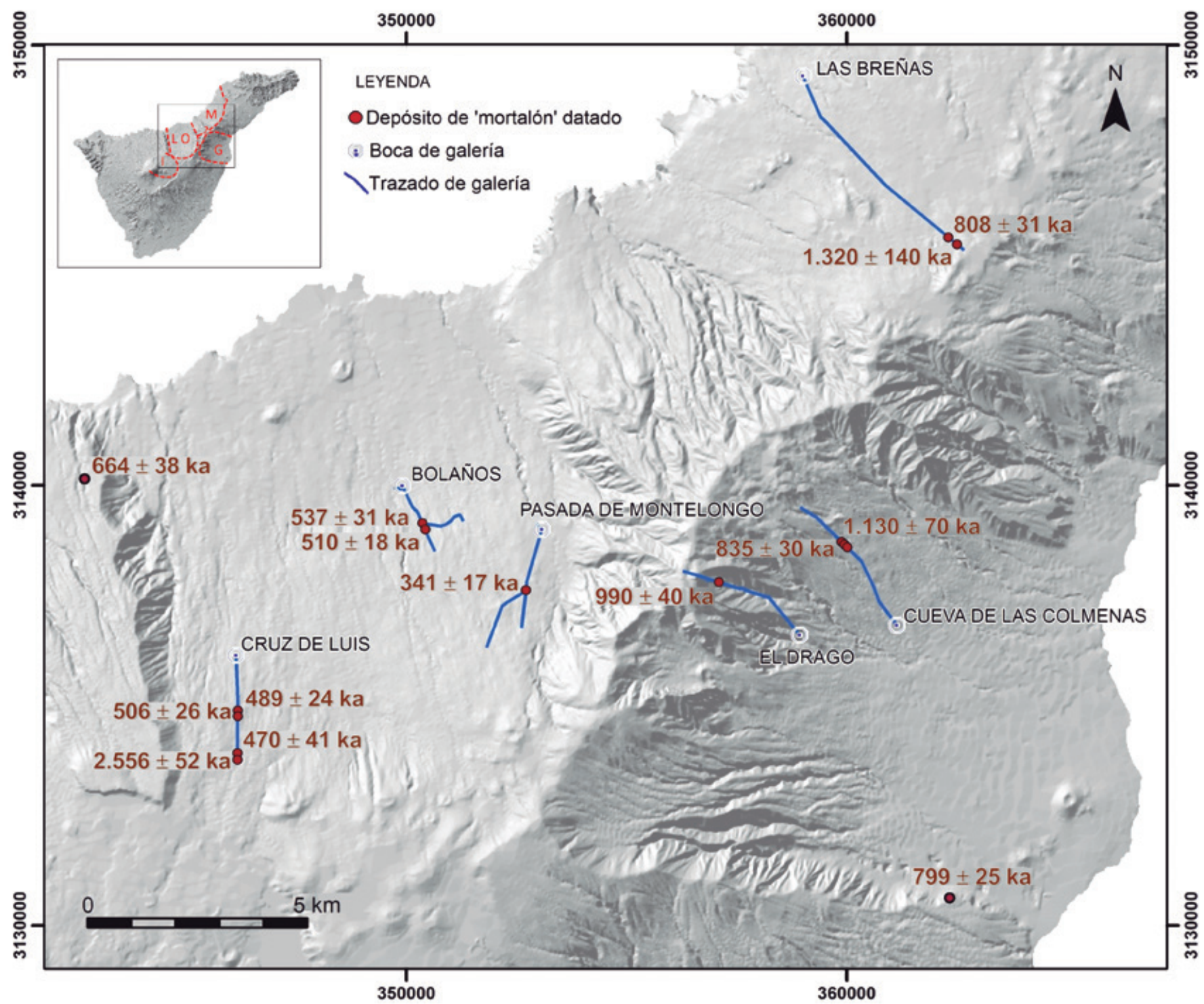

Figura 9. Mapa de situación de las galerías y de las muestras datadas, y edades obtenidas en este trabajo. Mapa base: GRAFCAN. Datos de trazado de las galerías: CIATF (2019).

Figure 9. Map with the location of the water galleries and the samples dated, and ages obtained in this study. Basemap: GRAFCAN. Gallery layout data: CIATF.

no se puede dilucidar si ambos tramos corresponden a depósitos del mismo deslizamiento o a dos 'mortalones' diferentes con edades separadas dos o tres decenas de miles de años. En Ferrer et al. (2020-este volumen), publicación que forma la segunda parte de este trabajo, se discuten estas consideraciones.

Las edades obtenidas en la galería Cruz de Luis coinciden con las de 532 ka y 498 ka aportadas por Boulesteix et al. (2013) para las lavas de relleno por encina del primer paquete de 'mortalón' en la galería Pino Soler, situada también en la cabecera del valle de La Orotava (ver apartado sobre las dataciones de La Orotava); por la situación, cotas y profundidad de ambas galerías (Figura 11), los depósitos de 'mortalón' pueden ser los mismos, como además corroboran las dataciones obtenidas en ambos casos. Las edades propuestas en torno a los 510-530 ka coinciden, igualmente, con la edad media reflejada por las dataciones de los depósitos de turbiditas provenientes del deslizamiento de La Orotava, sobre los 535 ka (verTabla 2b).

La edad de 532 ka se ha cuestionado anteriormente (ver apartado sobre la edad del deslizamiento de 


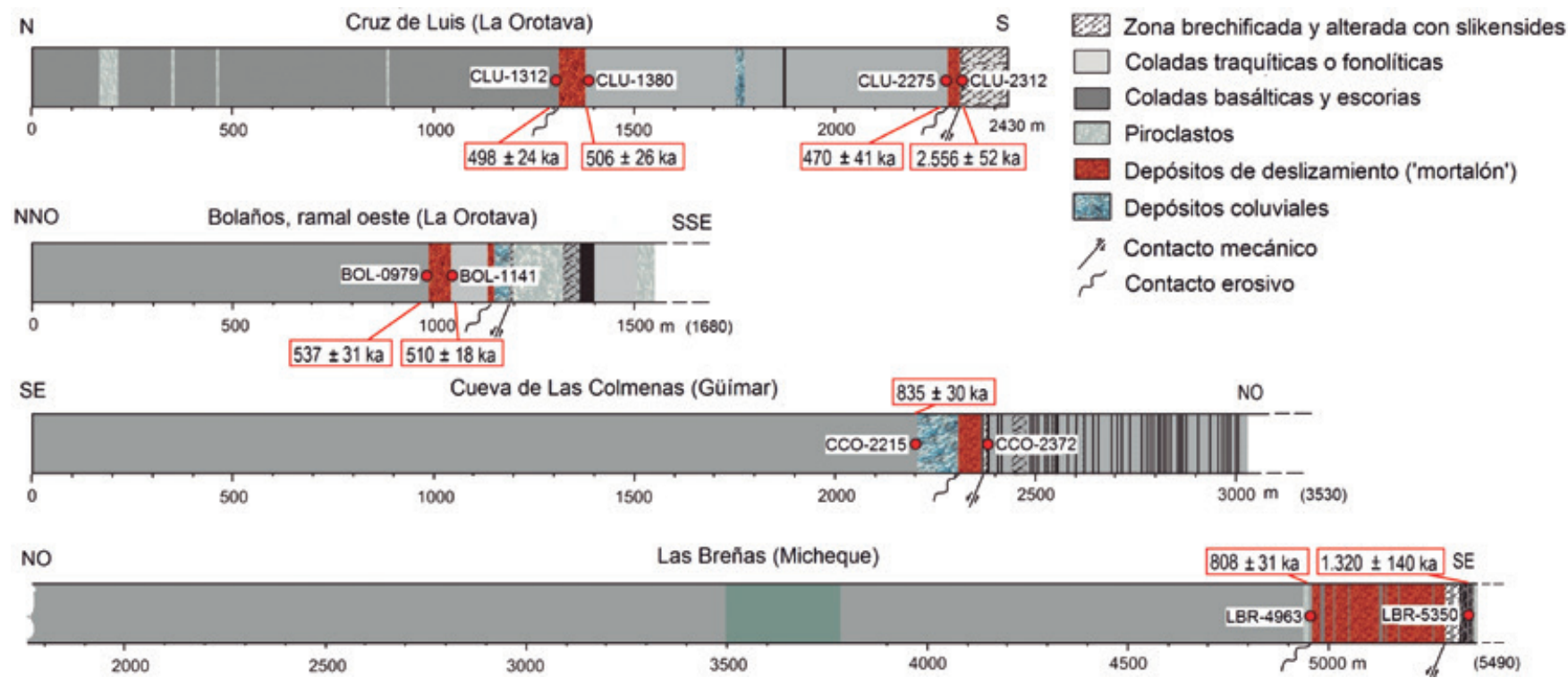

Figura 10. Esquemas de las galerías en que se tomaron muestras para datar a techo y a muro de los depósitos de deslizamiento ('mortalón'). Se han representado los números de muestra y las edades obtenidas. Entre paréntesis se ha indicado la longitud total de la galería en los casos en que no se llegó hasta el fondo.

Figure 10. Schematic sections of the galleries from which samples were collected for age determinations at the top and bottom of the landslide deposits ('mortalón). The sample numbers and the ages obtained have been represented. The total length of the gallery has been represented in brackets in the cases where the bottom was not reached in the field survey.

La Orotava) por no encajar en la edad asignada al deslizamiento de La Orotava, sobre los $560 \mathrm{ka}$, en el escenario asumido generalmente de un único deslizamiento de flanco. Pero ante un planteamiento de varios deslizamientos superpuestos en un mismo flanco volcánico, este dato, y los obtenidos en las nuevas dataciones de la galería Cruz de Luis, evidencian la ocurrencia de un deslizamiento en torno a los $530 \mathrm{ka}$. En efecto, los depósitos de 'mortalón' de las dos galerías podrían representar a un deslizamiento sobre los $530 \mathrm{ka}$, ya que en ninguna de ellas se han obtenido edades más antiguas sobre los paquetes de 'mortalón' (aunque no se dispone de dataciones sobre el segundo paquete de 'mortalón', más profundo, de la galería Pino Soler).

Cabe destacar que en los últimos cientos de metros de la galería Pino Soler, desde los 4.000 hasta el final $(4.840 \mathrm{~m})$, a muro del segundo tramo de 'mortalón', las coladas presentan un alto grado de fracturación y alteración, con una red de diques muy intensa, destacando la presencia de planos de fractura importantes, que podrían indicar la zona del plano de rotura y escarpe del deslizamiento.

En la galería Bolaños, en la zona media del valle y a menor cota que la galería Cruz de Luis, las dataciones de dos muestras a techo y muro del depósito de 'mortalón' atravesado por el ramal oeste de la galería (de unos $160 \mathrm{~m}$ de longitud), indicarían una edad para este depósito, y por tanto para el deslizamiento, entre 506 y $528 \mathrm{ka}$, considerando las incertidumbres de las dataciones (ya que los datos absolutos resultan incompatibles), similar al rango de edad establecido para el 'mortalón' de la galería Cruz de Luis (510-530 ka; o si se considera solo el depósito de 'mortalón' menos profundo, una edad en torno a los $500 \mathrm{ka}$ ).

Como resumen de los datos anteriores, las dataciones realizadas en rocas de las galerías del valle de La Orotava reflejan edades entre los 500 y 530 ka para las rocas por encima del primer paquete de 'mortalón' (el más cercano a bocamina); para la galería Cruz de Luis, también las rocas por encima del segundo depósito de 'mortalón'.

Con respecto a la datación realizada en la parte alta del escarpe occidental del valle de La Orotava, en coladas previas al deslizamiento (muestra TI-0002), la edad obtenida de 664 ka indicaría una edad menor para el deslizamiento, corroborando los datos de las muestras en galerías, sin poderse hacer mayores precisiones.

\section{Valles de Güímar y Micheque}

En el valle de Güímar no se dispone de dataciones previas en rocas de galerías, al menos ninguna publicada, por lo que las presentadas en este trabajo son las primeras. Se realizaron 2 dataciones en muestras de la galería Cueva de Las Colmenas, en rocas a techo y muro del paquete de 'mortalón' que atraviesa esta 


\begin{tabular}{|c|c|c|c|}
\hline Deslizamiento & Muestra & Situación y nombre de la galería & Edad (ka) \\
\hline \multirow{7}{*}{ La Orotava } & CLU -2312 & Muro del ‘mortalón' 2, Cruz de Luis & $2.556 \pm 52$ \\
\hline & CLU -2275 & Techo del 'mortalón' 2, Cruz de Luis & $470 \pm 41$ \\
\hline & CLU -1380 & Muro del 'mortalón' 1, Cruz de Luis & $506 \pm 26$ \\
\hline & CLU -1312 & Techo del 'mortalón' 1, Cruz de Luis & $498 \pm 24$ \\
\hline & BOL -1141 & Muro del 'mortalón', Bolaños & $510 \pm 18$ \\
\hline & BOL -0979 & Techo del 'mortalón', Bolaños & $537 \pm 31$ \\
\hline & $\mathrm{TI}-0002$ & Escarpe de Tigaiga & $664 \pm 38$ \\
\hline \multirow{3}{*}{ Güímar } & $\mathrm{CCO}-2372$ & Muro del 'mortalón', C. de las Colmenas & $4.130 \pm 120^{(*)}$ \\
\hline & $\mathrm{CCO}-2215$ & Techo del 'mortalón', C. de las Colmenas & $835 \pm 30$ \\
\hline & $\mathrm{GU}-0001$ & Escarpe de Güímar & $799 \pm 25$ \\
\hline \multirow[t]{2}{*}{ Micheque } & LBR -5350 & Muro del 'mortalón', Las Breñas & $1.320 \pm 140$ \\
\hline & LBR -4963 & Techo del ‘mortalón', Las Breñas & $808 \pm 31$ \\
\hline
\end{tabular}

(*) Edad no válida: dique cortado por el 'mortalón' atravesando una colada poco alterada.

Tabla 5. Dataciones Ar/Ar llevadas a cabo en 2014 en rocas procedentes de galerías y escarpes de La Orotava, Güímar y Micheque. Table 5. Ar/Ar ages of rocks from galleries and landslide scarps of La Orotava, Güímar and Micheque valleys.

galería, y 1 datación en una muestra de superficie de las coladas superiores del escarpe sur; una de las dos primeras, la muestra CCO-2372, fue desestimada por no considerarse válida (verTabla 5).

Los otros resultados obtenidos (Tabla 6) son coherentes con los datos disponibles en la bibliografía (Tabla 3a) que apuntan a una edad en torno a los $830-840$ ka para el deslizamiento: la muestra de la colada a techo del 'mortalón' en la galería Cueva de Las Colmenas, de $835 \pm 30 \mathrm{ka}$, y la de una colada superior en el escarpe sur, con $799 \pm 25 \mathrm{ka}$, que al considerar la incertidumbre daría un valor en torno a los $824 \mathrm{ka}$, en el orden de los rangos que indican los datos bibliográficos. No obstante, cabe la posibilidad de que la muestra tomada en el escarpe sur corresponda a una colada post-deslizamiento, a pesar de haber pretendido lo contrario al seleccionar la muestra, en cuyo caso la edad del deslizamiento sería $>799 \mathrm{ka}$, en consonancia con los otros datos propios para la edad del deslizamiento de Güímar; en ambos casos la edad está en un entorno razonable de la establecida para este deslizamiento a partir de las dataciones más relevantes disponibles en la literatura (Tabla 3a).

Con respecto a las dataciones realizadas para el deslizamiento de Micheque o Acentejo, los resultados de las muestras de materiales pre y postdeslizamiento de la Galería Las Breñas indican una edad >808 ka y $<1.320 \mathrm{ka}$, un rango amplio, pero con la edad menor en consonancia con una datación previa de $830 \pm 19$ ka en la galería Dornajos (Carracedo et al., 2009) (Tabla 4). Al ser más representativo el dato correspondiente a la colada inmediatamente a techo del 'mortalón', con $808 \pm 31 \mathrm{ka}$, puede asumirse este límite de edad para el paleodeslizamiento.

\section{Otras dataciones Ar/Ar(2007)}

Anteriormente a las nuevas dataciones radiométricas arriba descritas, los autores, en el marco de un proyecto de investigación sobre los grandes deslizamientos de La Orotava y Güímar, Ilevaron a cabo en 2007 tres dataciones $\mathrm{Ar} / \mathrm{Ar}$ en muestras tomadas en galerías (Tabla 7). Los análisis fueron realizados en el Berkeley Geochronology Center (BGC), CA (USA), en muestras de coladas a techo de depósitos de 'mortalón' en las galerías La Pasada de Montelongo (valle de La Orotava), El Drago y Cueva de Las Colmenas (valle de Güímar). Tanto en la Figura 9 como laTabla 6 se incluyen los datos referentes a estas dataciones. En el valle de Güímar no se disponía de dataciones previas en galerías. 


\begin{tabular}{|c|c|c|c|c|c|}
\hline & Muestra & $\begin{array}{l}\text { Colada o depósito volcánico datado } \\
\text { (pre/post deslizamiento) }\end{array}$ & $\begin{array}{c}\text { Edad } A \mathbf{r} / \mathrm{Ar} \\
( \pm 2 \sigma \mathrm{ka})\end{array}$ & Explicación & $\begin{array}{c}\text { Edad del } \\
\text { deslizamento } \\
\text { (ka) }\end{array}$ \\
\hline \multirow{4}{*}{$\begin{array}{c}\text { LA } \\
\text { OROTAVA }\end{array}$} & $\begin{array}{l}\text { CLU- } 2312 \\
\text { CLU- } 2275 \\
\text { CLU- } 1380 \\
\text { CLU- } 1312\end{array}$ & $\begin{array}{l}\text { Galeria Cruz de Luis } \\
\text { - Colada a muro del 'mortalón' } 2 \text { ( } 2.312 \mathrm{~m} \\
\text { de bocamina) } \\
\text { - Colada a techo del 'mortalón' } 2 \text { (2.275 m } \\
\text { de bocamina) } \\
\text { - Colada a muro del 'mortalón' } 1 \text { (1.380 m } \\
\text { de bocamina) } \\
\text { - Colada a techo del 'mortalón' } 1(1.312 \mathrm{~m} \\
\text { de bocamina) }\end{array}$ & $\begin{array}{r}2,556 \pm 52 \\
470 \pm 41 \\
506 \pm 26 \\
498 \pm 24\end{array}$ & $\begin{array}{l}\text { En esta galería no se puede asegurar que el } \\
\text { 'mortalón' 1, el menos profundo, sea } \\
\text { autóctono, ya que a muro aparece una } \\
\text { colada sin alterar, y podria indicar un } \\
\text { emplazamiento posterior a la rotura } \\
\text { principal del 'mortalón', tipo coluvial o } \\
\text { residual. Las edades de las coladas que lo } \\
\text { flanquean es de unos } 500 \text { ka, lo que } \\
\text { apoyaría esta hipótesis. } \\
\text { * Edad para el deslizamiento tomando las } \\
\text { incertidumbres de las dataciones. } \\
\text { ** Edad para el depósito de 'mortalón' } 1 \text {. }\end{array}$ & $\begin{array}{l}>510-530 * \\
\sim 500 \text { ** }\end{array}$ \\
\hline & $\begin{array}{l}\text { BOL-1141 } \\
\text { BOL-0979 }\end{array}$ & $\begin{array}{l}\text { Galeria Bolaños } \\
\text { - Colada a muro del 'mortalón' ( } 1.141 \mathrm{~m} \text { de } \\
\text { bocamina) } \\
\text { - Colada a techo del 'mortalón' ( } 979 \mathrm{~m} \text { de } \\
\text { bocamina) }\end{array}$ & $\begin{array}{l}510 \pm 18 \\
537 \pm 31\end{array}$ & $\begin{array}{l}\text { Las muestras proceden del ramal oeste de la } \\
\text { galeria. } \\
\text { * Considerando las incertidumbres. } \\
\text { × Considerando la incertidumbre de la } \\
\text { datación de la colada a muro del } \\
\text { 'mortalón'. }\end{array}$ & $\begin{array}{l}505-530 * \\
\sim 530{ }^{*}\end{array}$ \\
\hline & TI-0002 & $\begin{array}{l}\text { Colada de la parte superior del escarpe de } \\
\text { Tigaiga (escarpe oeste del deslizamiento) }\end{array}$ & $664 \pm 38$ & Depósitos anteriores al deslizamiento. & $<664$ \\
\hline & DAT $-3^{2}$ & $\begin{array}{l}\text { Galeria Pasada de Montelongo } \\
\text { Colada a techo del 'mortalón' } 1 \text { ( } 1.430 \mathrm{~m} \text { de } \\
\text { bocamina) }\end{array}$ & $341 \pm 17$ & $\begin{array}{l}\text { Colada de lava inmediatamente por encima } \\
\text { del primer tramo de 'mortalón', desde } \\
\text { bocamina, de los } 4 \text { que afloran en la galeria. }\end{array}$ & $>341$ \\
\hline \multirow{4}{*}{ GÖIMAR } & $\mathrm{CCO}-2215$ & $\begin{array}{l}\text { Galeria Cueva de Las Colmenas } \\
\text { Colada a techo del 'mortalón' }(2.215 \mathrm{~m} \text { de } \\
\text { bocamina) }\end{array}$ & $835 \pm 30$ & $\begin{array}{l}\text { Colada de lava inmediatamente por encima } \\
\text { del 'mortalón'. }\end{array}$ & $>835$ \\
\hline & GU-0001 & $\begin{array}{l}\text { Colada de la parte superior del escarpe Sur } \\
\text { de Güimar }\end{array}$ & $799 \pm 25 \mathrm{ka}$ & $\begin{array}{l}\text { Depósitos anteriores al deslizamiento. } \\
\text { * Considerando la incertidumbre. } \\
\text { ^ Considerando la colada posterior al } \\
\text { deslizamiento. }\end{array}$ & $\begin{array}{l}<824 * \\
>799 \wedge\end{array}$ \\
\hline & DAT- $2^{2}$ & $\begin{array}{l}\text { Galeria El Drago } \\
\text { Colada a techo del 'mortalón' } 2 \text { ( } 2.294 \mathrm{~m} \text { de } \\
\text { bocamina) }\end{array}$ & $\begin{array}{r}990 \pm 40 \\
(1.140 \pm 50)\end{array}$ & $\begin{array}{l}\text { Colada de lava inmediatamente por encima } \\
\text { del 'mortalón' más profundo desde } \\
\text { bocamina. }\end{array}$ & $\sim 1.100$ \\
\hline & DAT-1 ${ }^{2}$ & $\begin{array}{l}\text { Galeria Cueva de Las Colmenas } \\
\text { Colada a techo del 'mortalón' }(2.200 \mathrm{~m} \text { de } \\
\text { bocamina) }\end{array}$ & $\begin{array}{r}1.130 \pm 70 \\
(1.090 \pm 50)\end{array}$ & $\begin{array}{l}\text { Colada de lava inmediatamente por encima } \\
\text { del 'mortalón'. }\end{array}$ & $\sim 1.100$ \\
\hline MICHEQUE & $\begin{array}{l}\text { LBR-5350 } \\
\text { LBR-4963 }\end{array}$ & $\begin{array}{l}\text { Galeria Las Breñas } \\
\text { - Dique a muro del 'mortalón' ( } 5.350 \mathrm{~m} \text { de } \\
\text { bocamina) } \\
\text { - Colada a techo del 'mortalón' ( } 4.963 \mathrm{~m} \text { de } \\
\text { bocamina) }\end{array}$ & $\begin{array}{r}1.320 \pm 140 \\
808 \pm 31\end{array}$ & $\begin{array}{l}\text { La muestra de muro se toma a } 55 \mathrm{~m} \text { del } \\
\text { muro del 'mortalón', evitando el tramo } \\
\text { basal intensamente alterado y fracturado, } \\
\text { intruido por numerosos diques antiguos. }\end{array}$ & $>808$ \\
\hline
\end{tabular}

${ }^{1}$ Edad propuesta a partir de las dataciones de los depósitos de 'mortalón' o, en su caso, de rocas de los escarpes de deslizamiento.

${ }^{2}$ Muestras datadas en 2007 por los autores de este trabajo. Ver Apéndice 1 para detalles de las dataciones.

* Edades estimadas considerando las incertidumbres de algunas dataciones; ver explicaciones en el texto.

** Edad probable propuesta; ver explicaciones en el texto.

NOTA EXPLICATIVA:

En las primeras columnas se muestran los datos correspondientes a las muestras, su localización en las galerías y las edades obtenidas; en la penúltima columna se incluye la explicación sobre la posición y caracteristicas de cada muestra, su relación con los depósitos del deslizamiento ('mortalón') y su interés a efectos de datación del mismo; en la última columna se incluye la edad/es estimada/s para los deslizamientos.

Tabla 6. Nuevas edades Ar/Ar

Table 6. New Ar/Ar ages. 


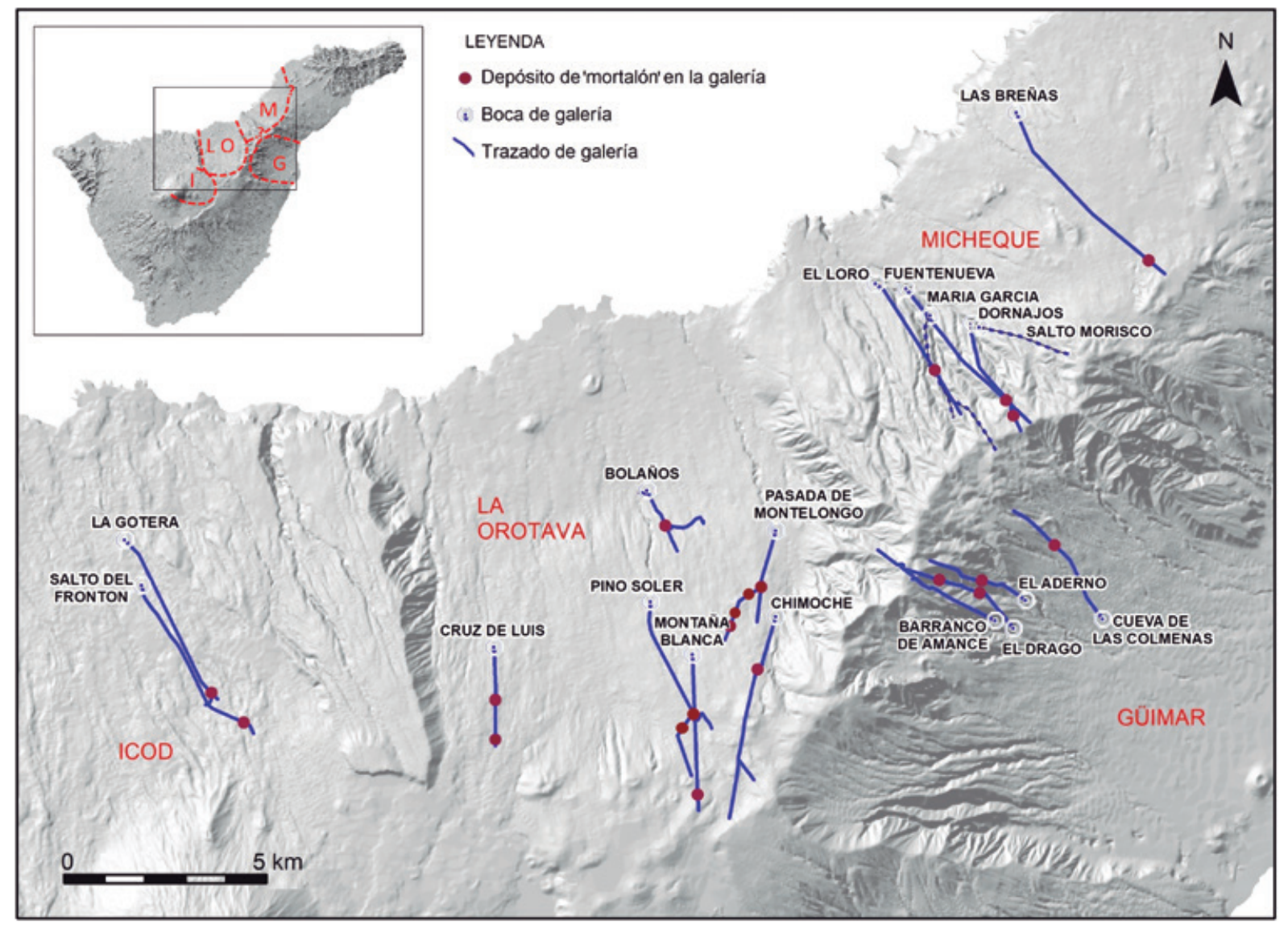

Figura 11. Mapa con la situación de las galerías que se citan en el texto en los valles de La Orotava, Güímar, Micheque e Icod. Se han marcado en cada una de ellas los depósitos de 'mortalón' a los que se hace referencia en el texto. Las galerías Salto Morisco y María García, en la zona de Micheque, se han marcado con línea de puntos, y se incluyen únicamente a efectos de localización. Mapa base: GRAFCAN. Datos de trazado de las galerías: CIATF (2019).

Figure 11. Map of the location of the galleries cited in the text in the valleys of La Orotava, Güímar, Micheque and Icod. The landslide deposits ('mortalón') referred to in the text have been marked on each of them. The Salto Morisco and María García galleries, in the Micheque area, marked with a dotted line, are included for location purposes only. Basemap: GRAFCAN. Gallery layout data: CIATF.

Los resultados, si bien fueron considerados fiables, presentan ciertas reservas en su interpretación, sobre todo a la luz de los resultados de las posteriores dataciones llevadas a cabo por los autores de este trabajo en 2014. Por su posible interés se comentan aquí algunos aspectos sobre estas dataciones, especialmente de las galerías del valle de Güímar.

En la muestra de la galería Pasada de Montelongo, en el valle de La Orotava, se obtuvo una edad de 341 ka; las muestras de las galerías El Drago y Cueva de Las Colmenas, en el valle de Güímar, proporcionaron edades mucho más antiguas y similares, en torno a 1.100 ka (Ferrer et al., 2008; Seisdedos, 2009).

El resultado obtenido de 341 ka queda lejos del límite mínimo de edad que indican las dataciones de la bibliografía y las otras propias presentadas en este trabajo para el deslizamiento de La Orotava. Cabe indicar que la galería La Pasada de Montelongo, de más de 3.000 $\mathrm{m}$, corta al menos 4 tramos de 'mortalón', y la mues- tra datada corresponde al techo del primer paquete de 'mortalón' desde la entrada a la galería, a $1.430 \mathrm{~m}$ de bocamina; la edad obtenida, a pesar de ser mucho más joven, es congruente en cuanto que es más moderna que la edad deducida para el probable deslizamiento más moderno en el valle (en torno a los $500 \mathrm{ka}$ ), ya que corresponde a una colada por encima de todos los niveles de 'mortalón' presentes en la galería. En Ferrer et al. (2020-este volumen) se discute la interpretación de este dato en el contexto de la ocurrencia de varios deslizamientos superpuestos en el valle de La Orotava.

Para el caso del deslizamiento de Güímar, los resultados de las 2 dataciones en muestras a techo del 'mortalón' de las galerías Cueva de Las Colmenas y EI Drago indican que éste habría sido anterior a 1,0-1,1 $\mathrm{Ma}$, dato incompatible con la edad deducida para el deslizamiento según dataciones previas en la literatura, entre 830 y $840 \mathrm{ka}$, y otra propia presentadas en este trabajo, ya que resultaría para los materiales de relleno 


\begin{tabular}{llll}
\hline Deslizamiento & Muestra & Situación y nombre de la galería & Edad (ka) \\
\hline La Orotava & DAT -3 & $\begin{array}{l}\text { Techo ‘mortalón' 1, Pasada de } \\
\text { Montelongo }\end{array}$ & $341 \pm 17$ \\
\hline \multirow{2}{*}{ Güímar } & DAT -2 & Techo 'mortalón' 2, El Drago & $\begin{array}{l}990 \pm 40 \\
(1.140 \pm 50)\end{array}$ \\
\cline { 2 - 4 } & DAT -1 & $\begin{array}{l}\text { Techo 'mortalón', Cueva de Las } \\
\text { Colmenas }\end{array}$ & $\begin{array}{l}1.130 \pm 70 \\
(1.090 \pm 50)\end{array}$ \\
\hline
\end{tabular}

Ver detalles de las dataciones en el Apéndice 1.

Tabla 7. Dataciones Ar/Ar en rocas procedentes de galerías de La Orotava y Güímar.

Table 7. Ar/Ar ages of rocks from galleries excavated in La Orotava and Güímar valleys.

del valle una edad más antigua que la de los materiales pre-deslizamiento datados en los escarpes. En la galería Cueva de Las Colmenas aparece un único tramo de 'mortalón' de más de $150 \mathrm{~m}$ de longitud (aunque en la visita realizada por los autores no se llegó al fondo de la galería), mientras que en la galería El Drago se cortan 2 paquetes de 'mortalón' de varios cientos de metros, separados entre ellos por centenares de metros de coladas; en esta galería la muestra se tomó a techo del paquete más profundo.

Si se asume la edad deducida de los datos bibliográficos (830-840 ka) para el deslizamiento de Güímar, las 2 dataciones no concuerdan; pero también es de consideración el hecho de que se haya obtenido la misma edad, en torno a 1,0-1,1 Ma, para el techo del 'mortalón' en las muestras de las dos galerías cercanas, coincidiendo con el rango que delimita la edad de la última fase de desarrollo de la dorsal NE, entre los 0,8 Ma y 1 Ma (Carracedo et al., 2009).

Aquí se ha optado por no considerar estas dos edades para la datación del deslizamiento del valle de Güímar, aunque quizás a la luz de futuros avances puedan descartarse una u otras. No obstante, en Ferrer et al. (2020-este volumen) se discuten las posibles interpretaciones de estos resultados.

\section{Resumen y discusión}

Las nuevas dataciones $\mathrm{Ar} / \mathrm{Ar}$ realizadas con la finalidad de ajustar la edad de los deslizamientos de Tenerife son concordantes, en general, con los datos isotópicos disponibles en la bibliografía, y proporcionan información representativa sobre la edad de los deslizamientos, especialmente en los casos de Güímar y Micheque, en los que se disponía de muy escasos datos previos, y solo una datación de rocas de galerías (galería Dornajos, en Micheque; Carracedo et al., 2009). En la Tabla 8 se resumen los datos disponibles en la bibliografía, incluidos en las Tablas 1 a 4 , y los propios de este trabajo, incluidos en la Tabla 6 .

Los datos son igualmente coherentes entre sí, máxime si se tienen en cuenta los rangos de las incertidumbres de cada edad, y pueden ser interpretados en el marco de las edades deducidas de los datos bibliográficos más fiables disponibles en la literatura. La única excepción son las edades de las dos muestras tomadas en la colada a techo del 'mortalón' de la galería Cueva de Las Colmenas, que presentan resultados dispares en los análisis de 2014 y 2007: 835 ka frente a 1,1 Ma.

En el caso del deslizamiento de La Orotava, los datos apuntan a una edad nueva y diferente, más temprana, de la asumida hasta ahora en la mayoría de los trabajos publicados a partir de dataciones de depósitos subaéreos (unos $560 \mathrm{ka}$ ). Las edades o rango de edades que aportan las nuevas dataciones realizadas en las galerías que atraviesan el valle sitúan la edad del deslizamiento en torno a los $530 \mathrm{ka}$, coincidiendo con la edad propuesta por Boulesteix et al. (2013) y con la edad de $\sim 535$ ka de las turbiditas submarinas provenientes del deslizamiento (Hunt et al., 2013).

La evidencia de estos datos hace que esta nueva edad se considere como representativa de un gran deslizamiento de flanco en La Orotava, y confirma la idea propuesta en este trabajo de varias grandes roturas de flanco superpuestas. Los nuevos datos refuerzan sin duda la edad en torno a los 530 ka para el deslizamiento, unos 30 ka después del deslizamiento datado en 560 ka a partir principalmente de rocas de los escarpes. En la publicación que constituye la Parte II de este trabajo (Ferrer et al., 2020-este volumen) se discute esta propuesta de deslizamientos superpuestos, a la luz de evidencias geológicas subaéreas y submarinas.

Las dataciones en galerías han proporcionado edades que pueden abrirse entre los $\sim 500$ y $~ 530 \mathrm{ka}$, por lo que no se descarta, a falta de más dataciones, la ocu- 


\begin{tabular}{|c|c|c|c|c|c|}
\hline \multicolumn{5}{|c|}{$\begin{array}{l}\text { Deslizamiento, depósitos datados y sus edades, y edad deducida para el } \\
\text { deslizamiento de la revisión bibliográfica de las dataciones }\end{array}$} & $\begin{array}{l}\text { Edad según } \\
\text { este trabajo }\end{array}$ \\
\hline \multirow{4}{*}{ Icod } & \multirow{3}{*}{$\begin{array}{l}\text { Depósitos } \\
\text { volcánicos } \\
\text { subaéreos }\end{array}$} & $\begin{array}{l}\text { Niveles superiores del escarpe } \\
\text { de cabecera del deslizamiento } \\
\text { (pared de Diego Hernández) }\end{array}$ & $173-183 \mathrm{ka}$ & \multirow{4}{*}{$\begin{array}{l}\sim 165-175 \mathrm{ka}^{1} \\
160-180 \mathrm{ka}^{2}\end{array}$} & \multirow{4}{*}{-} \\
\hline & & \begin{tabular}{|l|}
$\begin{array}{l}\text { Depósitos asociados } \\
\text { temporalmente al deslizamiento } \\
\text { (unidad El Abrigo) }\end{array}$ \\
\end{tabular} & $130-196 \mathrm{ka}$ & & \\
\hline & & $\begin{array}{l}\text { Relleno del valle dejado por el } \\
\text { deslizamiento }\end{array}$ & $161-198 \mathrm{ka}$ & & \\
\hline & \multicolumn{2}{|c|}{$\begin{array}{l}\text { Turbiditas submarinas profundas procedentes } \\
\text { del deslizamiento }\end{array}$} & $160-200 \mathrm{ka}$ & & \\
\hline \multirow{4}{*}{$\begin{array}{l}\text { La } \\
\text { Orotava }\end{array}$} & \multirow{3}{*}{$\begin{array}{l}\text { Depósitos } \\
\text { subaéreos }\end{array}$} & $\begin{array}{l}\text { Niveles superiores del escarpe } \\
\text { Este }\end{array}$ & $560-566 \mathrm{ka}$ & \multirow{3}{*}{$\sim 560 \mathrm{ka}$} & \multirow{4}{*}{$\begin{array}{l}510-530 \mathrm{ka} \\
\sim 500 \mathrm{ka}^{5}\end{array}$} \\
\hline & & $\begin{array}{l}\text { Niveles superiores del escarpe } \\
\text { Oeste y Macizo } \\
\text { de Tigaiga }\end{array}$ & $549 / 560 \mathrm{ka}$ & & \\
\hline & & $\begin{array}{l}\text { Relleno del valle dejado } \\
\text { por el deslizamiento }\end{array}$ & $540-730 \mathrm{ka}$ & & \\
\hline & \multicolumn{2}{|c|}{$\begin{array}{l}\text { Turbiditas submarinas profundas procedentes } \\
\text { del deslizamiento (en la Llanura Abisal de } \\
\text { Madeira) }\end{array}$} & $500-540 \mathrm{ka}$ & $\sim 535 \mathrm{ka}^{3}$ & \\
\hline \multirow{2}{*}{ Güímar } & \multicolumn{2}{|c|}{$\begin{array}{l}\text { Depósitos subaéreos de los escarpes y de } \\
\text { relleno del valle }\end{array}$} & $830-860 \mathrm{ka}$ & \multirow{2}{*}{$\begin{array}{c}\sim 830 \mathrm{ka}^{4} \\
830-840 \mathrm{ka}^{1}\end{array}$} & \multirow{2}{*}{$\sim 830 \mathrm{ka}$} \\
\hline & \multicolumn{2}{|c|}{$\begin{array}{l}\text { Turbiditas submarinas profundas procedentes } \\
\text { del deslizamiento }\end{array}$} & $830-850 \mathrm{ka}$ & & \\
\hline $\begin{array}{l}\text { Micheque } \\
\text { o } \\
\text { Acentejo }\end{array}$ & \multicolumn{2}{|c|}{$\begin{array}{l}\text { Depósitos subaéreos de los escarpes y de } \\
\text { relleno del valle }\end{array}$} & $560-830 \mathrm{ka}$ & $\geq 830 \mathrm{ka}$ & $\begin{array}{l}>808 \mathrm{ka} \\
<1.320 \mathrm{ka}\end{array}$ \\
\hline $\begin{array}{l}{ }^{1} \text { Considerar } \\
{ }^{2} \text { Considerar } \\
\text { del escarps } \\
{ }^{3} \text { Boulexteix } \\
{ }^{4} \text { Considerar } \\
{ }^{5} \text { Considerar } \\
\text { Ver explic: }\end{array}$ & $\begin{array}{l}\text { do las datacio } \\
\text { do solo las ed } \\
\text { y relleno tem } \\
\text { et al. (2013) } \\
\text { do las datacio } \\
\text { do las datacio } \\
\text { ciones en el te }\end{array}$ & $\begin{array}{l}\text { nes más representativas tanto de rocas } \\
\text { dades de los depósitos directamente rel } \\
\text { prano del valle. } \\
\text { estiman una edad similar, entorno a los } \\
\text { nes más representativas de rocas subaé } \\
\text { ones del nivel de mortalón menos profu } \\
\text { exto. }\end{array}$ & $\begin{array}{l}\text { subaéreas com } \\
\text { lacionados con } \\
530 \mathrm{ka} \text {, con d } \\
\text { reas. } \\
\text { indo de la Galer }\end{array}$ & $\begin{array}{l}\text { de sedimentos su } \\
\text { el deslizamiento: } r \\
\text { os dataciones suba } \\
\text { ía Cruz de Luis. }\end{array}$ & $\begin{array}{l}\text { marinos. } \\
\text { veles superiores } \\
\text { reas. }\end{array}$ \\
\hline
\end{tabular}

Tabla 8. Edades de los deslizamientos deducidas de las dataciones bibliográficas y edades estimadas según nuevas dataciones Ar/Ar en rocas de galerías.

Table 8. Ages of the landslides deduced from literature data and estimated ages according to new Ar/Ar data of rock from galleries.

rrencia de otro posible episodio de deslizamiento en torno a los $500 \mathrm{ka}$, hipótesis que se vería apoyada por dataciones de turbiditas procedentes de La Orotava de 505 ka (Weaver et al., 1992); esto implicaría, al menos, tres grandes roturas del flanco de La Orotava.

En los casos de los deslizamientos de Güímar y de Micheque, las dataciones realizadas aportan datos coincidentes con los disponibles hasta ahora, reforzan- do las edades que se consideran por la mayoría de los autores, en el entorno de los 830-840 ka. Debe tenerse en cuenta, sin embargo, la escasez de dataciones en ambos deslizamientos, lo que conduce a obtener límites más acotados para la edad, con menor incertidumbre; aun así, y en apoyo de las edades asignadas a estos dos deslizamientos, los datos disponibles presentan una buena concordancia entre ellos. 


\section{Conclusiones}

\section{Edades de los deslizamientos estimadas a partir de las dataciones bibliográficas}

Tras la revisión de los trabajos publicados en las últimas tres décadas (1990-2019), que incluyen dataciones válidas para estimar la edad de los deslizamientos más recientes de Tenerife -último millón de años-, se han deducido las siguientes edades como las más representativas: $165-175$ ka para Icod; $530-535$ y 560 ka para La Orotava; 830-840 ka para Güímar; y >830 ka para Micheque o Acentejo. En general, estas edades coinciden con los rangos de edad publicados en las últimas décadas, aunque en este trabajo han podido establecerse intervalos más precisos, así como cuestionar algunas de las dataciones por ser incompatibles. En la Tabla 8 se resumen los datos bibliográficos y los aportados en este trabajo.

En particular, para el deslizamiento de Icod, considerándose únicamente las edades de los depósitos directamente relacionados con la ocurrencia del deslizamiento, esto es, los niveles superiores del escarpe de cabecera y los rellenos tempranos del valle, resulta un rango entre 160 y $180 \mathrm{ka}$.

Para el deslizamiento de La Orotava se han identificado dos edades, separadas unos $30 \mathrm{ka}$, que probablemente representan dos diferentes grandes roturas de flanco superpuestas. Las dataciones de las lavas de los escarpes laterales permiten deducir una edad en torno a los $560 \mathrm{ka}$, a la que se ajustan la mayoría de las otras dataciones disponibles, considerando sus incertidumbres; sin embargo, algunas dataciones recientes de materiales subaéreos, proporcionan una edad entorno a los $530 \mathrm{ka}$, coincidentes con la edad promedio de los depósitos turbidíticos provenientes del deslizamiento, de $\sim 535 \mathrm{ka}$, aunque estos depósitos se han datado también en $505 \mathrm{ka}$.

Es de destacar la escasez de dataciones que existen para delimitar las edades de los deslizamientos de Güímar y, sobre todo, Micheque. Para el caso de Güímar la edad más representativa es de $830 \mathrm{ka}$, únicamente basada en un par de dataciones del escarpe sur y otra del relleno del valle; si se consideran las dataciones submarinas más fiables, se obtiene un rango entre 830 y 840 ka. Para el deslizamiento de Micheque solo puede establecerse su límite superior, $830 \mathrm{ka}$, a partir solo de una datación de lavas de relleno temprano del valle.

\section{Edades de los deslizamientos a partir de las nuevas dataciones Ar/Ar}

Se han realizado una serie de nuevas dataciones $\mathrm{Ar} /$ Ar para contrastar y delimitar en lo posible la edad de los deslizamientos de los valles de La Orotava, Güímar y Micheque, la mayoría en rocas procedentes de galerías excavadas en los rellenos de los valles. Por primera vez se han datado rocas de galerías del valle de Güímar; también se han datado rocas a muro de los depósitos de derrubios de los deslizamientos, donde hasta ahora se contaba con una única datación.

Las dataciones permiten deducir como edades más representativas las siguientes: $510-530$ ka para La Orotava; 830 ka para Güímar; y >808 ka para Micheque o Acentejo. Para los dos últimos casos, las edades coinciden con las deducidas de la revisión bibliográfica, si bien debe considerarse la escasez de dataciones disponibles en la literatura válidas para datar estos dos deslizamientos, lo que hace que se limiten o constriñan las edades; aun así, es de resaltar la coincidencia de los datos. En la Tabla 8 se resumen los datos deducidos de la bibliografía y los propios de este trabajo.

Para el valle de La Orotava, las nuevas dataciones permiten proponer una edad en torno a los 530 ka para un gran deslizamiento, y reforzar la hipótesis de varios (dos o tres) deslizamientos superpuestos, ocurridos cada pocas decenas de miles de años. En efecto, no se puede descartar la edad apuntada por la mayor parte de los datos de la literatura en torno a los $560 \mathrm{ka}$, lo que indicaría la ocurrencia de dos deslizamientos separados unos $30 \mathrm{ka}$, ambos de gran magnitud. Las nuevas dataciones permiten también jugar con un rango de edades entorno a los 500 ka, quizás denotando otro posible deslizamiento posterior.

Una serie de evidencias geológicas sin duda apoyan la ocurrencia de varios deslizamientos superpuestos en los flancos de la isla de Tenerife, como los lóbulos de los escarpes de cabecera de los deslizamientos, los depósitos diferenciados de las avalanchas rocosas submarinas procedentes de los deslizamientos o los diferentes depósitos de 'mortalón' que atraviesan muchas de las galerías excavadas en los rellenos de los valles.

Esto supone un nuevo planteamiento de los procesos de desmantelamiento de los flancos de las grandes islas volcánicas, y presenta un nuevo escenario para interpretar las dataciones, incluso algunas que hasta ahora se desechaban o no cuadraban con las edades propuestas al asumir la hipótesis de la ocurrencia de un único deslizamiento. Pero supone también una mayor complejidad y recurrencia de los procesos de inestabilidad de los flancos volcánicos y, por tanto, mayor dificultad para su datación y para establecer los límites temporales de los distintos deslizamientos, las relaciones geométricas entre ellos y su interrelación con otros procesos volcánicos constructivos, $y$, por demás, su influencia en la particular historia geológica de la isla.

En un futuro, con más dataciones, posiblemente se resuelva la historia detallada de los múltiples des- 
lizamientos ocurridos en el valle de La Orotava y, probablemente, en otros de la isla de Tenerife.

\section{Apéndice}

Material suplementario: http://www.igme.es/boletin/

\section{Agradecimientos}

Los datos, ideas y conclusiones que se presentan en este trabajo son resultado de más de una década de investigaciones, profundizando en algunos de los aspectos abordados en dos proyectos de investigación del Plan Nacional I+D (CGL2008-01423/BTE y CGL2004-00899) dedicados ambos al estudio de los grandes deslizamientos de flanco de la isla de Tenerife. Las dataciones y los trabajos de campo relacionados con la toma de muestras han sido financiados por proyectos propios del Instituto Geológico y Minero de España, así como todos los trabajos de laboratorio de las muestras datadas.

Los autores expresan su agradecimiento a Juan J. Coello, del Consejo Insular de Aguas de Tenerife, por su imprescindible colaboración en las investigaciones de campo y guía en las visitas a galerías; a nuestro inolvidable maestro José Manuel Navarro "el Maño" ( $\dagger$ ), que nos enseñó a desentrañar las claves de los deslizamientos de Tenerife; a la Dra. Julia Seisdedos, por sus trabajos de campo en las galerías deTenerife; $y$ a todos nuestros colegas que participaron en los proyectos de investigación, geólogos de la Universidad de La Laguna, la Universidad de Lisboa, la Universidad de Las Palmas de Gran Canaria y de la Consejería de Obras Públicas del Gobierno de Canarias. Agradecemos al Dr. Luis Somoza y a otro revisor anónimo su tiempo y dedicación en la revisión del manuscrito, que sin duda ha contribuido a mejorar su contenido.

\section{Referencias}

Abdel-Monem, A., Watkins, N.D. and Gast, P. 1972. Potassium-argon ages, volcanic stratigraphy and geomagnetic polarity history of the Canary Islands: Tenerife, La Palma and Hierro. American Journal of Science, 272, 805-825.

Ablay, G.J. and Hurlimann, M. 2000. Evolution of the norh flank of Tenerife by recurrent giant landslides. Journal of Volcanology and Geothermal Research, 103, 135-159, doi: 10.10 [6/50377-0273(00)00220-1.

Alonso, J.J. 1989. Estudio volcanoestratigráfico y volcanológico de los piroclastos sálicos del sur de Tenerife. Universidad de La Laguna, Secretariado de Publicaciones. $257 \mathrm{pp}$.
Ancochea, E., Fúster, J.M., Ibarrola, E., Cendrero, A., Coello, J., Hernán, F. et al. 1990. Volcanic evolution of the island ofTenerife (Canary Islands) in the light of new K-Ar data. Journal of Volcanology and Geothermal Research, 44, 231-249.

Ancochea, E., Huertas, M.J., Cantagrel, J.M., Coello, J., Fúster, J.M., Arnaud, N. and Ibarrola, E. 1999. Evolution of the Cañadas edifice and its implications for the origin of the Cañadas Caldera (Tenerife, Canary Islands). Journal of Volcanology and Geothermal Research, 88, 177-199.

Ancochea, E., Huertas, M.J., Cantagrel, J.M., Fúster, J.M. y Arnaud, N. 2000. Cronología y evolución del edificio Cañadas, Tenerife, islas Canarias. Boletín Geológico y Minero, 111 (2-3), 3-16.

Ancochea, E., Huertas, M.J., Fúster, J.M., Cantagrel, J.M., Coello, J. and Ibarrola, E. 1995. Geocronología de la Pared de la Caldera de las Cañadas (Tenerife, Islas Canarias). Boletín de la Real Sociedad Española de Historia Natural (Sec. Geología), 90, 107-124.

Arnaud, N., Huertas, M.J., Cantagrel, J.M., Ancochea, E. y Fuster, J.M. 2001. Edades 39Ar/40Ar de los depósitos de Roques de García (Las Cañadas, Tenerife). Geogaceta, 29, 19-22.

Biain, A., León, R., Urgeles, R., Somoza, L., Medialdea, T., Ferrer, M and González, F.J. 2015. Onshore and offshore geomorphological features of the El Golfo debris avalanche (El Hierro, Canary islands). In: Lamarche et al. (Eds.), Submarine Mass Movements and their Consequences. Advances in Natural and Technological Hazards Research, 41, 83-92. DOI 10.1007/978-3-319-20979-1_8.

Boulesteix, T., Hildenbrand, A., Gillot, P.Y. and Soler, V., 2012. Eruptive response of oceanic islands to giant landslides: new insights from the geomorphologic evolution of the Teide-Pico Viejo volcanic complex (Tenerife, Canary). Geomorphology, 138, 61-73.

Boulesteix, T., Hildenbrand, A., Soler, V., Quidelleur, X. and Gillot, P.Y. 2013. Coeval giant landslides in the Canary Islands: Implications for global, regional and local triggers of giant flank collapses on oceanic volcanoes. Journal of Volcanology and Geothermal Research, 257, 90-98.

Bravo, T. 1962. El Circo de Las Cañadas y sus dependiencias. Boletín de la Real Sociedad Española de Historia Natural (Sec. Geología), 60, 93-108.

Bravo Bethencourt, J. y Bravo, T. 1989. Esquema geológico de la Pared de Las Cañadas. En: Araña y Coello (Eds.), Los volcanes y la caldera del Parque Nacional del Teide (Tenerife, Islas Canarias), ICONA, 85-100.

Bryan, S.E., Martí, J. and Cas, R.A.F. 1998. Stratigraphy of the Bandas del Sur Formation: an extracaldera record of Quaternary phonolitic explosive eruptions from the Las Cañadas edifice, Tenerife (Canary Islands). Geological Magazi$n e, 135,605-636$.

Bryan, S.E., Martí, J. and Leosson, M. 2002. Petrology and geochemistry of the Bandas del Sur Formation, Las Ca- 
M. Ferrer et al., 2020. Geocronología de los megadeslizamientos deTenerife del último... Boletín Geológico y Minero, 131 (4): $903-940$

ñadas edifice, Tenerife (Canary Islands). Journal of Petrology, 43, 1815-1856.

Brown, R.J., Barry, T.L., Branney, M.J., Pringle, M.S. and Bryan, S.E. 2003. The Quaternary pyroclastic succession of southeast Tenerife, Canary Islands: explosive eruptions, related caldera subsidence, and sector collapse. Geological Magazine, 140, 265-288.

Cantagrel, J.M., Arnaud, N.O., Ancochea, E., Fuster, J.M. and Huertas, M.J. 1999. Repeated debris avalanches on Tenerife and genesis of Las Cañadas caldera wall (Canary Islands). Geology, 27, 739-742.

Carracedo, J.C. 1994. The Canary Islands: An example of structural control on the growth of large oceanic island volcanoes. Journal of Volcanology and Geothermal Research, 60, 3/4, 225-242, doi: 10.1016/0377-0273(94)90053-1.

Carracedo, J.C., Rodríguez Badiola, E., Guillou, H., Scaillet, S., Paterne, M., Pérez-Torrado, F.J. et al. 2006. Geocronología e historia volcánica del complejo volcánico del Teide y las dorsales deTenerife. En: Los volcanes del Parque Nacional del Teide. El Teide, Pico Viejo y las dorsales activas de Tenerife, $\mathrm{M}^{\circ}$ de Medioambiente, 69-97.

Carracedo, J.C., Rodríguez Badiola, E., Guillou, H., Paterne, M., Scaillet, S., Pérez Torrado, F.J. et al. 2007. Eruptive and structural history of Teide volcano and rift zones of Tenerife, Canary Islands. Geological Society of America Bulletin,119, 9/10, 1027-1051, doi: 10.1130/B26087.1.

Carracedo, J.C., Guillou, H., Rodríguez Badiola, E., Pérez-Torrado, F.J., Rodríguez González, A., Paris, R. et al. 2009. La dorsal NE de Tenerife: Hacia un modelo del origen y evolución de los rifts de islas oceánicas: Estudios Geológicos, 65 (1), 5-47, doi: 10.3989/egeol.39755.056.

Carracedo, J.C., Guillou, H., Nomade, S., Rodríguez Badiola, E., Pérez-Torrado, F.J., Rodríguez González, A. et al. 2011. Evolution of ocean-island rifts: The northeast rift zone of Tenerife, Canary Islands. Geological Society of America Bulletin, 123, 3/4, 562-584; doi: 10.1130/B30119.1.

CIATF, 2019. Consejo Insular de Aguas de Tenerife. https:// ciatf.maps.arcgis.com/apps/webappviewer/index.html?i$\mathrm{d}=8 \mathrm{~d} 42 \mathrm{~d} 177780043 e 89 d 9824 c e e 2166995$. Última consulta $5 / 12 / 2019$.

Coello, J. 1973. Las series volcánicas en subsuelos deTenerife. Estudios geológicos, 29-6, 491-512.

Coello, J. y Bravo, T. 1989. Correlación lito-estratigráfica de perforaciones (galerías) en la región central de Tenerife. En: Araña y Coello (Eds.), Los volcanes y la caldera del Parque Nacional del Teide (Tenerife, Islas Canarias), ICONA, 359-386.

Coello Bravo, J.J., Martín González, E. y Hernández Gutiérrez, L.E. 2014. Depósitos de tsunami originados por un deslizamiento gravitacional masivo en Tenerife (islas $\mathrm{Ca}$ narias). Vieraea, 42, 79-102.

Edgar, C.J., Wolff, J.A., Olin, P.H., Nichols, H.J., Pittari, A., Cas, R.A.F. et al. 2007. The late Quaternary Diego-Hernandez formation, Tenerife: volcanology of a complex cycle of voluminous explosive phonolitic eruptions. Geological Society of America Bulletin, 160, 59-85.

EMODnet-Geology Project. 2019. EASMEI2019/0P/0003. https://www.emodnet-geology.eu/map-viewer/?p=geological_events_and_probabilities.

Ferrer, M., González de Vallejo, L.I., Seisdedos, J., García, J.C., Coello, J.J., Casillas, R., Martín, C., Hernández, L.E. 2008. Large rockslides hazard in Tenerife island. Geological analysis and geomechanical modelling of instability mechanisms, IGME-CICYT CGL2004-00899. Informe inédito. Centro de Documentación del IGME, Madrid.

Ferrer, M., González de Vallejo, L., Seisdedos, J., Coello, J.J., García, J.C., Hernández, L. et al. 2013. Güímar and La Orotava megalandslides (Tenerife) and tsunamis deposits in Canary Islands. In: Margottini et al. (Eds), Landslide Science and Practice, vol. 5: Complex Environment. Springer, 27-34. ROMA ISBN 978-3-642-31426-1.

Ferrer, M., González de Vallejo, L.I. y García, J.C. 2020. Geocronología de los megadeslizamientos de Tenerife del último millón de años. Parte II. Nuevas aportaciones al conocimiento de los deslizamientos. Boletín Geológico y Minero, 131(4), 941-970.

Frenz, M., Wynn, R.B., Georgiopoulou, A., Bender, V.B., Hough, G., Masson, D.G. et al. 2009. Provenance and pathways of late Quaternary turbidites in the deepwater Agadir Basin, northwest African margin. International Journal of Earth Sciences, 98 (4), 721-733.

Huertas, M. J., Arnaud, N.O., Ancochea, E., Cantagrel, J.M. and Fuster, J.M. 2002. 40Ar/39Ar Stratigraphy of pyroclastic units from Cañadas Volcanic Edifice (Tenerife, Canary Islands) and their bearing on the structural evolution. Journal of Volcanology and Geothermal Research, 115, 351-365.

Hunt, J.E., Wynn, R.B., Masson, D.G., Talling, P.J. and Teagle, D.A.H. 2011. Sedimentological and geochemical evidence for multistage failure of volcanic island landslides: a case study from the Icod landslide on north Tenerife, Canary Islands. Geochemistry, Geophysics, Geosystems, 12 (12), 36 pp, doi:10.1029/2011GC003740.

Hunt, J.E., Wynn R.B., Talling, P.J. and Masson, D.G. 2013. Turbidite record of frequency and source of large volume (>100 km3) Canary Island landslides in the last $1.5 \mathrm{Ma}$ : Implications for landslide triggers and geohazards. Geochemistry, Geophysics, Geosystems, 14 (7), 2100-2123, doi:10.1002/ggge.20139.

Ibarrola, E., Ancochea, E., Fúster, J.M., Cantagrel, J.M., Coello, J., Snelling, N.J. and Huertas, M.J. 1993. Cronoestratigrafía del Macizo de Tigaiga: evolución de un sector del Edificio Cañadas (Tenerife, Islas Canarias). Boletín de la Real Sociedad Española de Historia Natural (Sec. Geología), 88, 57-72.

Krastel, S., Schmincke, H.U., Jacobs, C.L., Rihm, R., Le Bas, T.P. and Alibes, B. 2001. Submarine landslides around the Canary Islands. Journal of Geophysical Research, Solid Earth, 0106 (B3), 3977-3997. 
León, R., Somoza, L., Urgeles, R., Medialdea, T., Ferrer, M., Biain, A. et al. 2017. Multi-event oceanic island landslides: New onshore-offshore insights from El Hierro Island, Canary Archipelago, Marine Geology, 393, 156-175.

León, R., Palomino, D., Vázquez, J.T., Medialdea, T. and Somoza, L. 2019. A new scenario for the mass transport deposits west Canary volcanic province. Earth and Planetary Science Letters, 509, 27-37.

Madeira, J., Andrade, C. and Freitas, M.C. 2011. Reconocimientos de campo para identificación de depósitos de tsunamis. Parte 2: Report of the visit to Tenerife to assess the origin of the chaotic marine breccias of Teno-Buenavista region. Proyecto GRANDETEN II (CGL2008-01423). Informe inédito. Centro de Documentación del IGME, Madrid. 22 pp.

Martí, J., Hurlimann, M., Ablay, G.J. and Gudmundsson. A. 1997. Vertical and lateral collapses on Tenerife (Canary Islands) and other volcanic ocean islands. Geology, 25 (10), 879-882, doi:10.1130/0091-7613.

Martí. J., Mitjavila, J. and Araña, V. 1994. Stratigraphy, structure and geochronology of Las Cañadas caldera (Tenerife. Canary Islands). Geological Magazine, 131, 715-727, doi:10.1017/S0016756800012838.

Martí, J., Mitjavila, J. and Villa, I. 1990. Stratigraphy and K-Ar ages of the Cañada de Diego Hernández and their significance on the Las Cañadas caldera formation (Tenerife, Canary Islands). Terra Nova, 2, 148-153.

Masson, D.G., Watts, A.B., Gee, M.R.J., Urgeles, R., MitcheII, N.C., Le Bas, T. and Canals, M. 2002. Slope failures on the flanks of the western Canary Islands. Earth Science Reviews, 57, 1-35, doi:10.1016/S0012-8252(01)00069-1.

Mitjavila, J. and Villa, I. 1993. Temporal evolution of Diego Hernández formation (Las Cañadas, Tenerife) and confirmation of the age of the caldera using the 40Ar-39Ar method. $R e$ vista de la Sociedad Geológica de España, 6, 61-65.

Moore, J.G. 1964. Giant submarine landslides on the Hawaiian Ridge. In: Geological Survey Research 1964, U.S. Geological Survey Prof. Paper 501-D, D95-D98.

Moore, J.G., Clague, D.A., Holcomb, R.T., Lipman, P.W., Normark, W.R. and Torresan, M.E. 1989. Prodigious submarine landslides on the Hawaiian Ridge. Journal of Geophysical Research, 94, 17465-17484.

Navarro, J.M. and Coello, J. 1989. Depressions originated by landslide processes inTenerife. ESF Meeting on Canarian Volcanism, Lanzarote, 150-152.

Oehler, J.F., Lénat, J.F. and Labazuy, P. 2008. Growth and coIlapse of the Reunion Island volcanoes. Bulletin of Volcanology, 70, 717-742.

Palomino, D., Vázquez, J.T., Somoza, L., León, R., López-González, N. Medialdea, T. et al. 2016. Geomorphological features in the southern Canary Island Volcanic Province:The importance of volcanic processes and massive slope instabilities associated with seamounts. Geomorphology, 255, 125-139.

Paris, R., Coello, J.J., Martín, E., Kelfoun, K. and Nauret, F. 2017. Explosive eruption, flank collapse and megatsunami at Tenerife ca. 170 ka. Nature Communications, 8, 15246 doi: $10.1038 /$ ncomms 15246.

Pearce, T.J. and Jarvis, I. 1992. Composition and provenance of turbidite sands: Late quaternary, Madeira Abyssal Plain. Marine Geology, 109, 1-2, 21-51.

Pittari, A., Cas, R.A.F., Edgar, C.J., Nichols, H.J., Wolff, J.A. and Martí, J. 2006. The influence of palaeotopography on pyroclastic flow processes and facies architecture of a lithic-rich ignimbrite in a high gradient setting: the Abrigo Ignimbrite, Tenerife, Canary Islands. Journal of Volcanology and Geothermal Research, 152, 273-315.

Pittari, A., Cas, R.A.F., Wolff, J.A., Nichols, H.J., Larson, P.B. and Martí, J. 2008. The use of lithic clast distributions in pyroclastic deposits to understand pre- and syn-caldera collapse processes: A case study of the Abrigo Ignimbrite, Tenerife, Canary Islands. In: Developments in Volcanology, vol. 10, Elsevier, B.V., 97-142, DOI:10.1016/S1871644X(07)00003-4.

Rodríguez Losada, J.A. 2000. Itinerario geológico por los depósitos piroclásticos del sur de Tenerife. En: Astiz y García (Eds.), Curso Internacional de Volcanología y Geofisica Volcánica. Serie: Casa de Los Volcanes, 7. Servicio de publicaciones del Cabildo Insular de Lanzarote, 205-215.

Seisdedos, J. 2009. Los grandes paleo-desplazamientos de Güímar y La Oratava (Tenerife): Análisis geológico, mecanismos de inestabilidad y modelización geomecánica. Tesis Doctoral, UCM. 202 pp. ISBN: 978-84-692-1117-5.

Teide Group. 1997. Morphometric interpretation of the northwest and southeast slopes of Tenerife, Canary Islands. Journal of Geophysical Research, 102, 20325-20342.

Urgeles, R., Masson, D.G., Canals, M., Watts, A.B. and Le Bas, T. 1999. Recurrent large-scale landsliding on the west flank of La Palma, Canary Islands. Journal of Geophysical Research, 104, BII, 25331-25348.

Watts, A.B. and Masson, D.G. 1995. A giant landslide on the north flank of Tenerife, Canary Islands. Journal of Geophysical Research, 100, 24487-24498.

Weaver, P.P.E., Rothwell, R.G., Ebbing, J., Gunn, D. and Hunter, P.M., 1992. Correlation, frequency of emplacement and source directions of megaturbidites on the Madeira Abyssal Plain. Marine Geology, 109, 1-20.

Wynn, R.B., Weaver, P.P.E., Masson, D.G. and Stow, D.A.V., 2002. Turbidite depositional architecture across three interconnected deep-water basins on the northwest African margin. Sedimentology, 49, 1441-1462.

Recibido: junio 2020

Revisado: agosto 2020

Aceptado: noviembre 2020

Publicado: marzo 2021 